University of Missouri, St. Louis

IRL@UMSL

7-27-2007

\title{
Using Structured Employment Interviews to Predict Task and Contextual Performance
}

Brian M. Bonness

University of Missouri-St. Louis, brianbonness@hotmail.com

Follow this and additional works at: https://irl.umsl.edu/dissertation

Part of the Psychology Commons

\section{Recommended Citation}

Bonness, Brian M., "Using Structured Employment Interviews to Predict Task and Contextual Performance" (2007). Dissertations. 580.

https://irl.umsl.edu/dissertation/580

This Dissertation is brought to you for free and open access by the UMSL Graduate Works at IRL @ UMSL. It has been accepted for inclusion in Dissertations by an authorized administrator of IRL @ UMSL. For more information, please contact marvinh@umsl.edu. 
Using Structured Employment Interviews to Predict Task and Contextual Performance

Brian M. Bonness

M.A., Industrial and Organizational Psychology, University of Missouri - St. Louis, 2004

B.S., Psychology, Truman State University, 2000

A Dissertation Submitted to The Graduate School at the University of Missouri - St. Louis in partial fulfillment of the requirements for the degree Doctor of Philosophy in Industrial and Organizational Psychology

May 2007

$\underline{\text { Advisory Committee }}$

Therese Macan, Ph.D.

Chairperson

James Breaugh, Ph.D.

Miles Patterson, Ph.D.

Michael Beatty, Ph.D. 
Bonness, Brian, 2007, UMSL, p. 2

\begin{abstract}
This study investigated the extent to which structured interviews predict task and contextual performance dimensions. Participants recruited from undergraduate business courses at a mid-sized, Midwestern university participated in a structured interview and received performance assessments from three separate rating sources (self-assessment, performance assessment exercise, peer/supervisor assessors). Study results showed that the contextual performance dimensions of the interview significantly predicted contextual performance ratings provided in peer/supervisor assessor questionnaires and predicted these ratings above and beyond the prediction of the task dimension of the interview. Conversely, the task dimension of the interview did not predict task performance in any of the performance rating sources. Further, a paper-and-pencil measure of conscientiousness was found to be a good predictor of contextual performance ratings across the three performance rating sources. The contextual performance dimension of the interview, however, predicted a significant amount of variance in contextual performance ratings in the assessor questionnaires above and beyond the conscientiousness measure. Finally, both task and contextual dimensions of the interview predicted overall performance in the assessor questionnaires while the contextual dimension predicted overall performance above and beyond the prediction of the task dimension. Various exploratory analyses were also conducted and evaluated. The implications of the study results along with various limitations are discussed.
\end{abstract}


Bonness, Brian, 2007, UMSL, p. 3

\section{Acknowledgments}

I have worked very hard and for a long time on this dissertation project but I most certainly cannot begin to take full credit for its successful completion. Without all the wonderful people who have helped me in a range of capacities along the way, reaching this milestone in my life would not have been possible. First, thank you to all of my colleagues from the program over the last seven years - some I haven't seen for years and some who are no longer with us on this earth - it has been a long journey together and it has been my fortune to share this crazy and immensely challenging experience with all of you. Next, thank you to those subject matter experts who took the time out of their very busy schedules to help validate some of the materials for my study. Thank you to Jeff and Kim for listening to my analyses ideas and questions and for providing insight into problems I thought I might never solve. Thank you to Dr. Chernyshenko for providing the conscientiousness scale and to Dr. Jackson and Dr. Facteau for sending interview and measurement materials which provided great ideas for the materials in my own study. I must also thank my boss, Dave, for being understanding and flexible during those crazy weeks and months of collecting data, running analyses, and writing up the final paper. Thank you also to Dana, Shirley, Don, Ekin, and Peggy who let me steal away precious lecture time to come in and recruit participants from their classes. Thank you to the psychology department at UMSL for providing financial support to a starving graduate student. Thank you to Jim for listening to me complain and worry and for sharing his own dissertation experiences and struggles. Further, I have a great deal of gratitude for the seven graduate and undergraduate students (Graham, Angela, Adrianne, Mike, Phil, AJ, and Andrea) who served as research assistants. They did a wonderful job as 
Bonness, Brian, 2007, UMSL, p. 4

interviewers and were dependable as well as just fun to be around throughout the entire data collection phase. To my committee members (Therese, Jim, Miles, and Michael), you were wonderful to work with throughout the project. Thanks you for all your time and great ideas. And specifically to my advisor, Therese, you have done so much for me over the past several years. Thank you for being patient and for encouraging me when I wasn't sure I would make it. Lastly, I would like to thank my friends, my family, and my creator. To those friends of mine who have remained interested and invested in my progress, thank you for your support. Some of you have been especially close every step of the way (Noorshuhada and Kate), listening and sympathizing and encouraging me as I express all my anxiety and frustrations and threaten to quit altogether time after time. I would not have made it to this point without your support. And to my family who give meaning to all of this. To my Mom and Dad (Rick and Sarah), my brother and sister-inlaw (Bruce and Kelly), my two wonderful nephews (Cooper and Jayce), and my grandmother (Mary), thank you all so much for being there from the beginning and always. I hope to see all of you much more often now. And finally, I thank God for carrying me in His arms these past several years as I have become weak in both faith and character. When I had lost confidence and love for my own self, He did not, and for this, I am most thankful. 


\section{Table of Contents}

Section

Page

I. List of Tables...................................................... 8

II. List of Appendixes............................................ 9

II. Introduction...................................................... 10

a. Contextual Performance Defined.............................. 11

b. Importance of Contextual Performance to Organizations............ 14

c. Factors of Contextual Performance........................... 15

d. Contextual Performance Differentiated from Task Performance..... 17

e. Antecedents of Contextual Performance......................... 20

f. Predictive and Constructive Validity of Interviews................ 24

III. Hypotheses................................................ 33

IV. Method..................................................... 37

a. Participants................................................. 37

b. Materials.................................................. 38

i. Self-Assessment Questionnaire........................... 38

ii. Performance Assessment Exercise....................... 38

iii. Email Responses..................................... 39

iv. Interview............................................ 40

v. Assessor Questionnaire............................. 42

c. Procedure.................................................... 42

i. Self-Assessment Questionnaire....................... 42

ii. Performance Assessment Exercise....................... 43 
iii. Interview............................................... 45

iv. Interviewer Training..................................... 46

v. Assessor Questionnaires............................... 47

d. Predictor Measures.......................................... 48

i. Conscientiousness....................................... 48

ii. Task and Contextual Dimensions of the Interview.......... 49

iii. Average Contextual Performance........................ 50

iv. Overall Interview Score................................... 50

e. Inter-Rater Consistency ................................... 50

f. Criterion Measures................................................... 51

i. Task Performance..................................... 51

ii. Contextual Performance Dimensions..................... 52

iii. Average Contextual Performance......................... 54

iv. Overall Performance Item (Overall 1).................... $\quad 54$

v. Calculated Overall Performance (Overall 2).............. 55

vi. Exercise Overall Performance............................. 55

V. Results....................................................... 55

a. Descriptives.............................................. 55

b. Test for Interviewer Effect................................. 56

c. Test for Interviewer-Participant Gender Effect................. $\quad 57$

d. Impact of Second Interviewer............................. $\quad 58$

e. Impact of Exercise on Interview Performance.................. $\quad 58$

f. Comparison of Different Exercise Group Sizes................. $\quad 59$ 
g. Impact of Timesheet Minimum on Exercise Scores............. 61

h. Assessor Questionnaire Rating Scale........................ 62

i. Assessor Perspective.................................... 63

j. Participants with and without Assessors...................... 64

k. Summary of Preliminary Analyses.......................... 65

1. Correlation Patterns...................................... 65

m. Tests of Hypotheses...................................... 68

n. Interview and Contextual Performance..................... 69

o. Prediction Beyond the Task Dimension...................... 70

p. Interview and Task Performance.......................... 71

q. Conscientiousness and Contextual Performance............... 71

r. Prediction Beyond Conscientiousness..................... 72

s. Overall Performance.................................... 73

t. Interview Measure of Average Contextual Performance......... 75

u. Interview Measure of Conscientiousness..................... 76

v. Task Dimension of Interview............................ 79

VI. Discussion.............................................. 79

a. Summary of Findings.................................... 80

b. Limitations and Future Research........................... 89

VII. References............................................ 93

VIII. Tables.................................................... 101

IX. Appendixes............................................ 116 


\section{List of Tables}

Table

Page

1 SME Data for Timesheet Exercise Email Validation................

2 Correlations between Interviewer 1 and Interviewer 2 Scores.......

102

3 Correlations between Emails in Timesheet Exercise...............

103

$4 \quad$ Descriptives, Correlations \& Alphas for Study Variables.......... 104

$5 \quad$ Correlations between Interview Dimensions..................... 105

6a-61 Results for Hypothesis 1a................................ 106

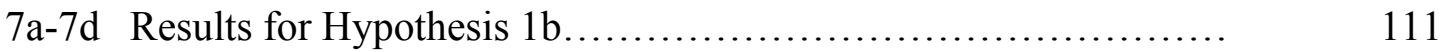

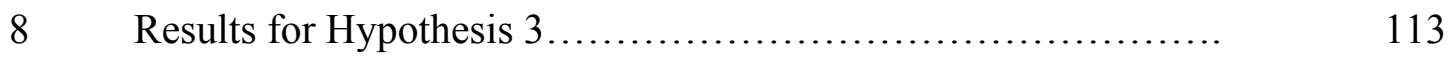

9a-9d Results for Hypothesis 4.................................. 114 


\section{List of Appendixes}

Appendix

Page

A Self-Assessment Questionnaire............................. 116

B Exercise Instructions and Sample Timesheet.................... 122

C SME Instructions for Sorting Emails and Email Responses.........

126

D Emails and Email Responses................................ 130

E Interview Guide............................................... 136

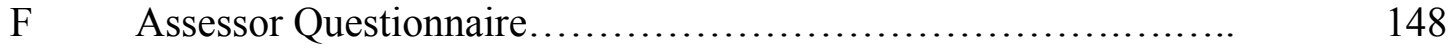

G Consent Form (Participants).............................. 152

$\mathrm{H} \quad$ Interviewer Training Guide................................ 154

I Instructions for Assessor Questionnaire........................ 169

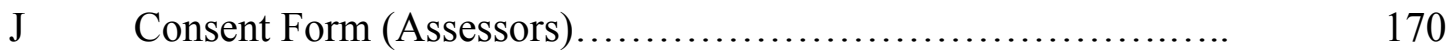


Using Structured Employment Interviews to Predict Task and Contextual Performance A substantial amount of research suggests that the performance domain is not unidimensional. Rather, it includes a dimension of behaviors that contribute to rolespecific task performance along with another dimension, contextual performance, which goes beyond the formal role of the employee and makes important contributions to organizations by supporting task performance (Borman \& Motowidlo, 1993). Contextual performance has been found to have a considerable impact on both judgments of overall performance (e.g., Borman \& Motowidlo, 1997) and various measures of organizational effectiveness (e.g., Podsakoff \& MacKenzie, 1997). Because it appears to have a substantial influence on performance evaluations as well as organizations in general, research investigating ways of predicting and selecting for contextual performance would be especially valuable.

Initial research efforts to identify the predictors of contextual performance have found that personality and job attitudes are the most consistent antecedents (Borman, Penner, Allen \& Motowidlo, 2001; Organ \& Ryan, 1995; Podsakoff, MacKenzie, Paine \& Bachrack, 2000). In addition to these antecedents, the employment interview has been studied as a potential predictor of contextual performance (Allen, Facteau \& Facteau, 2004; Latham \& Skarlicki, 1995). Gatewood and Field (1990) suggest that interviews have high predictive validity because they are inherently designed to measure extra-role behaviors, which generally make up contextual performance. Further, recent metaanalytic studies indicate that interviews typically measure constructs, such as personality and interpersonal skills, which are theoretically and empirically linked to contextual performance (Huffcutt, Conway, Roth \& Stone, 2001; Salgado \& Moscoso, 2002). This 
suggests that interviews might be a good tool for measuring and predicting contextual performance and might even predict contextual performance as strongly as they predict task performance. Finally, based on findings regarding the unique prediction of interviews among other important predictors (e.g., Cortina et al., 2000), interviews might predict contextual performance above and beyond paper-and-pencil personality tests.

The purpose of the current study is to investigate these possibilities by exploring further the use of structured employment interviews to predict contextual performance. Specifically, this study evaluated whether structured interviews predict contextual performance and how well they predict contextual performance relative to task performance. This study also tested whether interviews successfully predict contextual performance above and beyond what can be predicted by a paper-and-pencil test of conscientiousness. Finally, various supplemental research questions were explored.

Before elaborating on these research questions, this paper presents a review of the definition of contextual performance, its impact on organizational effectiveness, and the various sub-dimensions that make up contextual performance. Also reviewed is how contextual performance has been distinguished from task performance and the antecedents that have been found to predict contextual and task performance. Finally, the predictive and construct validity of interviews and the reasons why interviews are expected to be predictive of both task and contextual performance will be presented.

\section{$\underline{\text { Contextual Performance Defined }}$}

Selection research has traditionally focused on a one-dimensional conceptualization of performance that either includes task-related behaviors or a generic measure of overall job performance. In response to this narrow view of the performance 
Bonness, Brian, 2007, UMSL, p. 12

criterion domain, Borman and Motowidlo $(1993,1997)$ introduced the concept of contextual performance. Task performance and contextual performance separately contribute important value to organizations in distinct ways. Task performance promotes organizational effectiveness by contributing to the technical core of the organization. This can occur directly by transforming raw materials into the organization's products or indirectly by providing services necessary to support ongoing product creation. An example might be replenishing the supplies needed for production efforts. In comparison, contextual performance contributes to the social and psychological context in which the technical core of the organization functions. Borman and Motowidlo (1993) proposed a five-dimension model of contextual performance that includes: (1) persisting with enthusiasm and extra effort as necessary to complete one's own task activities; (2) volunteering to carry out task activities that are not formally part of one's own job; (3) helping and cooperating with others; (4) following organizational rules and procedures; and (5) endorsing, supporting and defending organizational objectives. Examples of contextual performance might include going out of one's way to help a co-worker complete a task, cooperating with a supervisor or with an organizational policy, or volunteering for extra responsibility.

The definition of contextual performance borrows heavily from several related concepts found in previous industrial and organizational psychology research. Barnard (1938) discussed the "informal organization" and the importance of employee cooperation for the good of the organization. A few decades later, Katz (1964) and Katz and Kahn (1978) discussed cooperative and helpful behaviors that go beyond the formal role of the employee and that are important for organizational functioning. More recently, 
Organ and his colleagues (e.g., Bateman \& Organ, 1983; Organ, 1988; Smith, Organ \& Near, 1983) formulated the concept of Organizational Citizenship Behavior (OCB). OCB was defined as extra-role, discretionary behavior that helps other organization members perform their jobs or shows support for the organization. The five dimensions of OCB include: (1) Altruism; (2) Conscientiousness; (3) Sportsmanship; (4) Courtesy; and (5) Civic Virtue. OCB includes behaviors that are neither required by an employee's organizational role nor directly related to the organization's formal compensation system. After questions arose concerning the discretionary and formal reward aspects of the definition, Organ (1997) updated the definition of OCB to be "contributions to the maintenance and enhancement of the social and psychological context that supports task performance" (Organ, 1997, p. 91), which is synonymous with Borman and Motowidlo's $(1993,1997)$ contextual performance. From this point on, the term "contextual performance" will be used to describe the specifics of the current study. When evaluating studies from previous research, however, the same terminology used in those studies will be used in an effort to remain consistent.

Contextual performance is also influenced quite heavily by two other related concepts. First, Prosocial Organizational Behavior (POB) is defined as behavior that is directed at an individual or group with the intention of promoting the welfare of that individual or group (Brief \& Motowidlo, 1986). POB consists of nine dimensions that map on closely to the five dimensions that comprise OCB. A final related concept is the Model of Soldier Effectiveness (MSE; Borman, Motowidlo \& Hanser, 1983), which similarly includes performance constructs that fall outside the technical core or task performance realm. These models (OCB, POB, MSE) have slight differences but each 
focuses on behaviors outside the technical core of organizations and that serve the important function of supporting the social and psychological core of the organization in which the technical core functions. Borman and Motowidlo (1993) considered the fivedimension model of contextual performance to be a parsimonious combination of OCB, POB, and the MSE.

One reason why contextual performance has gained research attention is because of its potential impact on important organizational bottom line variables. Next is a brief review of how contextual performance impacts various measures of organizational effectiveness. $\underline{\text { Importance of Contextual Performance to Organizations }}$

Contextual performance behaviors have an important impact on various measures of overall organizational effectiveness. As Podsakoff and MacKenzie (1997) noted, one way contextual performance might enhance organizational effectiveness is by increasing its efficiency. For example, managers might be more productive when employees are helping each other and avoiding conflict with co-workers, thus taking the burden off their manager. Also, when employees share ideas and ways of doing tasks, co-workers are more productive. Another way to increase organizational effectiveness is by limiting performance variability. For example, when employees remain conscientious and pick up the slack for co-workers, the work output throughout the company is more likely to remain consistent. Contextual performance behaviors may also boost organizational effectiveness by helping to attract and retain better employees when demonstrating high morale and cohesiveness to applicants. Finally, contextual performance is likely to allow a company to adapt better to changes in the environment. For example, when employees 
volunteer information about market or industry changes and seek out ways to respond to the changes or when employees actively develop their skills through training or taking on new responsibilities, the company is able to respond and adapt to changes. In addition to these suggestions, Borman and Penner (2001) point out that the growing number of teams in organizations, downsizing, the importance of having a service orientation, and the increase in global competition are all making contextual performance more important and making employees who display this behavior more valuable.

Although most models of contextual performance and related constructs have several dimensions, the research has consistently found a small number of general factors of contextual performance (Coleman \& Borman, 2000; Williams \& Anderson, 1991). Factors of Contextual Performance

The various dimensions of contextual performance found in the literature are generally reduced to two or three general factors. For example, Williams and Anderson (1991) used factor analysis to distinguish between person-directed or interpersonal organizational citizenship behavior, referred to as OCB-I, and organization-directed organizational citizenship behavior referred to as OCB-O. More recently, Coleman and Borman (2000) proposed a three-dimension model of contextual performance that includes the following dimensions: Personal Support, Organizational Support, and Conscientious Initiative. This study asked industrial and organizational psychologists to sort a list of 27 dimensions from related constructs in the contextual performance literature (e.g., OCB, POB, MSE). The three resulting dimensions represent broad categories that vary based on the target toward which the behavior is directed. Behaviors in the Personal Support dimension are directed toward and benefit individuals in the 
Bonness, Brian, 2007, UMSL, p. 16

organization; behaviors making up the Organizational Support dimension promote the organization; and Conscientious Initiative behaviors are directed toward an employee's job. The Personal Support dimension includes behaviors or concepts such as helping, cooperating with others, altruism, and interpersonal facilitation. It is essentially the same as the helping and cooperating dimension in the Borman and Motowidlo (1993) model of contextual performance. The Organizational Support dimension includes behaviors such as endorsing and supporting the organization, following its policies and rules, and remaining loyal and compliant to the company. This factor is a combination of the following rules and procedures and endorsing, supporting and defending dimensions in the Borman and Motowidlo (1993) model. Lastly, the Conscientiousness Initiative dimension includes behaviors such as persisting and remaining dedicated, and expending extra effort. It is essentially the same as the persisting and volunteering dimensions in the Borman and Motowidlo (1993) model.

The Personal Support and Organizational Support dimensions seem to map on nicely to the two-dimension distinction made by Williams and Anderson (1991). Personal Support is closely related to the OCB-I dimension while Organizational Support is very similar to the OCB-O dimension. The Coleman and Borman (2000) dimensions are also very similar to the Van Scotter and Motowidlo (1996) dimensions of Interpersonal Facilitation and Job Dedication - the latter involving promoting the company's best interests by following company rules and remaining compliant to the organization and one's job requirements. This dimension has elements of both Organizational Support and Conscientious Initiative. The Personal Support dimension is also very similar to the Altruism and Courtesy dimensions of OCB (Organ, 1988) while the Organizational 
Support dimension closely resembles the OCB dimensions of Sportsmanship and Civic Virtue (Organ, 1988). Finally, Conscientious Initiative is nearly the same as the Conscientiousness dimension of OCB (Organ, 1988). In summary, the literature is quite consistent in how contextual performance is labeled and defined and three distinct factors of contextual performance have been identified. Following Coleman and Borman (2000), the present study will evaluate each of the three dimensions of contextual performance (Personal Support, Organizational Support, Conscientious Initiative), along with task performance, as criterion variables when testing hypotheses. Along with the clear distinction between different dimensions of contextual performance, the research also contains strong support for the distinction between task and contextual performance.

\section{Contextual Performance Differentiated from Task Performance}

Although contextual and task performance have been found to be significantly correlated (r's range from .20 to .55 in Conway, 1999; Motowidlo \& Van Scotter, 1994; Van Scotter \& Motowidlo, 1996; Williams \& Anderson, 1991), the dimensions are considered unique in the way they contribute to an organization and in how they link to overall performance and certain dispositional characteristics (e.g., personality, cognitive ability). Regarding how each uniquely impacts organizations, task performance contributes to the technical core of an organization. It is generally role-prescribed and can be found on an employee's performance appraisal. Conversely, contextual performance is more general in nature rather than job specific and spans across many different jobs. It is not usually role prescribed or formally appraised. Several findings in the research combine to make a strong argument for distinguishing between task and contextual performance. 
Bonness, Brian, 2007, UMSL, p. 18

Conway (1996) demonstrated the distinction between task and contextual performance when 97 performance dimensions that had been sorted into either a task or contextual performance domain were found to correlate more strongly with dimensions in the same domain than with dimensions in the opposing domain. Further, Murphy and Shiarella (1997) found that the relationship between predictors (i.e., conscientiousness, cognitive ability) and performance changed depending on whether task or contextual performance was being evaluated and that predictive validity was highest when the importance placed on the two types of performance remained equal.

The distinction between task and contextual performance has also been evaluated by examining research on how the different performance dimensions influence judgments of overall performance. Borman and Motowidlo (1997) reviewed evidence that showed supervisors consider both task and contextual performance when rating overall performance and found that supervisors tend to weight task and contextual performance behaviors relatively equally when making overall performance ratings. For example, Motowidlo and Van Scotter (1994) made the distinction between the two types of performance by showing that task and contextual performance contributed independently to judgments of overall performance. Using regression analysis in a sample of 715 U.S. Air Force mechanics, they found that supervisor ratings of task performance predicted overall performance above and beyond the prediction of contextual performance and that contextual performance predicted overall performance above and beyond task performance. In a follow-up study, and again using a large sample of U.S. Air Force mechanics $(\underline{N}=1136)$, Van Scotter and Motowidlo (1996) found that one factor of contextual performance, Interpersonal Facilitation, as well as task performance each 
predicted unique variance in overall performance judgments by supervisors. They did not find, however, that a second dimension of contextual performance, Job Dedication, contributed uniquely to overall performance ratings. These findings were for nonmanagerial jobs. Conway (1999) later investigated the same relationships in management level positions and found that both Interpersonal Facilitation and Job Dedication contributed unique prediction to overall performance judgments.

Johnson (2001) used the relative weights method (see Johnson, 2000) to evaluate the relative contribution of three dimensions of contextual performance and three dimensions of task performance to overall performance judgments. Results showed that all three dimensions of contextual performance (Interpersonal Contextual Performance, Organizational Contextual Performance, Job-Task Contextual Performance) contributed significantly to overall judgments. Further, these results were consistent across eight different job families. Finally, Rotundo and Sackett (2002), in a policy capturing study, evaluated the relative importance of three dimensions of performance (task, citizenship, and counterproductive) and their impact on supervisors' performance ratings. They found that although task and counterproductive dimensions of performance tended to receive more weight, all three components of performance (including citizenship performance) significantly influenced overall performance.

In conclusion, performance does not appear to be unidimensional. Rather, researchers and supervisors seem to clearly recognize a distinct difference between task and contextual performance dimensions. Next is a review of the antecedents that are thought to contribute to contextual performance behaviors, how these antecedents 
Bonness, Brian, 2007, UMSL, p. 20

compare to those typically linked to task performance, and how the antecedents of both task and contextual performance relate to the constructs typically measured in interviews. Antecedents of Contextual Performance

Research shows a clear distinction between the antecedents that typically predict task performance (e.g., cognitive ability, job knowledge) and those that impact contextual performance (e.g., personality), illuminating further the distinction between these two dimensions of performance. Motowidlo et al. (1997) explored the possibility that task and contextual performance might have unique antecedents by proposing a model showing that personality is a relatively strong predictor of contextual performance while, in comparison, cognitive ability is a strong predictor task performance. The theory suggests that these unique antecedent variables affect the two performance dimensions through various mediating variables (e.g., habits, skills, knowledge). Personality is a possible antecedent to contextual performance because it is expected to be a better predictor of employee performance in situations in which expectations are less clearly defined, such as in situations where contextual performance behaviors are displayed (Bettencourt, Gwinner \& Meuter, 2001).

Constructs that have been studied as antecedents in the contextual performance literature and that have been found to have an empirical link to contextual performance include: job attitudes (e.g., satisfaction, fairness, organizational commitment), disposition (e.g., personality, affect), task characteristics (e.g., feedback), organizational characteristics (e.g., perceived organizational support, group cohesion), and leader behavior (e.g., transformational leader behavior) (Organ \& Ryan, 1995; Podsakoff, MacKenzie, Paine \& Bachrach, 2000). One of the most common variables found to be an 
antecedent of contextual performance is conscientiousness (Organ \& Ryan, 1995). In a meta-analysis by Organ and Ryan (1995), conscientiousness was found to be significantly related to two dimensions of contextual performance (i.e., Altruism, Compliance). In another review, Borman and Motowidlo (1997) uncovered a considerable amount of research evidence showing a stronger link between personality and contextual performance than personality and task performance. Specifically, they showed that the personality factors of work orientation, dependability, cooperativeness, and internal locus of control all had stronger correlations with contextual performance than with task performance.

More recently, Borman et al. (2001) reviewed several articles showing a link between personality and contextual performance. This review concluded that there is considerable support for the link between conscientiousness and contextual performance. They reported a mean uncorrected, sample-size weighted correlation between conscientiousness and self- and others' (e.g., peer, supervisor) ratings of contextual performance of .24. Included in the review, Neuman and Kickul (1998) found a significant link between conscientiousness and all five dimensions of OCB ( $\underline{r}^{\prime} s=.20$ to .41). Also, the results in Miller, Griffin and Hart (1999) showed that conscientiousness predicted contextual performance $(\underline{r}=.42)$ above and beyond neuroticism and extroversion. In addition to these findings, several important research studies have found that conscientiousness is not only related to contextual performance but is more strongly related to contextual performance than to task performance (e.g., LePine \& VanDyne, 2001; Motowidlo \& Van Scotter, 1994; Van Scotter \& Motowidlo, 1996). 
Further, the Motowidlo and Van Scotter (1994) study found that experience was a better predictor of task performance than of contextual performance while personality explained more variance in contextual performance than in task performance. In terms of personality, Work Orientation ( $(\underline{r}=.36)$, Dependability $(\underline{r}=.31)$, Cooperativeness $(\underline{r}=.22)$, and Internal Locus of Control $(\underline{r}=.26)$ all had significantly stronger correlations with contextual performance than with task performance. Experience $(\underline{r}=.34)$ was a significant correlate with task performance and this relationship was significantly stronger than the correlation with contextual performance $(\underline{r}=.16)$.

Van Scotter and Motowidlo (1996) also found interesting results when evaluating the correlations between task and contextual performance and various individual difference variables. Experience and job knowledge were correlated significantly higher with task performance than with Interpersonal Facilitation while two dimensions of personality (i.e., extroversion, agreeableness) were correlated significantly higher with Interpersonal Facilitation than with task performance. In addition, conscientiousness was significantly correlated with both Job Dedication and Interpersonal Facilitation. In another study that divided contextual performance into multiple dimensions, Johnson (2001) found that three dimensions of task performance tended to have stronger uncorrected correlations with cognitive ability than three dimensions of contextual performance (Interpersonal Contextual Performance, Organizational Contextual Performance, and Job-Task Contextual Performance). Meanwhile, uncorrected correlations with personality (agreeableness, dependability, achievement) tended to be stronger for the contextual performance dimensions than for the task dimensions. These results were consistent across eight different job families in a large organization. 
Also informative is the research from Project A, a large test validation research project conducted by the U.S. Army (see Cambell, 1990), that showed a relatively strong link between cognitive ability and a measure of task performance ( $\underline{r}=.33)$ compared to its relationship with a measure of contextual performance $(\underline{r}=.08)$. Conversely, three personality measures had significantly stronger correlations with contextual performance than with task performance. Further, dependability was especially highly correlated with the contextual performance criterion $(\underline{r}=.30)$. Finally, Bettencourt, Gwinner and Meuter (2001) completed two studies of different predictors of contextual performance and found that personality predicted customer service related contextual performance behaviors beyond both job attitudes and job knowledge.

Based on the research reviewed to this point, personality (especially conscientiousness) seems to be a consistent and moderately strong predictor of contextual performance. The reason why conscientiousness appears to be a good predictor of contextual performance becomes more evident when looking at the sub-traits that make up the global trait of conscientiousness. Roberts et al. (2005) evaluated the structure of conscientiousness more closely and concluded that the global trait is made up of six subtraits that link to important criterion variables, including work dedication. Of the six subtraits identified, four stand out as having a strong influence theoretically on contextual performance. First, industriousness is defined as hard working, ambitious, confident, and resourceful. Second, responsibility defines someone who likes to be of service to others, frequently contributes time and money to community projects, and tends to be cooperative and dependable. Third, individuals with a high level of traditionalism tend to comply with current rules, customs, norms, and expectations. They also dislike changes 
and do not challenge authority. Lastly, individuals scoring high on virtue tend to act in accordance with accepted rules of good or moral behavior and strive to be a moral exemplar. Based on these descriptions, responsibility is likely related to personal support, traditionalism and virtue appear closely linked to organizational support, and industriousness might be highly related to the conscientiousness initiative dimension.

On the other hand, cognitive ability, job knowledge, and job experience seem to be better predictors of task performance. Interestingly, these antecedents are constructs that have been found to be measured in the employment interview. The interview is among the most popular selection devices used in companies today and has very good predictive validity (e.g., Huffcutt \& Arthur, 1994; McDaniel, Whetzel, Schmidt \& Maurer, 1994). In fact, interviews predict job performance arguably better than paperand-pencil personality tests. In addition to studying their predictive validity, recent research has focused on determining the constructs that are measured by interviews. The most commonly measured constructs (e.g., personality, interpersonal skills) appear to be closely linked to contextual performance while other constructs found to be measured in interviews (e.g., cognitive ability, job knowledge, job experience) seem to be related to task performance.

\section{Predictive and Construct Validity of Interviews}

Consistently, interview research indicates that employment interviews are good selection devices with relatively high predictive validity. Several meta-analyses have collectively found that interviews predict performance with average validities in the high $.30 \mathrm{~s}$, with structured interviews predicting at an even higher level of validity, in the mid .50s (Huffcutt \& Arthur, 1994; Marchese \& Muchinsky, 1993; McDaniel, Whetzel, 
Schmidt \& Maurer, 1994; Schmidt \& Radar, 1999; Weisner \& Cronshaw, 1988) and as high as .62 in one meta-analysis (Wiesner \& Cronshaw, 1988). In addition to extensive research investigating the predictive validity of interviews, recent research has turned to studying the constructs that interviews measure. This research has tried to answer the question of why interviews predict so effectively.

Several qualitative and meta-analytic reviews of the interview literature have consistently found that structured interviews tend to measure such constructs as personality, general mental ability, social skills, job knowledge, and job experience (Huffcutt, Conway, Roth \& Stone, 2001; Moscoso, 2000; Posthuma et al., 2002; Salgado \& Moscoso, 2002). In the Salgado and Moscoso (2002) meta-analysis, social skills, which included communication skills (e.g., verbal, non-verbal) and interpersonal skills (e.g., developing and maintaining relationships), clearly had the strongest link to interviews. These results suggest that interviewers are influenced heavily by the inherent social nature of the interview process. Similarly, the Huffcutt, Conway, Roth and Stone (2001) meta-analysis found that the most common constructs measured by interviews are personality and applied social skills, a construct category closely related to and possibly influenced by personality. They found that conscientiousness was the most commonly rated construct in interviews, followed closely by interpersonal skills. Conscientiousness was also defined with such labels as responsibility, dependability, initiative, and persistence. Interpersonal skills were labeled as interpersonal relations, social skills, team focus, and the ability to work with people. Together, these two constructs accounted for more than $60 \%$ of all constructs measured by interviews in this meta-analysis. Regarding the measurement of personality in interviews, Barrick, Patton and Haugland (2000) found 
that highly structured interviews tended to measure the Big Five personality traits slightly better than low structured interviews.

A common theme that is present in these meta-analyses and reviews is that personality - primarily conscientiousness - is consistently measured by most types of interviews. The earlier review of the antecedents of contextual performance identified personality (i.e., conscientiousness or dependability) as one of the most important predictors of contextual performance and other constructs measured by interviews, such as interpersonal skills, should be related theoretically to contextual performance. Therefore, interviews should be expected to be a good predictor of contextual performance, and further, the reason why interviews are a good predictor of overall performance might be due, at least in part, to their strong link to the contextual dimension of performance. Interviews also measure constructs, such as cognitive ability, job knowledge and experience, and consequently, should be capable of predicting the task dimension of performance.

Unfortunately, almost all of the research on interviews to this point has neglected to distinguish between specific dimensions of performance and, instead, have evaluated the predictive quality of interviews using generic measures of overall performance. Upon searching the research, only two studies were found that designed interviews to specifically assess and predict contextual performance. First, Latham and Skarlicki (1995) evaluated the difference in how interviews that use situational questions and those that use behavioral questions predict two dimensions of contextual performance. Situational interviews (SI) use questions that ask applicants to explain how they would behave in a hypothetical work situation. Pattern behavior description interviews (PBDI) 
focus on applicants' past behaviors by asking them what they actually did in response to a specific work situation. In this particular study, the SI interviews were much more structured than the PBDI interviews. In fact, PBDI interviews did not include a structured scoring guide. The study evaluated how each type of interview predicted both OCB-I and OCB-O. Results showed that SI interview questions significantly correlated with both OCB-I $(\underline{\mathrm{r}}=.30)$ and OCB-O $(\underline{\mathrm{r}}=.50)$ while PBDI interview questions did not significantly correlate with either dimension ( $\mathrm{r}=.16$ and .02 for OCB-O and OCB-I respectively). A few reasons might explain the different prediction levels of the two types of interviews, but the most likely is the relative level of structure in each interview type. The most noticeable difference was the lack of a structured scoring guide in the PBDI for assessing interviewee responses. In addition, PBDI interview questions were formulated by essentially telling the interviewee the behavioral dimension and then asking for an example from past behavior that illustrated that dimension. This likely allowed interviewees to choose a high level example, which resulted in a small amount of variability in ratings.

More recently, Allen, Facteau and Facteau (2004) developed an interview to assess and predict contextual performance. They evaluated the link between various dispositional variables theoretically linked to contextual performance and the interview. These included personal initiative, empathy, perspective taking, helpfulness, positive affect, and conscientiousness. Using the three-dimension model developed by Coleman and Borman (2000), Allen et al. (2004) combined contextual performance ratings into the three dimensions (Personal Support, Organizational Support, Conscientiousness Initiative). 
Of the six dispositional variables measured in the study, four were found to be significantly correlated with one or more of the contextual performance dimensions in the interview. Personal initiative, which was defined as the extent to which people take an active and self-starting approach to work and go beyond what is formally required of a given job (Frese \& Fay, 1997), was correlated with Organizational Support, Conscientious Initiative, and overall interview scores. Overall interview scores were computed by averaging the scores across all dimensions and all ratings. Helpfulness was correlated with all three contextual performance dimensions in the interview as well as with overall interview scores. Empathy significantly correlated with Organizational Support. Finally, positive affect significantly correlated with Organizational Support and overall interview scores. Although conscientiousness was not significantly correlated with either interview scores or performance ratings of contextual performance, the researchers pointed out a low standard deviation $(\underline{\mathrm{SD}}=.25)$ in conscientiousness scores, which suggests the possibility that range restriction could have been partly or wholly responsible for this surprising outcome.

Concerning the link between interview scores and ratings of contextual performance, results in Allen et al. (2004) show that the interview dimensions of Conscientious Initiative and Organizational Support seem to be the best predictors of contextual performance. Conscientious Initiative interview ratings were significantly correlated with all three contextual performance dimensions $(\underline{\mathrm{r}}=.24, \underline{\mathrm{r}}=.27$, and $\underline{\mathrm{r}}=.32$ for Organizational Support, Conscientiousness Initiative, and Personal Support respectively) as well as overall co-worker ratings of contextual performance $(\underline{r}=.30)$. Organizational Support interview ratings were significantly correlated with the Organizational Support 
dimension of contextual performance ratings $(\underline{r}=.31)$. Finally, overall interview scores were significantly correlated with the Personal Support dimension of contextual performance ratings $(\underline{r}=.25)$. Additionally, regression analysis showed that overall interview scores predicted a significant amount of variance in each of the three contextual performance dimensions. Consequently, interview questions designed specifically to measure various dimensions of contextual performance seem to significantly predict coworker ratings of these contextual performance dimensions.

In another important result, the researchers did not find any difference between the two interview question types. Unlike in Latham and Skarlicki (1995), Allen et al. (2004) found that questions focusing on past behavior (PBDI) were just as predictive as questions focusing on future situations (SI). The consistency in prediction of the two types of questions is most likely a result of the steps taken in this study to standardize the structure across the two types of interviews.

Finally, one study has conducted a preliminary evaluation of how interviews predictt specific performance dimensions. Conway and Huffcutt (2005) used metaanalysis methodology ( $\underline{\mathrm{N}}=10$ multitrait-multimethod matrixes) to evaluate how well interviews predict task and contextual performance. These researchers categorized interviews and performance criteria into one of five dimensions: (1) Task; (2) Individual Citizenship; (3) Job/Organization Citizenship; (4) Leadership; or (5) Communication. Results showed that interviews only predicted specific dimensions moderately well (mean $\underline{r}=.29$ across all matched dimension correlations). When comparing predictive validity of the different types of interviews, task performance ( $(\underline{r}=.36)$ was predicted better than citizenship performance ( $\underline{r}=.29$ and $\underline{r}=.14$ for Individual Citizenship and 
Job/Organization Citizenship respectively). Lastly, task interviews tended to have better discriminant validity. In other words, task interviews predicted task performance $(\underline{r}=.36)$ better than citizenship performance $(\underline{r}=.22)$, while citizenship interviews predicted citizenship ( $\underline{r}=.29$ and $\underline{r}=.14$ for Individual Citizenship and Job/Organization Citizenship respectively) about the same as task performance ( $\underline{r}=.21$ and .10 for Individual Citizenship and Job/Organization Citizenship respectively). This study presents some interesting ideas and results but certain limitations encourage more research in this area. Most importantly, the interviews in the meta-analysis were not specifically designed to predict either task or contextual performance. Instead, the researchers reviewed studies and included those that contained both interviews and performance measures and then categorized them into one of the five dimensions. The present study explores the predictive validity of interviews specifically designed to predict task or contextual performance.

Based on the findings outlined in this review, interviews appear to predict generic measures of overall performance quite effectively and some preliminary evidence suggests that interviews might separately predict task and contextual performance dimensions. What needs to be examined further, however, is the predictive qualities of interviews specifically designed to measure contextual performance and how this compares to the predictive quality of interviews specifically designed to measure task performance. As reviewed earlier, interviews have been found to measure personality (i.e., conscientiousness) and interpersonal skills - constructs closely linked to contextual performance - while also measuring such constructs as general mental ability, job knowledge, and job experience, which have a relatively strong relationship with task 
performance. In fact, Murphy and Shiarella (1997) found that conscientiousness was more predictive of contextual performance while cognitive ability was more predictive of task performance. Therefore, interviews that collect information related to contextual performance behaviors should be expected to predict contextual performance and interviews that collect information concerning a candidate's job knowledge and experience should be expected to predict task performance.

In sum, the purpose of the present study is to contribute to the research by exploring further the possibility of using the employment interview to predict specific dimensions of performance (i.e., contextual, task). This study explored this possibility by partially replicating and then extending the research completed by Allen et al. (2004) as well as Conway and Huffcutt (2005). In their study, Allen et al. designed an interview to measure contextual performance. This interview, however, was not compared to a similar interview designed to measure task performance. The present study created interviews designed to concurrently evaluate both the task and contextual dimensions of performance. The present study also evaluated how well these different interview dimensions predict a measure of overall performance. Conway and Huffcutt (2005) offered a good preliminary view of how the different interview dimensions might compare, but the present study provides a unique and important contribution that extends this research. It evaluates the ideas presented in Conway and Huffcutt, but does so in a single study specifically designed to examine the predictive qualities of the different interview dimensions.

Next, the present study aims to extend the previous research by evaluating the predictive value of the contextual performance interview dimension over and above the 
influence of a paper-and-pencil test of conscientiousness. This will provide a better idea of whether interviews add any value to a selection process not already provided by a less expensive and less time consuming paper-and-pencil test.

Further, this study evaluates the potentially contrasting results obtained when collecting measures of contextual performance from different sources. Specifically, the present study collected self-ratings of performance as well as ratings provided by various other assessors of participant performance (e.g., work supervisors, work peers, classmates, professors, etc.). Some research has found that ratings of contextual performance from different sources (e.g., self, work peers, supervisor) do not always agree highly and can be uniquely linked to judgments of overall performance (e.g., Conway, 1999). Using multiple rating sources offers the opportunity to evaluate the study hypotheses thoroughly and to investigate further the relationship between different sources of ratings of contextual performance.

Finally, the present study adds to Allen et al. (2004) and other previous research in this area by going beyond measures provided by self and other assessors of participant performance and collecting measures of contextual performance within a performance assessment exercise. No previous studies were found that evaluated contextual performance in this manner. This study was able to explore how the performance measure obtained in the exercise compares to measures collected using self and assessor measures.

From this point forward, the term "assessor ratings" will refer to performance measures obtained from individuals identified by participants to assess their performance. This may include work supervisors, work peers, or others who have some knowledge of a 
Bonness, Brian, 2007, UMSL, p. 33

participant's performance at work, in school, or on related activities or projects. The method section of this paper outlines how participants distributed performance assessment questionnaires to assessors.

Hypotheses

First, as in Allen et al. (2004), the present study seeks to answer the question of whether interviews are capable of predicting contextual performance. Gatewood and Field (1990) suggest that the reason why interviews have such high predictive validity is because they are inherently designed to measure the types of behaviors that generally compose contextual performance. In addition, personality (i.e., conscientiousness) is one of the most consistent constructs found to predict contextual performance (e.g., Borman, Penner, Allen \& Motowidlo, 2001; Podsakoff, MacKenzie, Paine \& Bachrach, 2000) and also is one of the constructs, along with interpersonal skills, most consistently measured by interviews. Therefore, it was expected that interviews designed to predict contextual performance would effectively predict self-ratings and assessor ratings of contextual performance as well as contextual performance measures in the performance assessment exercise.

H1a: Structured interviews measuring contextual performance will predict ratings of contextual performance (Personal Support, Organizational Support, Conscientious Initiative) across all sources of performance ratings (self, assessor, exercise).

H1b: Structured interviews measuring contextual performance will predict ratings of contextual performance (Personal Support, Organizational Support, 
Conscientious Initiative) above and beyond interviews measuring task performance across all sources of performance ratings (self, assessor, exercise). Second, how does the prediction of contextual performance compare to that of task performance? First, interviews have been found to measure constructs (e.g., cognitive ability, job knowledge, job experience) empirically and theoretically linked to task performance. In addition, several meta-analytic studies have found strong predictive validity for interviews when predicting overall performance. Therefore, it was expected that interviews designed to measure task performance by collecting information regarding a candidate's knowledge and experience with specific work tasks or projects would effectively predict self-ratings and assessor ratings of task performance as well as task performance in the performance assessment exercise.

H2a: Structured interviews measuring task performance will predict ratings of task performance across all sources of performance ratings (self, assessor, exercise).

$\mathrm{H} 2 \mathrm{~b}$ : Structured interviews measuring task performance will predict task performance above and beyond interviews measuring contextual performance across all sources of performance ratings (self, assessor, exercise).

Third, do interviews predict contextual performance above and beyond what can be predicted by a paper-and-pencil test of conscientiousness? Recall that four of the subfactors of conscientious appear to have a strong theoretical link to the various dimensions of contextual performance (Roberts et al., 2005). Specifically, an individual who works hard and is ambitious and resourceful, qualities of someone who is industrious, could be expected to score high on a measure of Conscientiousness Initiative. Similarly, a person 
with a high level of virtue and traditionalism, who likes to follow rules and norms and set a good example for others, might be likely score high on a measure of Organizational Support. Lastly, responsibility, a characteristic of someone who likes to serve and cooperate with others and contribute time and effort to group projects, might influence one's level of Personal Support. Taken together, it was expected that one's score on a paper-and-pencil test of conscientiousness could predict ratings of contextual performance.

H3: A paper-and-pencil test of conscientiousness will predict ratings of contextual performance (Personal Support, Organizational Support, Conscientious Initiative) across all sources of performance ratings (self, assessor, exercise).

Further, the research has demonstrated that interviews predict job performance above and beyond conscientiousness and cognitive ability (Cortina et al., 2000). Similarly, it as expected that interviews would predict contextual performance above and beyond what can be predicted by a paper-and-pencil test of conscientiousness.

H4: Structured interviews measuring contextual performance will predict ratings of contextual performance (Personal Support, Organizational Support, Conscientious Initiative) above and beyond what can be predicted by a paper-andpencil test of conscientiousness across all sources of performance ratings (self, assessor, exercise).

In addition to these primary hypotheses, the present study also investigated various other research questions. First, do interviews designed to measure contextual performance and interviews designed to measure task performance each predict overall performance? Recall that Borman and Motowidlo (1997) reviewed various studies that 
Bonness, Brian, 2007, UMSL, p. 36

together concluded that supervisors consider both task and contextual performance behaviors when rating overall performance and that supervisors tend to weight task and contextual behaviors relatively equally when making overall ratings. Other studies (e.g., Johnson, 2001; Rotundo \& Sackett, 2002) also found that both task and contextual performance dimensions significantly impact judgments of overall performance. Based on these findings, it was expected that both types of interviews will have an effect on ratings of overall performance.

H5: Structured interviews measuring task performance will predict ratings of overall performance across all sources of performance ratings (self, assessor, exercise).

H6: Structured interviews measuring contextual performance will predict ratings of overall performance across all sources of performance ratings (self, assessor, exercise).

H7: Structured interviews measuring contextual performance will predict ratings of overall performance above and beyond interviews measuring task performance across all sources of performance ratings (self, assessor, exercise).

Finally, how will the results differ across measures of contextual performance provided by different sources (self, assessor, exercise)? It is possible that very different results are found for different rating sources. What implications will this have? Will any two sources be highly related to each other? It seems possible that the performance measure in the exercise could produce ratings similar to either self-ratings or assessor ratings, but probably not both. Self-ratings tend to be more lenient but assessor ratings 
Bonness, Brian, 2007, UMSL, p. 37

could turn out to be quite lenient as well. In addition, how might different rating sources impact the link between specific performance dimensions?

Another potentially interesting area for exploratory analyses involves the measures of overall performance. This study collected ratings of overall performance from participants and assessors but this measure could be somewhat different than a measure that simply combines the measures from the individual dimensions. The level of agreement between these two measures of overall performance was evaluated and the level of support for hypotheses 5, 6, and 7 across the different measures was examined.

\section{Method}

\section{$\underline{\text { Participants }}$}

One-hundred forty-six undergraduate college students recruited from business courses at a mid-sized, Midwestern University participated in this study. They were given extra credit in the courses from which they were recruited. Participant age ranged from 20 to 45 , with an average age of 25 . Fifty-six percent were men and $44 \%$ women. A majority of participants (75\%) were White, while $13 \%$ were Asian and $8 \%$ were Black. On average, participants reported having approximately eight years of work experience and slightly more than five employment interviews previous to this study.

All 146 participants described above participated in the interview and selfassessment portions of the study. Ninety-one percent $(\underline{\mathrm{N}}=133)$ from the larger group also completed the performance assessment exercise. They completed the exercise in groups of two or more. The 13 participants excluded from the exercise did not participate in this part of the study because their laboratory session did not include a group of two or more. Participants who showed up alone completed the interview portion and received assessor 
Bonness, Brian, 2007, UMSL, p. 38

questionnaires to distribute. Once laboratory sessions were complete, the data from the exercise for five participants was dropped from the analyses because these participants did not follow the directions. Therefore, a total of 128 participants were included in the analyses for the exercise. Finally, a total of 131 assessors returned questionnaires for 78 unique participants. Detailed demographic information for assessors is provided below. Of these 78 participants receiving assessor questionnaires, 65 had also participated in the exercise.

In summary, 146 participants were included in the analyses involving the selfassessment of performance; 128 were included in the analyses for the exercise; and 78 participants were included in the analyses of assessor questionnaires. These varying N's across rating sources, and the fact that slightly different sets of individuals participated in each phase of the study, must be considered when interpreting results and making conclusions.

$\underline{\text { Materials }}$

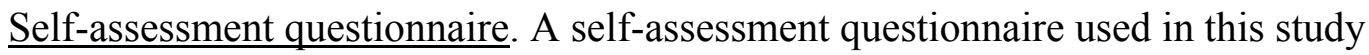
included a self-assessment of task, contextual, and overall performance, several items measuring conscientiousness, and various participant demographic and work background questions. It required approximately 20 minutes for completion. See Appendix A to view the self-assessment questionnaire.

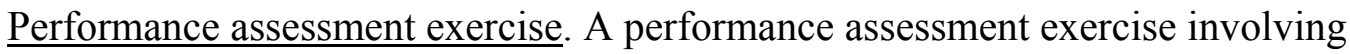
the processing of weekly employee timesheets for a fictitious company was designed for this study. This exercise allowed for the measurement of each of the three dimensions of contextual performance (i.e., Personal Support, Organizational Support, Conscientious 
Initiative) along with task performance. The exercise included a detailed set of instructions that outlined various rules and contingencies for processing the timesheets. Each timesheet involved a simple math element and required approximately two to three minutes on average to process. The exercise required concentration and attention to detail in order to perform at a high level of accuracy. See Appendix B to view the exercise instructions and a sample timesheet.

Email responses. To measure participants' level of contextual performance, a set of emails and email responses were developed. Participant responses to the emails were obtained during the performance assessment exercise. To identify the set of emails and responses to be used, subject matter experts (SMEs) reviewed a pool of emails and email responses and determined those that would serve as the best measure of each contextual performance dimension. SMEs consisted of 10 advanced level graduate students in the field of I/O psychology. All but one SME had at least a Masters degree in I/O. SMEs reviewed the dimensions of contextual performance first, and once familiar with the differences between dimensions, sorted each email into one of the three dimensions. Then, for each response linked to an email, SMEs indicated the level at which the response represented the contextual performance dimension into which they had sorted the email. For example, each response in a pool of responses generated for an email sorted into the Personal Support dimension was rated in terms of how much personal support it represented on a 5-point scale ranging from 1 (This response represents a low level of personal support) to 5 (This response represents a high level of personal support). See Appendix C for the materials used by SMEs to sort emails and rate email responses. 
Before beginning the study, the pool of emails evaluated by SMEs was narrowed down to two emails per contextual performance dimension for a total of six emails to be used in the exercise. First, two emails sorted into a dimension at a high level of SME agreement (i.e., at least seven of the 10 SMEs agreed on the dimension) were chosen to represent each of the three dimensions. Next, the means and standard deviations of the SME ratings for each possible response to an email were evaluated and a set of five responses that closely anchored to the points of a 5-point scale was chosen. That is, responses with mean values close to one of the points on the 5-point scale and with reasonably low standard deviations were chosen. The results of the SME ratings are provided in Table 1.

Each email provided the participant with an opportunity to demonstrate some level of performance in one of the three contextual performance dimensions. For example, one email was from a teammate who expressed concern about the timesheet task and how he/she would likely not finish the minimum requirement for the lottery in the allotted time. The participant then chose from five response options to the email, each representing a different level of Personal Support. Similar emails and response options for the Organization Support and Conscientious Initiative dimensions were delivered during the exercise. See Appendix D for the emails and responses that were used during the exercise.

Interview. Behavior-based interview questions were created for the present study. A pool of questions was developed to assess task performance as well as Personal Support, Organizational Support, and Conscientious Initiative. These questions were designed around some of the most common behavioral indicators used throughout the 
literature to define the performance dimensions (e.g., Allen et al., 2004; Coleman \& Borman, 2000; Smith et al., 1983; Van Dyne et al., 1994, Van Scotter et al., 2000; Williams \& Anderson, 1991). From the pool of questions, eight total questions were chosen; two were chosen for task performance and two were chosen for each of the three dimensions of contextual performance. Both task questions were asked of every participant. From the pair of questions for each contextual performance dimension, one question served as the primary question and the other was a backup question in the event that a participant had difficulty responding to the primary question.

The interview questions chosen were ones to which participants with little or no work experience could provide sufficient answers. The questions focused on how participants have behaved in situations from the past. An example question from the Personal Support dimension is, "Tell me about a time when you noticed that someone else (e.g., co-worker, classmate) needed help accomplishing an important task. How did you respond? What did you do?" This question provided the participant with an opportunity to discuss whether he/she helped the person in need and what exactly he/she did in response to the situation. It also allowed the participant to provide examples from a work context or from a school context if he/she did not have sufficient work experience from which to draw personal examples.

Behavioral indicators from the scale in Williams and Anderson (1991) that measures task performance, or "in-role behaviors," were used to develop task related interview questions. An example of a task question was, "Think about the last major task or project you worked on for your current or most recent job (or for a class at school). Focus on something you did alone rather than as part of a team. What steps did you take 
to complete the task or project?" Again, this question is general enough that a participant with most any level of work experience could provide a sufficient answer.

The final page of each interview guide included a scale for rating the participant's level of conscientiousness. See Appendix E to view the interview guide that was used in this study.

Assessor questionnaire. An assessor questionnaire included items for assessing the task, contextual, and overall performance level of the target individual along with several demographic and work background questions. Participants in the study identified appropriate assessors to complete this questionnaire. Assessors included supervisors, work peers, and others who had some knowledge of a participant's performance at work, in school, or on related activities or projects. See Appendix F to view the assessor questionnaire.

Procedure

Data were collected for the present study in multiple stages.

$\underline{\text { Self-assessment questionnaire. First, the self-assessment questionnaire was }}$ distributed to undergraduate college students in business courses from which participants were directly recruited. The self-assessment questionnaire was distributed during the initial class visit to recruit participants. This was done in an effort to limit the time requirement placed on participants when they later attended a laboratory session to complete the performance assessment exercise and structured interview. Before completing the self-assessment questionnaire, participants reviewed and signed a consent form. See Appendix G to view the consent form distributed to participants. 
Performance assessment exercise. Second, participants attended a separate laboratory session where they participated in the performance assessment exercise and structured interview. Before beginning the exercise, participants were given directions and shown a sample timesheet with several errors that needed to be corrected. Participants were told that their performance on the timesheet task would impact their opportunity to be enrolled in two separate lotteries - one at the individual level and one at the team level. They were informed that this reward would be directly linked to the number of timesheets they processed accurately. The lottery was an important incentive in this study for two reasons. First, it was intended to encourage participants to take the study seriously and demonstrate sincere effort when working on the timesheet exercise. Second, the lottery theme played an important role in some of the emails and email response options distributed to participants while working on the timesheet exercise. In this way, the lottery encouraged a focus on both task and contextual behaviors.

Participants were given 25 minutes to process as many timesheets as possible and were told that a minimum number of timesheets had to be processed accurately in order to be enrolled in the lotteries. If participants successfully processed the minimum number of timesheets, then each timesheet would count for one lottery chance for the individual lottery and one chance for the team lottery. The minimum timesheet requirement was an important detail because it was a theme used in several of the emails distributed throughout the exercise. The timesheet minimum was originally set at 10 timesheets and then changed to seven timesheets after eight sessions were conducted. This change was made for reasons that are explained in detail in the results section. 
After the experimenter provided a short introduction to the exercise and then read through the first page of instructions, participants were placed in separate rooms where they worked on the timesheet task. Participants were told that they would be working as an accounting assistant for a fictitious company, HRX Consulting. As an accounting assistant, the participant's job was to process weekly timesheets that were turned in by employees of the company. Further, participants were told that although they would be working on the timesheets alone in their private offices and would receive an individual reward for working on the exercise, their work output would be combined with that of the other individuals in the work team to get a group measure of performance. The participant's teammates for the exercise consisted of the other participants in the study session who were also accounting assistants working on the same timesheet task. The experimenter acted as the team leader. Before beginning the exercise, participants introduced themselves to each of their teammates in the study session. The intention was to set up a sense of accountability to teammates and team leader which would help maintain the realism of the task and of the emails distributed throughout the exercise. Creating a group situation allowed participants the opportunity to display contextual performance behaviors directed at each other and the group while working on the exercise.

While processing timesheets, participants received various emails from their teammates and/or team leader. These emails were delivered in the form of paper printouts passed under the door of each participant's office. All participants in the study received the same six emails, spaced throughout the 25-minute time period of the exercise. Each email provided an opportunity to respond back to the sender by simply checking the 
response most closely representative of how the participant would personally respond. Once participants checked a response, they slid the email reply back under the door. Participants were asked to respond to each email promptly before returning back to working on the timesheets. Participants were also told that they may be responsible for following through on any actions they agreed to take in their email response. Participants were encouraged to behave in the same way they would behave if actually on the job in a real work situation.

Interview. Following the performance assessment exercise, participants participated in a structured interview lasting approximately 15-20 minutes. Seven graduate and advanced undergraduate students, along with the experimenter, served as interviewers in this study. In the interview, interviewers provided a brief introduction, letting participants know what to expect during the interview process. Participants were not allowed to ask questions (aside from general interview process questions) and the interviewer did not disclose any ancillary information beyond the standard introduction and process information. The same five questions were asked of each participant in the study. Questions were asked in random order for each interview. Interviewers took notes during the interview and scored the participant on each interview response using the scale provided in the interview guide. Interviewers had time when the interview was finished to review their notes and modify any ratings if necessary. Once finished assessing interview responses, interviewers rated the participant on their level of conscientiousness using a scale on the last page of each interview guide. Interviewers did not ask any additional questions for the rating of conscientiousness. Instead, interviewers were instructed to use 
Bonness, Brian, 2007, UMSL, p. 46

the other information gathered throughout the interview to help determine the rating of conscientiousness.

Interviewer training. Interviewers in this study participated in a two-part training session lasting a total of three hours and conducted by the experimenter. Topics covered in the training session included behavior-based structured interviews, note taking procedures, rating procedures and common rater errors, and an in-depth understanding of the task and contextual performance dimensions. The training session provided the opportunity to practice asking interview questions, taking notes, and making ratings. See Appendix $\mathrm{H}$ for the guide used in the interviewer training.

After discussing the basics of structured interviews, trainees practiced kicking off the interview and then asking the questions in the interview guide. The experimenter role played examples of good, poor, and moderate quality interview responses to all of the questions. During the role play responses, trainees took notes and then made ratings. Following an example interview response, trainees compared notes and ratings with each other and talked about what they heard and what influenced their choice of rating. Completing this training exercise in groups and using the same role play response examples for all interviewer trainees helped establish consistency between interviewers before beginning the study.

To help ensure that training was transferred to actual study interviews and in order to maintain consistency and quality of the interviews throughout the study, the interviews were audio taped and reviewed by the experimenter. After the first few interviews and then periodically throughout the study, the experimenter provided feedback and reminders to interviewers concerning how they could implement the 
strategies discussed in the interviewer training. Additionally, when a second interviewer was present for a laboratory session, the extra interviewer sat in on an interview and took notes and made ratings while the "lead interviewer" conducted the interview. These situations were used to obtain inter-rater correlations, which are discussed in the measures section.

Assessor questionnaires. Once finished with the performance assessment exercise and interview, participants were asked to deliver questionnaires to two assessors who were either their work supervisor, work peer, or someone else who otherwise had knowledge of their behavior at work, in school, or on related activities or projects. Participants were given two self-addressed envelopes with the questionnaires and consent forms enclosed. See Appendix I for the instructions given to participants for delivering the assessor questionnaires.

Participants solicited individuals from work, school, or other related activities to serve as assessors for this study. In all, 131 questionnaires were received for 78 unique participants in the weeks that followed the laboratory sessions. Assessors were not compensated for completing the questionnaire. Assessor age ranged from 18 to 62 with an average age of nearly 34 . Fifty-seven percent were women and $43 \%$ men. A large majority of assessors (83\%) were White, while 5\% were Asian and 5\% were Black. Seventy-two percent of assessors rated the target participant in a work context, while $20 \%$ provided ratings based on behavior at school, and $8 \%$ made ratings based on "other related activities/projects." Assessors consisted of supervisors (32\%), co-workers (37\%), and individuals in other types of relationships (31\%) with the participant (e.g., classmate 
at school). Assessors reported having worked for an average of 14.8 years and had observed the behavior of the target participant for an average of 2.7 years.

The questionnaire packet instructed assessors to read the consent form provided, complete the questionnaire, and then place the self-addressed stamped envelope with completed questionnaire enclosed in the mail. Assessors were told that returning the questionnaire would signify their informed consent. This was intended to maintain anonymity of the assessor and increase the likelihood of returned questionnaires. See Appendix $\mathrm{J}$ for the consent form delivered to assessors.

\section{Predictor Measures}

Conscientiousness. Six 10-item facet scales developed by Chernyshenko (2002) were used to measure conscientiousness. The items on these scales were designed around the six sub-dimensions of conscientiousness outlined in Roberts et al. (2005). Items for this measure were incorporated into the self-assessment questionnaire. An example item is: "I try to do the best at anything I do." Participants responded to these items on a 4point scale ranging from 1 (Strongly Disagree) to 4 (Strongly Agree). Twenty seven of the items were negatively worded and thus had to be reverse scored for the analyses. Coefficient alpha for the entire 60-item scale was .89. Coefficient alpha for the six individual dimensions on the scale, each having 10 items, was as follows: Responsibility (.62), Traditionalism (.76), Virtue (.65), Self-Control (.78), Order (.87), and Industriousness (.78).

Conscientiousness was also assessed in the interview using a 5-point scale ranging from 1 (Very Low level of conscientiousness) to 5 (Very High level of conscientiousness). The definition of conscientiousness in Roberts et al. (2005) was 
provided and the instructions above the rating scale read, "Based on the information gathered in the interview, please assess the participant's level of conscientiousness."

Interestingly, the conscientiousness measure collected in the interview was only moderately correlated with the 60-item conscientiousness measure collected in the selfassessment $(\underline{r}=.24, \underline{p}<.01)$. In fact, the interview measure of conscientiousness was much more strongly correlated with a measure of overall interview performance (Overall Interview Score), which averaged the task and contextual performance dimensions together $(\underline{r}=.82, \underline{p}<.01)$. Interviewers may have treated the conscientiousness measure as an "overall measure" of interview performance rather than focusing exclusively on the conscientious elements of the participant's interview responses when making the rating.

Task and contextual dimensions of the interview. The anchors on the interview scale were slightly different for each question. The scale for the Personal Support question ranged from 1 (Failed to provide a clear example of...helping someone accomplish an important task...example did not clearly display any of the behavioral indicators) to 5 (Clearly described one of more excellent examples of...helping someone accomplish an important task...example displayed multiple behavioral indicators). The structure of the scale remained the same throughout the interview but the wording was modified slightly to fit the theme of each question. The scale for each question was accompanied by a list of behavioral indicators illustrative of the performance dimension.

The three contextual performance dimensions on the interview (PS, OS, CI $)^{1}$ were highly intercorrelated $(\underline{r}$ 's $=.38, .43$, and $.53 ; \underline{p}$ 's $<.01)$. This suggests that the contextual performance dimensions in the interview were highly related and perhaps might be considered a single broad dimension of contextual performance. This finding is not

\footnotetext{
${ }^{1} \mathrm{PS}=$ Personal Support; OS=Organizational Support; $\mathrm{CI}=$ Conscientious Initiative
} 
surprising considering recent studies that have found the dimensions of OCB to be highly interrelated (e.g., LePine, Erez \& Johnson, 2002). This is strong support for entering the contextual performance dimensions into the regression models as a set.

The two task performance related questions on the interview were structured in the same manner as the contextual performance questions. Responses were rated using the same scale format but with wording relevant to the task questions. The correlation between the two task questions was significant $(\underline{r}=.39, \underline{p}<.01)$.

Average contextual performance. An average score that combined the three contextual performance dimensions of the interview was obtained by simply averaging the scores on the three contextual performance related questions. For exploratory purposes, this measure was used as an alternative to entering the individual contextual performance dimensions of the interview into the regression models as a set. The findings of the two approaches will be compared.

Overall interview score. An overall score for the interview was calculated. This score simply consisted of an average between the task and contextual dimensions of the interview. It did not include the conscientiousness item.

\section{$\underline{\text { Inter-Rater Consistency }}$}

To obtain a measure of inter-rater consistency for the interview dimensions, correlations were calculated for the small sample of interviews $(\underline{\mathrm{N}}=17)$ that included two interviewers providing ratings for a single participant. The correlations between interviewers for the variables calculated in the interview are presented in Table 2. The correlations ranged from .50 to .74 and all were significant at the $\alpha=.05$ level or better. 
Bonness, Brian, 2007, UMSL, p. 51

\section{$\underline{\text { Criterion Measures }}$}

Task performance. Task performance was measured by evaluating participants' performance on the timesheet task in the performance assessment exercise. It was also evaluated in the self-assessment and assessor questionnaires.

For the timesheet exercise, task performance was measured in two ways. One measure was the raw number of timesheets processed accurately (Raw Task Score) and the second measure was the percentage of timesheets processed accurately compared to the total number of timesheets processed (Percent Task Score). The percentage measure offered a type of "standardized" score for task performance that would be less impacted by the timesheet minimum requirement and provided a truer measure of accuracy. These two measures of task performance in the exercise were strongly correlated $(\underline{r}=.73, \underline{p}<.01)$.

Errors on the timesheets might have occurred in any of the following areas: project code, overtime hours, addition of hours in total daily hours column, addition of hours in total weekly hours row, addition of expenses, circling IR for immediate reimbursement, checking the appropriate "Checked" box, and the employee and supervisor signatures.

The present study also collected self-ratings and assessor ratings of task performance using five items from a scale developed by Williams and Anderson (1991) and used again in Allen and Rush (1998). An example item is: “Adequately complete assigned duties." Participants rated these task performance items on a scale that was modified slightly from the original research in order to maintain consistency across measures in the present study. The rating scale in this study ranged from 1 (Almost Never display this behavior) to 5 (Almost Always display this behavior) and used the following 
stem for the self-assessment questionnaire: "When given the opportunity to display the following behaviors on the job or during school or other related activities/projects, I..." The items and rating scale were reworded slightly for the assessor questionnaire.

Coefficient alpha for the task performance scale in the self-assessment questionnaire was .66. Coefficient alpha in the assessor questionnaire was .76. In response to the relatively low alpha found for the self-assessment questionnaire, the individual items were examined. One item in particular seemed to be potentially confusing or misinterpreted by participants. Dropping this item raised coefficient alpha to .70 for the self-assessment and .83 for the assessor questionnaires. It was decided to use this modified, 4-item task performance scale for the study analyses.

Contextual performance dimensions. The three dimensions of contextual performance (PS, OS, CI) were assessed in the performance assessment exercise as well as in the self-assessment and assessor questionnaires. In the exercise, responses to the six emails, two in each dimension, were used to determine the participants' level of contextual performance. Each email had five response options and each response option equated to a value on a 5-point scale ranging from 1 (Low level of [the contextual performance dimension]) to 5 (High level of [the contextual performance dimension]). The two responses in a given contextual performance dimension were averaged together to generate the participant's level of performance in that dimension. Correlations between the email scores are reported in Table 3.

The two emails in the Personal Support dimension were significantly correlated $(\underline{r}=.20, \underline{p}<.05)$ as were the two emails in the Conscientious Initiative dimension $(\underline{r}=.37$, $\underline{\mathrm{p}}<.01)$. The two Organizational Support emails were not significantly correlated $(\underline{\mathrm{r}}=-.06)$. 
This might be because they were measuring the OS dimension in two distinct ways. Specifically, the first email did not ask the participant to actually sacrifice anything in order to support the larger group. Rather, it assessed the participant's support for the "organization" through his/her reaction to another team member who was complaining about the task. In a somewhat different approach to the OS dimension, the second email asked the participant if he/she wanted to donate any lottery chances earned in the exercise to the pool of chances for the larger group. This is more clearly requiring the participant to sacrifice something in order to display a high level of Organizational Support. The mean difference ( $\underline{\mathrm{M}}=4.29$ for the first OS email; $\underline{\mathrm{M}}=3.34$ for the second OS email) shows that participants were much more reluctant to offer a high level of support in the second email than in the first. Although these data suggest the two emails might be tapping different elements of Organizational Support, they were designed to assess the same construct and both were determined by SMEs to assess Organizational Support. Consequently, the two emails were averaged together for the study analyses.

Contextual performance was also measured using 32 items from a scale developed by Allen et al. (2004). An example item is: "Put a lot of effort into fulfilling my responsibilities." Similar to the task performance scale, participants rated the contextual performance items on a rating scale that was slightly different from the original research in order to maintain consistency across measures in the present study. The rating scale ranged from 1 (Almost Never display this behavior) to 5 (Almost Always display this behavior) and used the following stem: "When given the opportunity to display the following behaviors on the job or during school or other related 
Bonness, Brian, 2007, UMSL, p. 54

activities/projects, I..." The items and rating scale were reworded slightly for the assessor questionnaire.

The items on this measure were originally designed to reflect the five dimensions of OCB. Allen et al. (2004) combined the items to reflect the same three dimensions of contextual performance evaluated in the present study. As in Allen et al., the present study averaged together items representing a given dimension to obtain scores for the three broader dimensions of contextual performance (PS, OS, CI). For the selfassessment, coefficient alpha for all 32 items across the three contextual performance dimensions was .90 . Coefficient alpha for each of the three contextual performance dimensions was as follows: .74 for Personal Support; .78 for Organizational Support; and .82 for Conscientious Initiative. For the assessor questionnaire, coefficient alpha for all items was .96. It was .92 for Personal Support, .90 for Organizational Support, and .92 for Conscientious Initiative.

$\underline{\text { Average contextual performance. An average contextual performance score was }}$ computed for each of the three rating sources. This score was obtained by calculating the average of the ratings for the three contextual performance dimensions (PS, OS, CI).

Overall performance item (Overall 1). Overall performance was measured in two ways in the self-assessment and assessor questionnaires. First, one item with a 5-point scale was developed for this study. On the self-assessment questionnaire, the scale ranged from 1 (My overall job performance Does Not Meet standards and expectations) to 5 (My overall job performance Exceeds standards and expectations). For the assessor questionnaire, the scale ranged from 1 (His/her overall job performance Does Not Meet 
standards and expectations) to 5 (His/her overall job performance Exceeds standards and expectations).

Calculated overall performance (Overall 2). For the second measure of overall performance collected in the questionnaires, an average score that combined task and contextual performance was computed. Depending on the job and the goals of a particular organization, it is possible that task and contextual performance might be weighted differently when computing an average score of this sort. Because this study does not evaluate a specific job in an actual organization, however, it is difficult to determine how much relative weight should be given to one dimension or the other if weighted differently. As a result, equal weight was given to the task and contextual performance dimensions when calculating this overall measure.

Exercise overall performance. An overall performance measure was also calculated for the exercise. To do this, the scores for the task and contextual performance dimensions were standardized and then averaged together. Again, task and contextual performance dimensions received equal weight.

\section{Results}

\section{$\underline{\text { Descriptives }}$}

Overall means and standard deviations were calculated for all variables in the study and are presented in Table 4. This table includes means and standard deviations for interview scores, self-assessment ratings including conscientiousness, scores on the timesheet exercise, and assessor questionnaire ratings. Table 4 also includes a correlation matrix showing the relationships between these variables as well as coefficient alphas (in the diagonal) where appropriate. All coefficient alphas were acceptable, ranging from .70 
for the self-assessment measure of task performance to .96 for the assessor questionnaire measure of Average Contextual Performance. Among the interview ratings, the OS dimension seemed to receive relatively low scores on average. In the exercise, however, PS was the dimension that received a relatively low mean score. Interestingly, the relationship between the Task and Average Contextual Performance measures was quite strong for two of the three performance rating sources $(\underline{r}=.60, \underline{p}<.01$ for the selfassessment questionnaire; $\underline{\mathrm{r}}=.68, \mathrm{p}<.01$ for the assessor questionnaires). Also interesting is the weaker than expected correlation between the two conscientiousness measures $(\underline{\mathrm{r}}=.24, \underline{\mathrm{p}}<.01$ for the interview and self-assessment measures). Although not strongly related to each other, both conscientiousness measures were strong and consistent correlates with performance measures across all three rating sources. Finally, ratings on the assessor questionnaires tended to be somewhat higher than the other rating sources across all dimensions. Based on the literature (e.g., Harris \& Schaubroeck, 1988), selfassessment ratings might have been expected to be similar to or higher than the assessor ratings. All measures in the self-assessment were significantly correlated with measures in the assessor questionnaires ( $\underline{\text { ' }}$ s ranged from .31 for PS to .48 for Overall 2 , $\underline{p}$ 's $<.01$ ). Performance measures from the exercise were not consistently correlated with measures from the other two rating sources.

\section{$\underline{\text { Test for Interviewer Effect }}$}

An important first step before testing hypotheses was to check for any differences in ratings among the eight interviewers in this study. A one-way analysis of variance (ANOVA) was performed with interviewers as the independent variable. The dependent variables consisted of each interview dimension, including task, the three contextual 
performance dimensions, and the conscientiousness measure. A significant main effect was found for interviewer for the Organizational Support dimension $[\underline{F}(7,138)=3.31$, $\left.\underline{\mathrm{p}}<.01, \underline{\text { eta }}^{2}=.14\right]$ as well as for the Conscientiousness measure $[\underline{\mathrm{F}}(7,138)=3.28, \underline{\mathrm{p}}<.01$, $\left.\underline{\text { eta }}^{2}=.14\right]$. Significant main effects were also found for Average Contextual Performance $\left[\underline{F}(7,138)=2.47, \underline{p}<.05, \underline{e t a}^{2}=.11\right]$ and the Overall Interview Score $[\underline{F}(7,138)=2.36, \underline{p}<.05$, $\left.\underline{\text { eta }}^{2}=.11\right]$. When evaluating the means comparisons tests, a total of two significant differences were found between interviewers among the 112 possible comparisons for these four interview dimensions. Although these interviewer effects did not pose a strong concern, the interviewer variable was controlled in subsequent preliminary analyses when interview scores served as the dependent variable. Further, standardized interview scores were used in analyses for hypotheses where interview scores served as the predictor variable. In addition, any correlations presented from this point forward between interview scores and performance measures, including those presented in Table 4, are based on standardized interview scores.

\section{Test for Interviewer-Participant Gender Effect}

Another potential concern related to interviewer ratings was the possibility of finding an interviewer-participant gender effect. To test for the presence of this effect, a 2 (interviewer gender: male, female) X 2 (participant gender: male, female) analysis of covariance (ANCOVA) was conducted with each of the interview dimensions (Task, PS, OS, CI, Conscientiousness) serving as dependent variables. The interviewer variable was included as a covariate. To do this, seven dummy variables were created to represent the eight levels of the interviewer variable. To determine whether a gender effect was present, the interaction between interviewer and participant gender was examined. After 
Bonness, Brian, 2007, UMSL, p. 58

controlling for the influence of interviewer, results did not show a significant interaction between interviewer gender and participant gender for any of the interview dimensions. Impact of Second Interviewer

Yet another issue related to the interview that could have impacted the analyses for hypotheses was the fact that some interviews were conducted with a second interviewer observing. In order to ensure that this situation did not affect interview scores, a one-way analysis of covariance (ANCOVA) was performed where the two levels of the independent variable were interviews conducted one-on-one and interviews conducted with a second interviewer observing and making ratings. Interviewer was controlled again by including it in the analyses as a covariate. No significant effects were found for any of the interview dimensions including the conscientiousness measure. In other words, after controlling for the influence of the interviewer variable, interviewers did not rate participants any differently on the interview items when an extra interviewer was in the room observing than when interviews were conducted alone. Stated another way, participants did not respond differently in any significant way in the interview when a second interviewer was present.

\section{Impact of Exercise on Interview Performance}

One final issue that could have potentially influenced interview scores was whether participants completed the timesheet exercise before going through the interview. Recall that a small group of participants $(\underline{N}=17)$ arrived to their study session alone and thus did not participate in the exercise portion of the study. These individuals continued straight to the structured interview portion of the study. All other participants completed the timesheet exercise before continuing to the interview. The question, 
therefore, was whether those who did not experience the exercise first performed any differently in the interview than those who completed the exercise. To help answer this question, a one-way analysis of covariance (ANCOVA), again controlling for interviewer, was performed. Whether the participant completed the timesheet exercise was the independent variable and the various interview dimensions served as the dependent variables. After accounting for the variance associated with interviewer, no significant differences were found between participants who completed the exercise and those who did not for any of the interview dimensions.

\section{Comparison of Different Exercise Group Sizes}

Participants signed up for laboratory sessions in blocks of six participants. The hope was that at least three participants would show up for each session. The reason for setting the minimum group number at three was that the emails distributed throughout the exercise were more realistic when participants worked in groups of three or more. At times, however, only one or two participants arrived for their assigned session. In situations where only one participant arrived, that participant completed the interview and assessor questionnaire portions of the study but not the exercise. When two participants showed up, they completed the exercise portion of the study along with the interview and assessor questionnaire portions. To investigate whether participants in groups of two behaved any differently than participants in groups of three or more when processing timesheets and responding to emails, a pair of one-way analyses of variance (ANOVAs) were conducted. Results of these analyses helped decide whether it would be appropriate 
to keep the exercise data for the 27 participants $^{2}$ who completed the exercise in groups of two.

The first ANOVA compared groups of two participants to groups of three or more with the dependent variables being participants' performance on the timesheet task and their response to the various emails distributed throughout the exercise. The second ANOVA examined the differences between all six possible group sizes (groups of 2, 3, 4, 5,6 , and 7). In both cases, participants' responses to the second OS email appeared to be affected to some extent. In the first case, a significant main effect was found $\left[\underline{\mathrm{F}}(1,126)=5.85, \underline{\mathrm{p}}<.05, \underline{\mathrm{eta}}^{2}=.04\right]$ where groups of two $(\underline{\mathrm{M}}=3.78, \underline{\mathrm{SD}}=1.19)$ responded significantly higher on the second OS email than did groups of three or more $(\underline{\mathrm{M}}=3.22$, $\underline{\mathrm{SD}}=1.04)$. Groups of two $(\underline{\mathrm{M}}=4.15, \underline{\mathrm{SD}}=0.66)$ also scored higher $[\underline{\mathrm{F}}(1,126)=9.59, \underline{\mathrm{p}}<.01$, \left.${\underline{\text { eta }^{2}}}^{2} .07\right]$ on the average score across the two emails measuring Organization Support (i.e., Exercise OS score) than groups of three or more $(\underline{\mathrm{M}}=3.72, \underline{\mathrm{SD}}=0.63)$. In the second ANOVA, the second OS email $\left[\underline{\mathrm{F}}(5,126)=3.39, \underline{\mathrm{p}}<.01, \underline{\mathrm{eta}}^{2}=.12\right]$ and the Exercise OS score $\left[\underline{\mathrm{F}}(5,126)=3.68, \underline{\mathrm{p}}<.01, \underline{\mathrm{eta}}^{2}=.13\right]$ were again affected by group size. In this case, mean comparisons tests showed that the differences were between groups of two $(\underline{\mathrm{M}}=4.15, \underline{\mathrm{SD}}=0.66)$ and groups of five $(\underline{\mathrm{M}}=3.46, \underline{\mathrm{SD}}=0.69)$ for the Exercise OS score. After encountering these differences, groups of two and groups of five were excluded from the analyses to see if the group size differences were exclusive to those two group sizes. Results of these subsequent analyses showed that differences continued to surface, this time between groups of three and groups of seven for the second OS email. In summary, the group differences do not seem to be unique to only those participants in groups of two. It is possible that these effects of group size are partly a

\footnotetext{
${ }^{2}$ One participant from this group was dropped from the analyses for not following directions.
} 
result of the low N's, which ranged from six to 38. As a precaution, the group size variable will be accounted for in any analyses that include the performance measures from the exercise as dependent variables.

\section{$\underline{\text { Impact of Timesheet Minimum on Exercise Scores }}$}

For the first 22 participants, the required timesheet minimum was set at 10 timesheets. This was communicated to participants in the exercise instructions as well as in two of the emails distributed while participants worked on the timesheets. Based on pilot work, it was thought that a requirement of 10 would allow for most participants to easily complete the minimum in less than the time allotted and then process more if they chose. As a result, participants would have an opportunity to display contextual performance behaviors without being restricted by the timesheet minimum requirement. After collecting data from the first 22 participants, it became evident that requiring 10 timesheets might be too demanding. On average, the first 22 participants processed only slightly more than $10(\underline{\mathrm{M}}=10.14, \underline{\mathrm{SD}}=4.65)$ timesheets. It was thought that this could potentially affect participant performance and responses during the exercise. Thus, the decision was made to change the minimum requirement to seven timesheets. This allowed participants to process, on average, more timesheets than the minimum requirement.

In the end, changing the timesheet minimum requirement did not have a significant impact. A one-way analysis of variance (ANOVA) was performed to test whether performance measures collected during the exercise differed between those in the 10-timesheet group and those in the 7-timesheet group. No significant differences were found for any of the task or contextual performance measures. As a result, the data 
from the exercise for the 22 participants in the group receiving the 10-timesheet minimum instructions remained in the analyses for the hypotheses.

\section{Assessor Questionnaire Rating Scale}

The assessor questionnaires completed by individuals familiar with a participant's behavior at work, in school, or during other related projects or activities were distributed with an error in the rating scale for items eight through 37 . Rather than the scale anchors

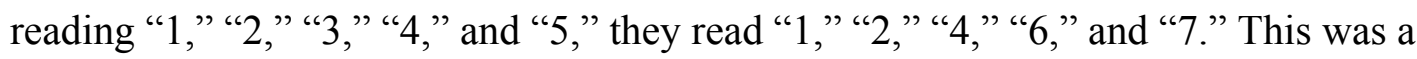
researcher mistake and was only corrected after 85 of $131(65 \%)$ assessors had completed and returned questionnaires. Some assessors used the correct scale anchors from a previous page in the questionnaire, but many followed directions diligently and consequently used the flawed anchors. When entering the data for the questionnaires with the incorrect anchors, 4's were converted to 3's, 6's were converted to 4's, and 7's were converted to 5's to be consistent with the first seven items and with the questionnaires returned after fixing the mistake. Because these scores were converted by the researcher, it was important to test whether the different questionnaire "versions" had an impact on how assessors responded. To do this, a one-way analysis of variance (ANOVA) was performed with assessor questionnaire version (incorrect scale vs. correct scale) being the independent variable and each of the task and contextual performance measures on the questionnaire serving as the dependent variables. This analysis was performed on both the complete set of 131 assessor questionnaires as well as the smaller sample representing 78 participants, in which case multiple assessor questionnaires for individual participants were averaged together. In both analyses, no significant differences were found for any of 
Bonness, Brian, 2007, UMSL, p. 63

the assessor questionnaire performance dimensions. Consequently, no changes in the remaining study analyses were made and all assessor questionnaires were included.

\section{Assessor Perspective}

An additional issue that arises when evaluating the assessor scores in this study is that questionnaires were received from supervisors, co-workers, and a number of other assessors with various relationships to participants including professors and classmates. Further, 53 of the 78 participants for whom assessor questionnaires were received had two assessors return questionnaires. In 34 of these cases (64\%), the two assessors were from two different perspectives (e.g., supervisor and co-worker). Because a number of unique assessor-participant relationships were represented, it was important to check whether differences in this relationship affected ratings on the questionnaires.

Assessors chose from 5 options on the last page of the questionnaire describing their relationship with the target participant. The options were: “I am this person's supervisor," "I am this person's co-worker," "I am this person's classmate at school," "I am familiar with this person's performance on other related activities/projects," and "Other. Please explain." To test whether the assessor-participant relationship impacted assessor ratings on the various measures in the questionnaire, a one-way analysis of variance (ANOVA) was performed where the independent variable was the assessor group with five levels and the dependent variables were the different performance measures in the assessor questionnaire (Task, PS, OS, CI, Average Contextual Performance, Overall Performance). These analyses did not produce any significant differences between assessor groups for any of the performance measures. As a result, the various assessors were combined within and across participants when performing 
analyses for the hypotheses. This means that when a participant received two questionnaires, even if from assessors with different relationships to the participant (e.g., supervisor and co-worker), the scores on the two questionnaires were averaged together. It also means that all 78 participants were included in analyses involving assessor questionnaires regardless of the perspective from which assessors provided ratings. Participants with and without Assessors

An interesting question that arose while collecting the data and realizing that approximately half of all participants would not have an assessor questionnaire linked to the rest of their data was whether these participants differed on the other performance variables from participants who did have assessor questionnaires returned. A one-way analysis of variance (ANOVA) was performed to determine whether those participants without any assessor questionnaires had performance scores on the self-assessment and exercise that were any different from the scores for participants who had at least one assessor questionnaire returned. A significant main effect was found when looking at the Exercise Raw Task Score $\left[\underline{\mathrm{F}}(1,126)=5.42, \underline{\mathrm{p}}<.05, \underline{\text { eta }}^{2}=.04\right]$ as well as the Exercise Overall Performance Score $\left[\underline{\mathrm{F}}(1,126)=6.25, \underline{\mathrm{p}}<.05\right.$, eta $\left.^{2}=.05\right]$. For the Raw Task Score, those participants with no questionnaires $(\underline{\mathrm{M}}=4.63, \underline{\mathrm{SD}}=2.81)$ completed more timesheets accurately than those who did have assessor questionnaires returned for them $(\underline{\mathrm{M}}=3.57$, $\underline{\mathrm{SD}}=2.35)$. It is not very clear why this effect occurred and the effect size was very small. If anything, it would be expected that this effect would occur in the opposite direction those who performed better on the timesheet exercise might be less reluctant to deliver questionnaires to others. An alternative explanation might be that those participants who performed poorly on the timesheet task sought to justify their poor performance by 
asking others (i.e., assessors) to rate their performance knowing that this would uncover their "true" performance score. A significant difference was not found when evaluating the Exercise Task Percent Score. In a similar finding for the Exercise Overall Performance Score, participants with no assessor questionnaires received higher standard scores on the exercise $(\underline{\mathrm{M}}=.13, \underline{\mathrm{SD}}=.60)$ than those with at least one questionnaire returned $(\underline{\mathrm{M}}=-.12, \underline{\mathrm{SD}}=.53)$. Again, maybe those who performed poorly in the exercise felt more compelled to distribute the assessor questionnaires in an effort to make up for their low performance in the exercise.

\section{Summary of Preliminary Analyses}

In summary, interview ratings from all interviews and from all interviewers will be included in the analyses for hypotheses. Standardized interview scores will be used when performing analyses that include interview ratings as the predictor variable. Also, the exercise ratings for participants from all group sizes and from both timesheet minimum groups will be included. The group size variable will be controlled for when evaluating the performance measures from the exercise. Next, all assessor questionnaires, including those containing the rating scale error, will be included. Finally, when performing analyses involving the assessor questionnaire ratings, assessors across the various groups (e.g., supervisors, co-workers, other) will be combined, and multiple assessor questionnaires collected for individual participants will be averaged together.

\section{Correlation Patterns}

The first step in evaluating the hypotheses in this study was to examine the individual correlations between interview dimensions and performance dimensions. If the pattern of correlations suggests that the interview and performance dimensions are related 
in the predicted manner, then multiple regression analyses will be used to evaluate the relationships further. The pattern of correlations was evaluated for each of the three performance rating sources (i.e., self-assessment, exercise, assessor questionnaires). Refer to Table 4 for the correlations between interview dimensions and all three sources of performance ratings. The correlations between interview dimensions and performance dimensions in Table 4 were calculated using standardized interview scores.

The table of correlations seems to contain a number of notable themes. First, the task dimension was not a significant predictor of task performance in any of the performance measure sources but showed significant correlations with the PS $(\underline{r}=.20$, $\underline{\mathrm{p}}<.05)$ and Average Contextual Performance $(\underline{\mathrm{r}}=.16, \underline{\mathrm{p}}<.05)$ dimensions of the selfassessment, the CI ( $\underline{r}=.30, \underline{p}<.01)$ and Average Contextual Performance $(\underline{r}=.23, \underline{p}<.01)$ dimensions in the exercise, and the PS $(\underline{\mathrm{r}}=.33, \underline{\mathrm{p}}<.05)$, OS $(\underline{\mathrm{r}}=.27, \underline{\mathrm{p}}<.05), \mathrm{CI}(\underline{\mathrm{r}}=.22$, $\underline{\mathrm{p}}<.05)$, and Average Contextual Performance $(\underline{\mathrm{r}}=.30, \underline{\mathrm{p}}<.05)$ dimensions on the assessor questionnaires. Although this trend suggests that the relationship between the task dimension of the interview and the task performance measures (Hypotheses $2 \mathrm{a}$ and $2 \mathrm{~b}$ ) might not be testable, it does increase the anticipation in examining whether the contextual performance dimensions of the interview predicted performance in the various rating sources above and beyond the prediction of the task dimension.

The contextual performance dimensions of the interview did not have a strong pattern of correlations with the self-assessment questionnaires and exercise. Only the OS dimension of the interview was significantly correlated with the OS dimension of the self-assessment $(\underline{r}=.17, \underline{p}<.05)$ while the $\mathrm{CI}$ dimension was correlated with the $\mathrm{CI}$ dimension of the exercise $(\underline{r}=.19, \underline{p}<.05)$. The contextual performance dimensions of the 
interview were more consistently related to measures in the assessor questionnaires. Significant correlations ranged from $\underline{r}=.23$ to $\underline{r}=.41$ and included a significant correlation between the PS dimension of the interview and Task performance $(\underline{r}=.35, \underline{p}<.01)$. The OS dimension of the interview correlated significantly only with the PS dimension of the assessor questionnaires.

Similar to the individual contextual performance dimensions in the interview, the Average Contextual Performance dimension from the interview was not consistently correlated with measures from the self-assessment and exercise. It was correlated only with the OS $(\underline{r}=.16, \underline{p}<.05)$ and Average Contextual Performance $(\underline{r}=.17, \underline{p}<.05)$ dimensions in the self-assessment. This measure showed much stronger relationships with ratings in the assessor questionnaires. Specifically, it was correlated significantly with Task ( $\underline{\mathrm{r}}=.34, \underline{\mathrm{p}}<.01)$, PS $(\underline{\mathrm{r}}=.43, \underline{\mathrm{p}}<.01)$, OS $(\underline{\mathrm{r}}=.32, \underline{\mathrm{p}}<.01)$, CI $(\underline{\mathrm{r}}=.34, \underline{\mathrm{p}}<.01)$, and Average Contextual Performance $(\underline{\mathrm{r}}=.38, \underline{\mathrm{p}}<.01)$.

The conscientiousness measure from the interview showed a somewhat stronger pattern across the various performance measures. In sum, it correlated significantly with the OS $(\underline{r}=.23, \underline{p}<.05)$ and Average Contextual Performance $(\underline{r}=.20, \underline{p}<.05)$ dimensions in the self-assessment; it correlated significantly with the PS $(\underline{\mathrm{r}}=.18, \underline{\mathrm{p}}<.05), \mathrm{CI}(\underline{\mathrm{r}}=.20$, $\underline{\mathrm{p}}<.05)$ and Average Contextual Performance $(\underline{\mathrm{r}}=.25, \underline{\mathrm{p}}<.01)$ dimensions in the exercise; and it correlated significantly with the Task $(\underline{\mathrm{r}}=.23, \underline{\mathrm{p}}<.05)$, PS $(\underline{\mathrm{r}}=.47, \underline{\mathrm{p}}<.01)$, OS $(\underline{\mathrm{r}}=.39$, $\mathrm{p}<.01), \mathrm{CI}(\underline{\mathrm{r}}=.32, \underline{\mathrm{p}}<.01)$, and Average Contextual Performance $(\underline{\mathrm{r}}=.42, \underline{\mathrm{p}}<.01)$ dimensions in the assessor questionnaires.

Finally, the conscientiousness measure from the self-assessment appears to be the most consistent predictor of performance across the three rating sources. It was 
significantly correlated with all performance measures in the self-assessment as well as the assessor questionnaires and with the OS dimension in the exercise. Surprisingly, the conscientiousness measure was significantly and negatively correlated with the Task Raw Score $(\underline{\mathrm{r}}=-.23, \underline{\mathrm{p}}<.05)$ and Task Percent Score $(\underline{\mathrm{r}}=-.18, \underline{\mathrm{p}}<.05)$.

\section{Tests of Hypotheses}

After evaluating the various patterns of correlations, it was determined appropriate to test Hypotheses $1 \mathrm{a}$ and $1 \mathrm{~b}$ using multiple regression analyses. Because the contextual performance dimensions (PS, OS, CI) of the interview were found to be highly intercorrelated (see Table 5) just as in Allen et al. (2004), they were entered into the regression equations as a set rather than individually. Then, in cases where the contextual performance interview dimensions, as a set, were found to be significant predictors, the individual betas for interview dimensions and performance dimensions were evaluated.

Because the contextual performance dimensions were highly intercorrelated, a check of the multiple regression assumption of no perfect multicollinearity was performed as a precaution before proceeding with testing the hypotheses. When entering the three contextual performance dimensions of the interview into each regression equation as a set, the tolerance levels ranged from .70 to .83 , which is much higher than the common cutoff of .20 . Scores below .20 signal a problem with multicollinearity. In addition, the variance-inflation factors (VIF) ranged from 1.20 to 1.41 , again safely distant from the arbitrary but widely accepted cutoff of 4.0. In conclusion, it was decided that the no perfect multicollinearity assumption was not violated. 
Bonness, Brian, 2007, UMSL, p. 69

\section{$\underline{\text { Interview and Contextual Performance }}$}

Hypothesis 1a stated that structured interviews measuring contextual performance would predict ratings of contextual performance (PS, OS, CI) across all three sources of performance ratings (self, assessor, exercise). To test this hypothesis, a multiple regression analysis was performed with the three contextual performance dimensions of the interview entered in as a set of predictors. This analysis was completed for each of the contextual performance dimensions as well as Average Contextual Performance for each of the three performance rating sources.

Results of the analyses for Hypothesis 1a are presented in Tables 6a-61. Results show that significant effects were not found for any of the contextual performance dimensions in the self-assessment or exercise rating sources. The contextual performance dimensions did, however, predict a significant amount of variance in each of the dependent variables from the assessor questionnaires (PS, OS, CI, Average Contextual Performance). For PS, the overall model was significant $[\underline{F}(3,74)=5.98, \underline{p}<.01)$ and accounted for $20 \%$ of the variance in PS $(\underline{\mathrm{R}}=.44, \underline{\mathrm{p}}<.01)$. Only the beta for the PS dimension of the interview was significant $(\underline{\beta}=.25)$, suggesting that it predicted $6 \%$ of the variance in the PS performance measure by itself.

The contextual performance interview dimensions also significantly predicted OS $[\underline{\mathrm{F}}(3,74)=4.06, \underline{\mathrm{p}}<.01]$ and accounted for $14 \%$ of the variance $(\underline{\mathrm{R}}=.38, \underline{\mathrm{p}}<.01)$. Again, the PS dimension of the interview had the only significant beta $(\beta=.25)$, predicting $7 \%$ of the variance in the PS performance dimension on its own. Next, the set of contextual performance dimensions significantly predicted $\mathrm{CI}[\underline{\mathrm{F}}(3,74)=5.04, \underline{\mathrm{p}}<.01]$ and accounted for $17 \%$ of the variance $(\underline{\mathrm{R}}=.41, \underline{\mathrm{p}}<.01)$. The beta for the PS dimension of the interview 
was significant again $(\underline{\beta}=.38)$, accounting for $15 \%$ of the variance in the $\mathrm{CI}$ performance dimension. Finally, the regression model was significant when evaluating the Average Contextual Performance measure of assessor questionnaires $[\underline{F}(3,74)=5.49, \underline{p}<.01]$. The set of contextual performance interview predictors accounted for $18 \%$ of the variance in Average Contextual Performance $(\underline{\mathrm{R}}=.43, \underline{\mathrm{p}}<.01)$. Again, PS had the only significant beta $(\underline{\beta}=.32)$. Based on these results, Hypothesis 1a was supported, but for the assessor rating source only.

\section{Prediction beyond the Task Dimension}

Hypothesis $1 \mathrm{~b}$ subsequently predicted that structured interviews measuring contextual performance would predict ratings of contextual performance above and beyond interviews measuring task performance across all sources of performance ratings. Because significant regression models were not found for the self-assessment and exercise rating sources, this hypothesis was tested only for the assessor questionnaire rating source. Results can be found in Tables 7a-7d. Using hierarchical multiple regression analyses, results showed that the Task dimension of the interview significantly predicted PS $[\underline{F}(1,76)=9.46, \underline{p}<.01]$. This first model accounted for $11 \%$ of the variance in PS $(\underline{\mathrm{R}}=.33, \underline{\mathrm{p}}<.01)$. The second model, containing the three contextual performance dimensions of the interview, was also significant $[\underline{F}(3,73)=2.89, \underline{p}<.05]$, suggesting that the contextual performance dimensions predicted a significant amount of variance $(9 \%)$ above and beyond what was predicted by the Task dimension $\left(\underline{\Delta \mathrm{R}^{2}}=.09, \underline{\mathrm{p}}<.05\right)$. None of the individual betas were significant for the second model. The same analysis was conducted for OS, CI, and Average Contextual Performance as the dependent variables. In the case of $\mathrm{CI}$ and Average Contextual Performance, the contextual performance 
interview dimensions added significant prediction beyond the task dimension. For CI, the second model predicted an additional $12 \%$ of the variance beyond the prediction of the Task dimension $\left(\underline{\Delta \mathrm{R}^{2}}=.12, \underline{\mathrm{p}}<.05\right)$. The individual beta for PS was significant $(\underline{\beta}=.38)$. Also, the contextual performance dimensions predicted an additional $10 \%$ of the variance in Average Contextual Performance $\left(\underline{\Delta \mathrm{R}^{2}}=.10, \underline{\mathrm{p}}<.05\right)$. Again, the PS dimension had the only significant beta $(\underline{=}=.29)$. The contextual performance dimensions did not, however, predict any additional variance in OS beyond the prediction of the Task dimension of the interview. Together, these results offer good support for Hypothesis $1 \mathrm{~b}$ when considering the assessor questionnaire rating source.

\section{Interview and Task Performance}

Hypotheses $2 \mathrm{a}$ and $2 \mathrm{~b}$ offered predictions similar to $\mathrm{H} 1 \mathrm{a}$ and $\mathrm{H} 1 \mathrm{~b}$ but for the Task dimension of the interview and the Task dimension of performance. Because none of the correlations between these dimensions in all three performance rating sources were significant, these hypotheses were not tested further.

\section{Conscientiousness and Contextual Performance}

Hypothesis 3 incorporated the paper-and-pencil test of conscientiousness collected on the self-assessment. In this hypothesis, it was proposed that the measure of conscientiousness would predict ratings of contextual performance (PS, OS, CI) across all sources of performance ratings (self, assessor, exercise). After obtaining strong correlations between this measure of conscientiousness and the various performance measures, simple regression analyses were used to test this hypothesis further. As the Table 8 displays, the Conscientiousness measure was a significant predictor of all contextual performance measures in the self-assessment and assessor questionnaires and 
Bonness, Brian, 2007, UMSL, p. 72

for the OS dimension in the exercise. Conscientiousness was an especially strong predictor of measures in the self-assessment, where it predicted $11 \%$ of the variance in $\mathrm{PS}, 35 \%$ of the variance in $\mathrm{OS}, 21 \%$ of the variance in CI, and $30 \%$ of the variance in Average Contextual Performance. This provides strong support for Hypothesis 3 , especially for the self-assessment and assessor questionnaire rating sources.

\section{$\underline{\text { Prediction beyond Conscientiousness }}$}

Hypothesis 4 then stated that structured interviews measuring contextual performance would predict ratings of contextual performance above and beyond what could be predicted by the paper-and-pencil test of conscientiousness across all sources of performance ratings. Recall that in the results for Hypothesis 1a, the contextual performance dimensions of the interview were found to be significant predictors only in the assessor questionnaire measure. Consequently, Hypothesis 4 was tested only for the assessor questionnaire measure. Refer to Tables 9a-9d for results. Using hierarchical multiple regression analyses, significant prediction above and beyond conscientiousness was found for PS $[\underline{\mathrm{F}}(3,73)=5.38, \underline{\mathrm{p}}<.01]$, OS $[\underline{\mathrm{F}}(3,73)=3.78, \underline{\mathrm{p}}<.05]$, CI $[\underline{\mathrm{F}}(3,73)=5.08$, $\underline{\mathrm{p}}<.01]$, and for Average Contextual Performance $[\underline{\mathrm{F}}(3,73)=5.27, \underline{\mathrm{p}}<.01]$. The contextual performance dimensions of the interview, as a set, added $15 \%, 12 \%, 15 \%$, and $15 \%$ of variance prediction to the PS, OS, CI, and Average Contextual Performance ratings in assessor questionnaires respectively. This provides strong support for Hypothesis 4 within the assessor questionnaire rating source. Similar to results in earlier hypotheses, the PS dimension of the interview had the only significant beta in each of these analyses. 
Bonness, Brian, 2007, UMSL, p. 73

\section{Overall Performance}

Hypotheses involving overall performance were tested using both the single-item measure of overall performance from the self-assessment and assessor questionnaires (i.e., Overall Performance Item) as well as the calculated average between the task and contextual performance dimensions on these questionnaires (i.e., Calculated Overall Performance). These measures are also referred to in the results tables as "Overall 1" and "Overall 2." The correlation between the two overall performance measures was significant for both the self-assessment $(\underline{\mathrm{r}}=.43, \underline{\mathrm{p}}<.01)$ and assessor questionnaires $(\underline{\mathrm{r}}=.68$, $\mathrm{p}<.01)$. In addition to these overall performance measures from the two questionnaires, the Exercise Overall Performance measure was considered. This measure averaged together the two performance dimensions (task, contextual) measured in the exercise.

Hypothesis 5 proposed that the Task dimension of the interview would predict measures of overall performance across the three rating sources. Because the Task dimension of the interview showed a significant correlation with the Calculated Overall Performance measure from the assessor questionnaires rating source only, this was the only relationships evaluated for this hypothesis. Results showed that the Task dimension of the interview was a significant predictor $[\underline{\mathrm{F}}(1,76)=4.22, \underline{\mathrm{p}}<.05]$ of Calculated Overall Performance (Overall 2), accounting for $5 \%$ of the variance $(\underline{\mathrm{R}}=.23, \underline{\mathrm{p}}<.05)$. This provides partial support for Hypothesis 5, when considering Calculated Overall Performance from the assessor questionnaires.

Similarly, Hypothesis 6 predicted that the contextual performance dimensions of the interview would predict overall performance measured in the three performance rating sources. Based on the correlations pattern, the two measures of Overall 
Performance from the assessor questionnaires were evaluated in these analyses. Similar to the Task dimension, the contextual performance dimensions of the interview significantly predicted Calculated Overall Performance in the assessor questionnaires $[\underline{\mathrm{F}}(3,74)=5.65, \underline{\mathrm{p}}<.01]$. The contextual performance dimensions of the interview accounted for $19 \%$ of the variance in this overall performance measure $(\underline{\mathrm{R}}=.43, \underline{\mathrm{p}}<.01)$. The PS dimension of the interview had the only significant beta $(\underline{\beta}=.34)$. The contextual performance dimensions failed to predict the Overall Performance Score (Overall 1) from the assessor questionnaires. Hypothesis 6 was only partially supported.

Next, to evaluate whether the contextual performance dimensions of the interview predicted overall performance above and beyond the prediction of the Task dimension (Hypothesis 7), a hierarchical multiple regression analysis was performed with Calculated Overall Performance in the assessor questionnaires serving as the dependent variable. Results from this analysis showed that the contextual performance dimensions of the interview significantly predicted variance in this measure of overall performance above and beyond the prediction of the Task dimension of the interview $[\underline{F}(3,73)=4.00$, $\mathrm{p}<.05]$. Specifically, the contextual performance dimensions of the interview predicted an additional $13 \%$ of the variance beyond the prediction of the Task dimension $\left(\underline{\Delta R^{2}}=.13\right.$, $\mathrm{p}<.05)$. Once again, the PS dimension of the interview had the only significant individual beta $(\underline{\beta}=.34)$. This provides support for Hypothesis 7 but only for this specific measure of overall performance in the assessor questionnaires rating source.

Although not discussed in the hypotheses section, a test of whether the Task dimension of the interview predicted Calculated Overall Performance from the assessor questionnaires was performed. Although the Task dimension was a significant predictor 
Bonness, Brian, 2007, UMSL, p. 75

of this measure in Hypothesis 5, results showed that the Task dimension did not predict any significant variance above and beyond what was already accounted for by the set of contextual performance dimensions.

\section{Interview Measure of Average Contextual Performance}

Because the contextual performance dimensions of the interview were so highly intercorrelated, they were added to the regression analyses above as a set rather than individually. Another possibility would have been to simply average these dimensions together and use a single contextual performance score as the predictor where appropriate. The Average Contextual Performance measure from the interview was calculated and had a strong pattern of correlations with performance measures across the three rating sources. As a result, it might be useful to compare the results presented above to findings obtained when using the Average Contextual Performance measure as the predictor rather than the individual contextual performance interview dimensions.

In order to compare these two approaches, the same analyses as conducted for hypotheses 1a, 1b, 4, 6, and 7 were performed using the Average Contextual Performance measure from the interview. The Average Contextual Performance measure was predictive of each dimension in the assessor questionnaires as well as the OS and Average Contextual Performance dimension in the self-assessment. Recall that results for H1a showed that the contextual performance dimensions as a set did not predict any of the dimensions in the self-assessment. When considering the influence of the Task dimension of the interview (H1b), however, the Average Contextual Performance measure did not predict any unique variance in the self-assessment performance measures beyond what was accounted for by the Task dimension of the interview. Just as with the 
contextual performance dimensions as a set, the Average Contextual Performance measure predicted a significant amount of variance in PS, CI, and Average Contextual Performance in the assessor questionnaires above and beyond the Task dimension of the interview. It did not predict any unique variance in the OS dimension.

For the remaining analyses, the results for the Average Contextual Performance measure of the interview continued to correspond very closely with the results for the individual contextual performance dimensions. Specifically, the average measure predicted each assessor questionnaire measure above and beyond the variance predicted by the self-assessment of conscientiousness. It also significantly predicted both Overall Performance measures in the assessor questionnaires - the set of contextual performance dimensions predicted only Calculated Overall Performance. When accounting for the Task dimension, however, the average measure predicted unique variance only in the Calculated Overall Performance measure (Overall 2), just like the individual contextual performance dimensions of the interview. In conclusion, although some small differences in results surfaced, the same basic pattern of relationships developed when testing the average measure of contextual performance from the interview as when testing the individual contextual performance dimension of the interview as a set.

\section{Interview Measure of Conscientiousness}

An interesting pattern that arises from studying the correlations between interview dimensions and performance dimensions is that the conscientiousness measure obtained in the interview appears to be the most consistent and strongest predictor of performance measures across the three different sources of ratings. The question, however, is whether the conscientiousness measure was assessing anything unique from the task and 
contextual performance dimensions of the interview. Recall that interviewers were asked to consider the information gathered throughout the interview to help determine this rating. Consequently, this measure of conscientiousness might actually be a measure of a participant's overall performance on the interview and might not include anything unique from the task and contextual performance dimensions of the interview. In fact, it was correlated with the Overall Interview Score quite strongly $(\underline{\mathrm{r}}=.82, \underline{\mathrm{p}}<.01)$. It was also very strongly related to the Average Contextual Performance measure from the interview $(\underline{\mathrm{r}}=.77, \underline{\mathrm{p}}<.01)$ as well as the Task dimension $(\underline{\mathrm{r}}=.68, \underline{\mathrm{p}}<.01)$

In order to explore whether the conscientiousness dimension of the interview predicted any unique variance in the performance measures, several simple and multiple hierarchical regression analyses were performed using the conscientiousness dimension along with the contextual and task dimensions of the interview as the predictors and the various performance measures across both contextual and task dimensions as the dependent variables.

Results of these analyses showed that the conscientiousness measure from the interview was a strong and consistent predictor of performance measures across the three rating sources. Specifically, it predicted a significant amount of variance in the selfassessment performance dimensions of OS $\left(\underline{\mathrm{R}}^{2}=.05\right)$ and Average Contextual Performance $\left(\underline{\mathrm{R}}^{2}=.04\right)$. The conscientiousness dimension also significantly predicted the $\mathrm{PS}\left(\underline{\mathrm{R}}^{2}=.03\right), \mathrm{CI}\left(\underline{\mathrm{R}}^{2}=.05\right)$, and Average Contextual Performance $\left(\underline{\Delta \mathrm{R}^{2}}=.07\right)$ dimensions of the exercise above and beyond the influence of the group size variable. Then, in its strongest relationships, the interview measure of conscientiousness significantly predicted all task and contextual performance dimensions in the assessor questionnaires 
$\left(\underline{\mathrm{R}}^{2}\right.$ 's $=.05, .22, .16, .10$, and .18 for Task, PS, OS, CI, and Average Contextual Performance respectively) as well as Calculated Overall Performance $\left(\underline{\mathrm{R}}^{2}=.13\right)$.

Next, analyses that included the task and contextual performance dimensions of the interview in the initial step and the conscientiousness dimension in the second step were performed to test for unique variance prediction. The conscientiousness dimension did not predict any unique variance in the self-assessment and exercise measures. It did, however, predict a significant amount of unique variance in three of the assessor questionnaire performance dimensions. First, conscientiousness predicted a significant amount of variance in the PS dimension above and beyond the task and contextual performance dimensions $\left(\underline{\mathrm{R}}^{2}=.05\right)$. Next, it predicted an additional $7 \%$ of variance in the OS dimension $\left(\underline{\Delta \mathrm{R}}^{2}=.07\right)$. Finally, the conscientiousness dimension predicted $5 \%$ of variance beyond the task and contextual performance interview dimensions in the Average Contextual Performance measure $\left(\underline{\Delta \mathrm{R}^{2}}=.05\right)$. Although the conscientiousness measure did not account for a large amount of unique variance, these results provide at least moderate support for the conclusion that the conscientiousness item was measuring something beyond what was being captured by the task and contextual performance interview questions.

This interview measure of conscientiousness also predicted variance in performance measures above and beyond the prediction of the paper-and-pencil measure of conscientiousness. Specifically, it predicted significant variance in each of the contextual performance measures and the Calculated Overall Performance (Overall 2) measure in the assessor questionnaires as well as the PS, CI, and Average Contextual Performance dimensions of the exercise above and beyond the paper-and-pencil measure. 
Bonness, Brian, 2007, UMSL, p. 79

This seemed quite plausible considering the smaller than expected correlation between these two measures of conscientiousness.

\section{$\underline{\text { Task Dimension of Interview }}$}

The Task dimension of the interview surprisingly did not correlate significantly with any of the task measures. Interestingly, though, the Task dimension of the interview did correlate significantly with several of the contextual performance dimensions across all three rating sources. First, the Task dimension of the interview was significantly correlated with the self-assessment measures of PS $(\underline{r}=.20, \underline{p}<.05)$ and Average Contextual Performance $(\underline{r}=.16, \underline{p}<.05)$. It was also significantly correlated with the exercise measures of $\mathrm{CI}(\underline{\mathrm{r}}=.30, \underline{\mathrm{p}}<.01)$ and Average Contextual Performance measure $(\underline{\mathrm{r}}=.23, \underline{\mathrm{p}}<.01)$. The Task dimension also correlated significantly with the PS $(\underline{\mathrm{r}}=.33$, $\underline{\mathrm{p}}<.05)$, OS $(\underline{\mathrm{r}}=.27, \underline{\mathrm{p}}<.05), \mathrm{CI}(\underline{\mathrm{r}}=.22, \underline{\mathrm{p}}<.05)$, and Average Contextual Performance $(\underline{\mathrm{r}}=.30, \underline{\mathrm{p}}<.05)$ as well as Calculated Overall Performance $(\underline{\mathrm{r}}=.23, \underline{\mathrm{p}}<.05)$.

Upon further investigation of the influence of the Task dimension of the interview on contextual performance dimensions, hierarchical multiple regression analyses showed that the Task dimension predicted unique variance $(6 \%)$ above and beyond the influence of the contextual performance dimensions only for the CI dimension of the exercise. It did not predict any unique variance above and beyond the contextual performance dimensions of the interview for any of the self-assessment or assessor questionnaire measures.

\section{Discussion}

The present study focused on how a well-established predictor of job performance, the employment interview, predicts task and contextual dimensions of 
performance. A substantial amount of research suggests that both task and contextual performance play an important role in the broader performance domain, each having a considerable impact on judgments of employee performance (Borman \& Motowidlo, 1997; Johnson, 2001; Podsakoff \& MacKenzie, 1997; Rotundo \& Sackett, 2002). One reason why interviews are relatively good predictors of performance might be because they are able to effectively assess the contextual performance dimension. The present study tested this idea by investigating whether interviews designed specifically to measure different dimensions of performance (task, contextual) were able to predict each of those dimensions effectively. This study conducted structured interviews in a laboratory setting and collected performance measures across three different rating sources.

In order to make conclusions based on results in this study, several relationships across the various interview and performance dimensions and across the three different performance rating sources must be considered. In each hypothesis, results varied quite drastically across the different interview dimensions and across the different rating sources. In general, support for hypotheses was much stronger when focusing on assessor questionnaire ratings compared to the self-assessment ratings and exercise measures.

\section{$\underline{\text { Summary of Findings }}$}

The first theme that becomes clear when reviewing the findings of this study is that the Task dimension of the interview did not correlate significantly with any of the Task measures across the various performance rating sources. As a result of these initial findings, the hypotheses regarding the Task dimension of the interview ( $\mathrm{H} 2 \mathrm{a}$ and $\mathrm{H} 2 \mathrm{~b})$ were not tested. It is not clear whether this lack of a relationship was a result of the 
interviews not sufficiently assessing task related information or if the questionnaires and performance assessment exercise did not effectively measure the task performance construct. In this study, the task dimension was difficult to define because the study did not focus on one specific job. The questions on both the interview and the questionnaires were very broad in nature in order to allow for a wide range of participant work experiences. It is possible that contextual performance behaviors influenced the task dimension in both the predictor and criterion to some extent.

In contrast to the results found for the Task dimension of the interview, the contextual performance dimensions were strong and consistent predictors of contextual performance, as well as task performance in some cases. The contextual performance dimensions of the interview significantly predicted all dimensions of contextual performance in the assessor questionnaires and predicted PS, CI, and Average Contextual Performance above and beyond the prediction of the Task dimension of the interview. These findings concur with Allen et al. (2004), which found that interviews measuring contextual performance predicted contextual performance ratings provided by work peers. For example, Allen et al. (2004) found a correlation of $\underline{r}=.40$ when evaluating the relationship essentially equivalent to the interview measure of Average Contextual Performance and the assessor questionnaire measure of Average Contextual Performance in the present study. A significant correlation of $\underline{r}=.38$ was found between these two variables in the present study.

Interestingly, the PS dimension of contextual performance was the only individual dimension to significantly and consistently predict the outcome measures by itself. In fact, it provided the only significant betas throughout the entire analyses. The PS question 
Bonness, Brian, 2007, UMSL, p. 82

on the interview asked participants to describe a time when they noticed that someone else (e.g., co-worker, classmate) needed help accomplishing an important task and then asked participants how they responded in that situation. This particular question might have been the one that most clearly fell into the contextual performance realm and the easiest to distinguish from task related questions. It might also have been the one for which it was easiest for participants to come up with clear and detailed examples from their work experience. As a result, this question might have provided the richest information for making valid and reliable ratings. PS was also the only one of the three contextual performance dimensions to be significantly correlated with task performance in the assessor questionnaires $(\underline{\mathrm{r}}=.35)$.

Although the Task dimension of the interview was not a strong predictor of task performance, it did correlate significantly with several contextual performance measures in the self-assessments (PS, CP), exercise (CI, Average Contextual Performance), and assessor questionnaires (PS, OS, CI, Average Contextual Performance). When considering the influence of contextual performance dimensions, however, the Task dimension did not predict any unique variance in any of these measures except for the exercise measure of CI. In addition, the influence of the Task interview dimension did not prevent the contextual performance dimensions of the interview from predicting unique variance in contextual performance measures, especially in assessor questionnaires.

In contrast to the results found for the assessor questionnaires rating source, the contextual performance dimensions of the interview did not predict a significant amount of variance in any of the self-assessment and exercise measures. Because the interview significantly predicted variance in assessor questionnaires, one might expect that it would 
also predict variance in self-assessment measures. These two measures are generally correlated at a moderate level (Harris \& Schaubroeck, 1988) and, in the present study, all correlations between self-assessment and assessor questionnaire measures were significant and ranged from $\underline{\mathrm{r}}=.23$ to $\underline{\mathrm{r}}=.49$. In addition, the dimensions and questions on the two questionnaires were exactly the same. Nevertheless, self-assessment measures did not have a strong connection to the interview.

In fact, the paper-and-pencil measure of conscientiousness was the only consistent predictor of performance measures in the self-assessment. Why this measure was able to predict self-assessment performance measures and the interview was not able to do so on a consistent basis is not completely clear. One possible reason for this discrepancy is method bias. The paper-and-pencil measure of conscientiousness was collected in the same questionnaire as the self-assessment of performance and contained questions and a rating scale that were very similar. It is possible that once a participant finished rating themselves on the various performance items, many containing a theme of conscientiousness, they continued rating the conscientiousness items very similarly.

The self-assessment measure of conscientiousness was also a strong and consistent predictor of contextual performance measures in the assessor questionnaires. As strong a predictor as this paper-and-pencil measure was, however, the contextual performance dimensions of the interview predicted significant amounts of variance in the assessor questionnaire measures of PS, OS, CI, and Average Contextual Performance above and beyond the prediction of conscientiousness. This suggests that while paperand-pencil measures of conscientiousness are an important predictor of performance, they 
Bonness, Brian, 2007, UMSL, p. 84

do not completely degrade the value of using interviews to predict contextual dimensions of performance.

Regarding the performance measures in the exercise, neither the Task nor the contextual performance dimensions correlated consistently with self-assessment or assessor questionnaire measures. In fact, not one set of matching performance dimensions between the exercise and the assessor questionnaires was significantly correlated. It is possible that the timesheet task and the emails did not effectively measure the constructs of interest. The task was more difficult than anticipated based on pilot testing and participants might not have taken it as seriously as hoped. The task was timed and was probably somewhat novel to most and, consequently, some participants who generally perform very well in the task performance dimension might not have performed at a high level on this particular task.

The most surprising results of the study might have been the significant and negative correlations between the paper-and-pencil measure of conscientiousness and the task performance measures in the exercise. Conscientiousness was negatively correlated with both the Raw Task Score $(\underline{r}=-.23, \underline{\mathrm{p}}<.05)$ and the Percent Task Score $(\underline{\mathrm{r}}=-.18, \underline{\mathrm{p}}<.05)$. It is not clear why these relationships occurred but one explanation might be that participants with a high level of conscientiousness spent a lot of time reading the instructions and emails, and in doing so, did not leave themselves much time to work on the timesheets. Then, in rushing to get the timesheets done, both their Raw Task Score and Percent Task Score may have suffered. An alternative way to state this, of course, is that maybe low conscientiousness participants did not spend a lot of time reading the 
instructions and emails but rather started immediately on the timesheets and subsequently found the task quite simple.

As suspected, the paper-and-pencil measure of conscientiousness was significantly correlated with contextual performance measures. It was also correlated with task performance but not to the same extent. For example, the correlation between conscientiousness and self-assessment of task was $\underline{r}=.39$ while it was $\underline{r}=.54$ for Average Contextual Performance. In similar results for the assessor questionnaires, the correlation with task performance was $\underline{r}=.32$ while the correlation with Average Contextual Performance was $\underline{r}=.40$. In the exercise, the only significant and positive correlation with any of the performance dimensions was with OS $(\mathrm{r}=.24)$. Considering these relationships, it appears that conscientiousness is an important determinant of both dimensions of performance but is a somewhat stronger antecedent of the contextual performance dimension, a finding that concurs with previous research (e.g., Borman et al., 2001; Cambell, 1990; Organ \& Ryan, 1995).

In contrast to these results, and somewhat unexpectedly, the paper-and-pencil measure of conscientiousness did not correlate very strongly or consistently with the contextual performance dimensions of the interview. In fact, the conscientiousness measure correlated significantly only with the CI dimension ( $(\underline{r}=.21)$ and the Average Contextual Performance measure from the interview ( $\underline{r}=.19)$. Based on past research (Huffcutt, Conway, Roth \& Stone, 2001; Moscoso, 2000; Posthuma et al., 2002; Salgado $\&$ Moscoso, 2002), the conscientiousness measure was expected to be a strong and consistent correlate with all contextual performance dimensions of the interview. Despite this finding, interviews were still found to be effective predictors of contextual 
performance measures in the assessor questionnaires, and predicted these measures above and beyond the prediction of the conscientiousness measure.

The final hypotheses of this study focused on two alternative measures of overall performance. Both the Task dimension and the contextual performance dimensions of the interview significantly predicted Calculated Overall Performance (Overall 2) in the assessor questionnaires. Subsequent analyses showed that the contextual performance dimensions of the interview predicted this overall measure above and beyond the Task dimension but the Task dimension did not predict any additional variance in the overall measure after accounting for the influence of the contextual performance dimensions. This is interesting considering that this measure weighted the task and contextual dimensions equally. It is possible that the contextual performance dimensions of the interview were not only predicting the contextual performance portion of the overall performance measure but also accounting for a sufficient portion of the task dimension. In fact, PS was the only significant predictor $(\underline{r}=.35)$ of the task dimension in assessor questionnaires. This is only one way of combining the two dimensions. In an organization, a hiring manager might decide to weight one dimension more than the other depending on the job and the organization's mission and goals. Even if the Task dimension of overall performance is weighted more heavily, these results suggest that the contextual performance dimensions of the interview remain important.

After evaluating the hypotheses using the three individual dimensions of contextual performance in the interview as a set of predictors in the regression analyses, an alternative way of presenting the contextual performance dimensions of the interview was considered. Specifically, the three individual dimensions (PS, OS, CI) were 
combined together into a single Average Contextual Performance dimension. The individual dimensions were highly intercorrelated and research suggests that they are alternative measures of the same latent variable (LePine et al., 2002), so entering them into the analyses as a single score seemed to be an appropriate alternative for comparison. These analyses did not produce any strong patterns of unique results. Across all study hypotheses, results using the Average Contextual performance measure essentially replicated the results obtained when entering the dimensions into the analyses as a set. In the end, using the single average score might have been simpler analyses but keeping the individual dimensions of contextual performance separated allowed for evaluating the individual dimensions and thus discovering that the PS dimension was clearly the most consistent and strongest individual predictor.

Another measure added to the interview for exploratory purposes was the conscientiousness item. This item was significantly but not highly correlated with the paper-and-pencil measure of conscientiousness and was strongly correlated with both the Task and contextual performance dimensions of the interview and even more so with the Overall Interview Score. It was initially thought that the conscientiousness item on the interview was simply an alternative measure of overall interview performance. As a result, it was not expected to predict any unique variance in performance measures above and beyond the influence of the other interview dimensions. When assessing the prediction of the conscientiousness item compared to the other dimensions of the interview, however, it did predict added variance in the assessor questionnaire measures above and beyond the influence of the Task and contextual dimensions of the interview. Further, when compared to the paper-and-pencil measure of conscientiousness, it 
predicted unique variance in the assessor questionnaires in addition to the contextual performance measures in the exercise. These results suggest that if interviewers are trained to focus on the definition of conscientiousness and provide a valid rating of conscientiousness in the interview, it could possibly be a highly valuable predictor added to the interview.

In summary, the research had shown that interviews were good predictors of overall job performance but now there is some evidence suggesting that interviews can be good predictors of individual performance dimensions, in particular contextual performance. Results of the present study compare favorably to typical results found in previous studies of interviews. Meta-analytical research has reported predictive validities in the $.30 \mathrm{~s}$ for interviews in general and in the $.50 \mathrm{~s}$ for structured interviews (Huffcutt \& Arthur, 1994; Marchese \& Muchinsky, 1993; McDaniel, Whetzel, Schmidt \& Maurer, 1994; Schmidt \& Radar, 1999; Weisner \& Cronshaw, 1988). In comparison, the present study found that interviews were correlated with assessor ratings consistently in the $.30 \mathrm{~s}$ and .40s. Although these relationships were almost completely exclusive to the assessor questionnaires rating source, this is very similar past research findings which focus mostly on supervisor ratings.

The present study also found that the contextual performance dimensions of the interview were clearly the more consistent and stronger predictors of performance compared to the Task dimension, and only the contextual dimensions of the interview predicted the Task dimension in performance measures. The contextual performance dimensions of the interview also predicted contextual performance above and beyond both Task and conscientiousness and predicted unique variance in overall performance 
while the Task dimension did not. The Personal Support dimension was a particularly strong predictor of performance measures. Taken together, these results suggest that the interviews in this study were good predictors of contextual performance ratings provided by outside assessors and predicted these ratings more effectively than measures of task performance. Despite these findings, however, this study does not support a conclusion that interviews are unable effectively predict task performance.

Limitations and Future Research

The present study was not without limitations. First, the participant sample consisted of undergraduate business college students, which means the results are somewhat difficult to generalize to the broader population. One concern going into this study was that many participants would not have sufficient work experience to draw upon for both performance ratings and interview examples. Fortunately, however, participants reported having over eight years of work experience on average. For those few who did not have extensive work experience, interview questions and questionnaire items were worded in a way that allowed participants to draw from other related experiences, such as projects in school.

Regarding the structured interviews in this study, one limitation was that the interviews included only one question for each contextual performance dimension and two for the task dimension for a total of 5 questions. This might have presented a measurement concern but it is also very much like real organizations where hiring managers are likely to ask a single question for each competency or skill dimension. In addition, results when combining the contextual performance dimensions into a single average measure were nearly identical to results when considering individual contextual 
performance dimensions. Still, the ideal situation would be to have several interview questions for the task dimension and several questions for the contextual performance dimensions. This would increase reliability of the predictor measures and provide the opportunity to evaluate the measurement quality of individual questions.

Interviewers were also highly inexperienced and might not have provided ratings similar to what a typical, experienced interviewer in an organization might provide. In an effort to counter this limitation, interviews were highly structured and patterned from professionally developed employment interviews. Further, interviewers were trained, their interviews were audio recorded, and feedback was provided throughout the study. Despite the training and ongoing feedback, however, a small interviewer effect was found for two of the questions. This issue was addressed by using standardized interview scores in the study analyses where appropriate. Future studies might try to use actual hiring managers with extensive experience and training in structured interviewing.

Also a concern on the interview was the general nature of the wording in the task performance questions. Developing a task question that uniquely related to each participant's experience would not have been practical and would have lessened the standardization and control in the study. The way in which the questions were worded, however, might have allowed other non-task related information to impact a participant's response. This concern was also applicable to the self-assessment and assessor questionnaires because the task items on these questionnaires were similarly worded in a very general way. Again, this might have allowed for non-task related information to influence ratings more so than if the task items had been based on a specific job and specific tasks. 
Another limitation was the level of realism in the performance assessment exercise. Participants worked on an administrative task and were asked to reply to several emails while working on the task. The introduction to the exercise and instructions were intended to place participants into a realistic work situation. In the end, the task might not have been typical of what participants were used to doing in their actual jobs and the emails might have seemed somewhat unusual. Although participants likely found it easy to identify an email response, the way in which they responded (i.e., circling one of five possible responses on a paper printout and sliding it under a door) might have distracted them from their true behavior. In addition, seeing all possible response options on the emails might have helped participants identify the variables being studied, thus allowing them to respond in a socially desirable manner. Regardless of whether the exercise was an effective measure in this study, however, it was an important step in an area of research that has very seldom used of this type of methodology. Future researchers are encouraged to expand on this idea and explore better ways of collecting performance data using actual work tasks. Ideally, a research study investigating these same issues would study a specific job in a real organization, thus allowing for a more detailed description of the task dimension in the interviews and performance measures.

Other limitations were related to the assessor questionnaire portion of the study. Participants distributed questionnaires to assessors and many participants might have chosen only those individuals who were likely to rate them favorably. In the end, assessor ratings were only slightly higher than self-assessment and exercise ratings. In addition, assessors were assured confidentiality which hopefully encouraged them to provide truthful ratings. No mechanism was in place, however, to be sure that assessors were who 
they reported to be on the questionnaires and that they provided truthful ratings. Many assessors (over two-thirds) provided ratings based on a work relationship with the target participant. Future studies might focus on obtaining assessor ratings strictly based on work behaviors and might develop a way to distribute questionnaires directly to assessors.

Another limitation was the relatively small sample size of assessor questionnaires. Questionnaires were returned for almost exactly half of all participants who participated in the self-assessment and exercise portion of the study. Interestingly, the ratings from the assessor questionnaires provided the most consistent significant results in this study. The interview dimensions rarely predicted any of the self-assessment and exercise measures and almost always predicted the assessor questionnaire measures. Future studies should try to gather many more assessor questionnaires to further explore these effects.

Additional research could also look at results for specific group breakdowns within assessors. That is, results for supervisors could be compared to results for co-workers and these two groups could be compared to other types of assessors from whom questionnaires are gathered (e.g., classmates).

In conclusion, this study hopefully provided valuable and new information about why interviews predict work performance. It extends the research in an important area and suggests that interviews might be a good predictor of contextual performance. Of course, many more studies need to be completed to investigate these ideas further, but the present study provides a formidable start. It also serves as a reminder that the research community need not forget to focus on the criterion side of the predictor-criterion relationship. 


\section{References}

Allen, T. D. \& Rush, M. C. (1998). The effects of organizational citizenship behavior on performance judgments: A field study and a laboratory experiment. Journal of Applied Psychology, 83, 2, 247-260.

Allen, T. D., Facteau, J. D., \& Facteau, C. L. (2004). Structured interviewing for OCB: Construct validity, faking, and the effects of question type. Human Performance, $17,1,1-24$.

Barnard, C. I. (1938). The functions of the executive. Cambridge, MA: Harvard University Press.

Barrick, M. R. \& Mount, M. K. (1991). The big five personality dimensions and job performance: A meta-analysis. Personnel Psychology, 44, 1-26.

Barrick, M. R. Patton, G. K. \& Haugland, S. N. (2000). Accuracy of interview judgments of job applicant personality traits. Personnel Psychology, 53, 925-951.

Bateman, T. S. \& Organ. D. W. (1983). Job satisfaction and the good soldier: The relationship between affect and employee "citizenship." Academy of Management Journal, 26, 587-595.

Beaty, J. C., Cleveland, J. N., \& Murphy, K. R. (2001). The relation between personality and contextual performance in "strong" versus "weak" situations. Human Performance, 14, 2, 125-148.

Bettencourt, L. A., Gwinner, K. P., \& Meuter, M. L. (2001). A comparison of attitude, personality, and knowledge predictors of service-oriented organizational citizenship behaviors. Journal of Applied Psychology, 86, 1, 29-41. 
Binning, J. F. \& Barrett, G. V. (1989). Validity of personnel decisions: A conceptual analysis of the inferential and evidential bases. Journal of Applied Psychology, $74,478-494$.

Borman, W. C. \& Motowidlo, S. J. (1993). Expanding the criterion domain to include elements of contextual performance. In N. Schmitt \& W. C. Borman (Eds.), Personnel selection in organizations. San Francisco: Jossey-Bass.

Borman, W. C. \& Motowidlo, S. J. (1997). Task performance and contextual performance: The meaning for personnel selection research. Human Performance, 10, 2, 99-109.

Borman, W. C. \& Penner, L. A. (2001). Citizen performance: Its nature, antecedents, and motives. In B. Roberts \& R. Hogan (Eds.), Personality psychology in the workplace: Decade of behavior. Washington, DC: American Psychological Association.

Borman, W. C., Motowidlo, S. J., \& Hanser, L. M. (1983). A model of individual performance effectiveness: Thoughts about expanding the criterion space. In Integrated criterion measurement for large scale computerized selection and classification. Symposium presented at the $91^{\text {st }}$ annual convention of the American Psychological Association, Washington, DC.

Borman, W. C., Penner, L. A., Allen, T. D., \& Motowidlo, S. J. (2001). Personality predictors of citizenship performance. International Journal of Selection and Assessment, 9, 52-69.

Brief, A. P. \& Motowidlo, S. J. (1986). Prosocial organizational behaviors. Academy of Management Review, 11, 710-725. 
Cambell, J. P. (1990). An overview of the army selection and classification project (Project A). Personnel Psychology, 43, 231-239.

Chernyshenko, O. S. (2003). Applications of ideal point approaches to scale construction and scoring in personality measurement: The development of a six-faceted measure of conscientiousness. Dissertation Abstracts International, 63, 11, 5556B.

Coleman, V. I. \& Borman, W. C. (2000). Investigating the underlying structure of the citizenship performance domain. Human Resources Management Review, 10, 2544.

Conway, J. M. (1996). Additional construct validity evidence for the task-contextual performance distinction. Human Performance, 9, 309-329.

Conway, J. M. (1999). Distinguishing contextual performance from task performance for managerial jobs. Journal of Applied Psychology, 84, 1, 3-13.

Conway, J. M. \& Huffcutt, A. I. (2004). Validity of interview dimensions for predicting performance dimensions: A construct-level analysis. In Using structured employment interviews to predict multiple dimensions of performance. Special event presented at the $19^{\text {th }}$ annual conference of the Society for Industrial and Organizational Psychology, Chicago, IL.

Cortina, J. M., Goldstein, N. B., Payne, S. C., Davison, H. K., \& Gilliland, S. W. (2000). The incremental validity of interview scores over and above cognitive ability and conscientiousness scores. Personnel Psychology, 53, 2, 325-351. 
Frese, M. \& Fay, D. (1997). The concept of personal initiative: Operationalization, reliability and validity in two German samples. Journal of Occupational \& Organizational Psychology, 70, 139-161.

Gatewood, R. D. \& Field, H. S. (1990). Human resource selection. Chicago: Dryden Press.

Harris, M. M. \& Schaubroeck, J. (1988). A meta-analysis of self-supervisor, self-peer, and peer-supervisor ratings. Personnel Psychology, 41, 43-62.

Huffcutt, A. I. \& Arthur, W. (1994). Hunter and Hunter (1994) revisited: Interview validity for entry-level jobs. Journal of Applied Psychology, 79, 184-190.

Huffcutt, A. I., Conway, J. M., Roth, P. L., \& Stone, N. J. (2001). Identification and meta-analytic assessment of psychological constructs measured in employment interviews. Journal of Applied Psychology, 86, 5, 897-913.

Johnson, J. W. (2001). The relative importance of task and contextual performance dimensions to supervisor judgments of overall performance. Journal of Applied Psychology, 86, 5, 984-996.

Johnson, J. W. (2000). A heuristic method for estimating the relative weight of predictor variables in multiple regression. Multivariate Behavioral Research, 35, 1-19.

Katz, D. (1964). The motivational basis of organizational behavior. Behavioral Science, 9, 131-146.

Katz, D. \& Kahn, R. L. (1978). The social psychology of organizations. New York: Wiley. 
Latham, G. P. \& Skarlicki, D. P. (1995). Criterion-related validity of the situational and patterned behavior description interviews with organizational citizenship behavior. Human Performance, 8, 2, 67-80.

Locke, E. A., \& Latham, G. P. (1990). A theory of goal setting and task performance. Englewood Cliffs, NJ: Prentice-Hall.

LePine, J. A. \& VanDyne, L. (2001). Voice and cooperative behavior as contrasting forms of contextual performance: Evidence of differential relationships with Big Five personality characteristics and cognitive ability. Journal of Applied Psychology, 86, 326-336.

LePine, J. A., Erez, A., \& Johnson, D. E. (2002). The nature and dimensionality of organizational citizenship behavior: A critical review and meta-analysis. Journal of Applied Psychology, 87, 1, 52-65.

Marchese, M. C. \& Muchinsky, P. M. (1993). The validity of the employment interview: A meta-analysis. International Journal of Selection and Assessment, 1, 18-26.

McDaniel, M. A., Whetzel, D. L., Schmidt, F. L., \& Maurer, S. D. (1994). The validity of employment interviews: A comprehensive review and meta-analysis. Journal of Applied Psychology, 79, 599-616.

Miller, R. L., Griffin, M. A., \& Hart, P. M. (1999). Personality and organizational health: The role of conscientiousness. Work and Stress, 13, 7-19.

Moscoso, S. (2000). Selection interview: A review of validity evidence, adverse impact and applicant reactions. International Journal of Selection and Assessment, 8, 4, $237-247$. 
Motowidlo, S. J. \& Van Scotter, J. R. (1994). Evidence that task performance should be distinguished from contextual performance. Journal of Applied Psychology, 79, 4, $475-480$.

Motowidlo, S. J., Borman, W. C., \& Schmit, M. J. (1997). A theory of individual differences in task and contextual performance. Human Performance, 10, 2, 7183.

Murphy, K. R. \& Shiarella, A. H. (1997). Implications of the multidimensional nature of job performance for the validity of selection tests: Multivariate frameworks for studying test validity. Personnel Psychology, 50, 823-854.

Neuman, G. A. \& Kickul, J. R. (1998). Organizational citizenship behaviors: Achievement orientation and personality. Journal of Business and Psychology, $13,263-279$.

Organ, D. W. \& Ryan, K. (1995). A meta-analytic review of attitudinal and dispositional predictors of organizational citizenship behavior. Personnel Psychology, 48, 775802.

Organ, D. W. (1997). Organizational citizenship behavior: It's construct clean-up time. Human Performance, 10, 2, 85-97.

Organ, D. W. (1988). Organizational citizenship behavior: The good soldier syndrome. Lexington, MA: Lexington.

Podsakoff, P. M. \& MacKenzie, S. B. (1997). Impact of organizational citizenship behavior on organizational performance: A review and suggestions for future research. Human Performance, 10, 2, 133-151. 
Podsakoff, P. M., MacKenzie, S. B., Paine, J. B., \& Bachrach, D. G. (2000).

Organizational citizenship behaviors: A critical review of the theoretical and empirical literature and suggestions for future research. Journal of Management, $26,3,513-563$

Posthuma, R. A., Morgeson, F. R., \& Campion, M. A. (2002). Beyond employment interview validity: A comprehensive narrative review of recent research and trends over time. Personnel Psychology, 55, 1-81.

Roberts, B. W., Chernyshenko, O. S., Stark, S., \& Goldberg, L. R. (2005). The structure of conscientiousness: An empirical investigation based on seven major personality questionnaires. Personnel Psychology, 58, 103-139.

Rotundo, M. \& Sackett, P. R. (2002). The relative importance of task, citizenship, and counterproductive performance to global ratings of job performance: A policycapturing approach. Journal of Applied Psychology, 87, 1, 66-80.

Salgado, J. F. \& Moscoso, S. (2002). Comprehensive meta-analysis of the construct validity of the employment interview. European Journal of Work and Organizational Psychology, 11, 3, 299-324.

Schmidt, F. L. \& Radar, M. (1999). Exploring the boundary conditions for interview validity: Meta-analytic validity findings for a new interview type. Personnel Psychology, 52, 445-464.

Smith, C. A., Organ, D. W., \& Near, J. P. (1983). Organizational citizenship behavior: Its nature and antecedents. Journal of Applied Psychology, 68, 653-663. 
Van Dyne, L., Graham, J. W., \& Dienesch, R. M. (1994). Organizational citizenship behavior: Construct redefinition, measurement, and validation. Academy of Management Journal, 37, 4, 765-802.

Van Scotter, J. R. \& Motowidlo, S. J. (1996). Interpersonal facilitation and job dedication as separate facets of contextual performance. Journal of Applied Psychology, 81, 5, 525-531.

Van Scotter, J. R., Motowidlo, S. J., \& Cross, T. C. (2000). Effects of task performance and contextual performance on systemic rewards. Journal of Applied Psychology, $85,4,526-535$.

Wiesner, W. H. \& Cronshaw, S. F. (1988). A meta-analytic investigation of the impact of interview format and degree of structure on the validity of the employment interview. Journal of Occupational Psychology, 61, 275-290.

Williams, L. J. \& Anderson, S. E. (1991). Job satisfaction and organizational commitment as predictors of organizational citizenship and in-role behaviors. Journal of Management, 17, 3, 601-617. 
Tables

Table 1: SME Data for Timesheet Exercise Email Validation

\begin{tabular}{|c|c|c|c|c|c|c|c|c|c|c|c|c|}
\hline \multirow{3}{*}{ Email } & \multirow{3}{*}{$\begin{array}{c}\mathrm{CP} \\
\text { Dimension }\end{array}$} & \multirow{3}{*}{$\begin{array}{c}\text { Dimension } \\
\text { Agreement* }\end{array}$} & \multicolumn{10}{|c|}{ Response Options Chosen to be Scale Anchors on 1-5 Scale } \\
\hline & & & \multicolumn{2}{|c|}{1} & \multicolumn{2}{|c|}{2} & \multicolumn{2}{|c|}{3} & \multicolumn{2}{|c|}{4} & \multicolumn{2}{|c|}{5} \\
\hline & & & $\mathbf{M}$ & SD & M & SD & $\mathbf{M}$ & SD & M & SD & $\mathbf{M}$ & SD \\
\hline 1 & $\mathrm{CI}$ & $9 / 10$ & 1.00 & 0.00 & 1.60 & 0.52 & 2.80 & 0.92 & 4.30 & 0.48 & 4.80 & 0.42 \\
\hline 2 & OS & $7 / 10$ & 1.00 & 0.00 & 1.50 & 0.53 & 2.70 & 0.48 & 4.20 & 0.79 & 4.50 & 0.53 \\
\hline 3 & $\mathrm{CI}$ & $10 / 10$ & 1.00 & 0.00 & 1.80 & 0.63 & 2.90 & 0.57 & 4.70 & 0.48 & 4.80 & 0.42 \\
\hline 4 & PS & $9 / 10$ & 1.40 & 0.52 & 2.00 & 0.82 & 3.00 & 0.67 & 4.00 & 0.47 & 5.00 & 0.00 \\
\hline 5 & PS & $8 / 10$ & 1.00 & 0.00 & 1.80 & 0.42 & 2.80 & 0.79 & 4.00 & 0.82 & 4.80 & 0.42 \\
\hline 6 & OS & $8 / 10$ & 1.00 & 0.00 & 2.00 & 0.00 & 3.10 & 0.74 & 4.20 & 0.42 & 5.00 & 0.00 \\
\hline
\end{tabular}

*Represents the number of SMEs out of 10 total who sorted the email into the Contextual Performance (CP) dimension $\mathrm{CI}=$ Conscientious Initiative; OS = Organizational Support; PS = Personal Support 
Bonness, Brian, 2007, UMSL, p. 102

Table 2: Correlations between Interviewer 1 and Interviewer 2 Scores

\begin{tabular}{ccccccc}
\hline Task & PS & OS & CI & Consc & Avg CP & Overall \\
\hline $.50^{*}$ & $.69^{* *}$ & $.53^{*}$ & $.72^{* *}$ & $.70^{* *}$ & $.74^{* *}$ & $.67^{* *}$ \\
\hline
\end{tabular}

$\mathrm{N}=17$

** Correlation is significant at the 0.01 level

* Correlation is significant at the 0.05 level

$\mathrm{PS}=$ Personal Support; OS = Organizational Support; $\mathrm{CI}=$ Conscientious Initiative; Avg CP = Average of PS, OS, CI; Overall $=$ Average of Task and Contextual dimensions 
Bonness, Brian, 2007, UMSL, p. 103

Table 3: Correlations Between Emails in Timesheet Exercise

\begin{tabular}{ccccccc}
\hline & PS-1 & PS-2 & OS-1 & OS-2 & CI-1 & CI-2 \\
\hline PS-1 &. & & & & & \\
PS-2 & $.20^{*}$ &. & & & \\
OS-1 & -.04 & .04 &. & & \\
OS-2 & $.20^{*}$ & .11 & -.06 &. & & \\
CI-1 & .01 & .01 & $.22^{*}$ & .00 &. & \\
CI-2 & .11 & .11 & $.23^{*}$ & -.09 & $.37^{* *}$ &. \\
\hline N = 128 & \multicolumn{7}{c}{} & & \\
** Correlation is significant at the 0.01 level & & & \\
$*$ Correlation is significant at the 0.05 level \\
PS = Personal Support; OS = Organizational Support; CI = Conscientious Initiative
\end{tabular}


Table 4: Means, Standard Deviations, Correlations, and Coefficient Alphas for All Study Variables

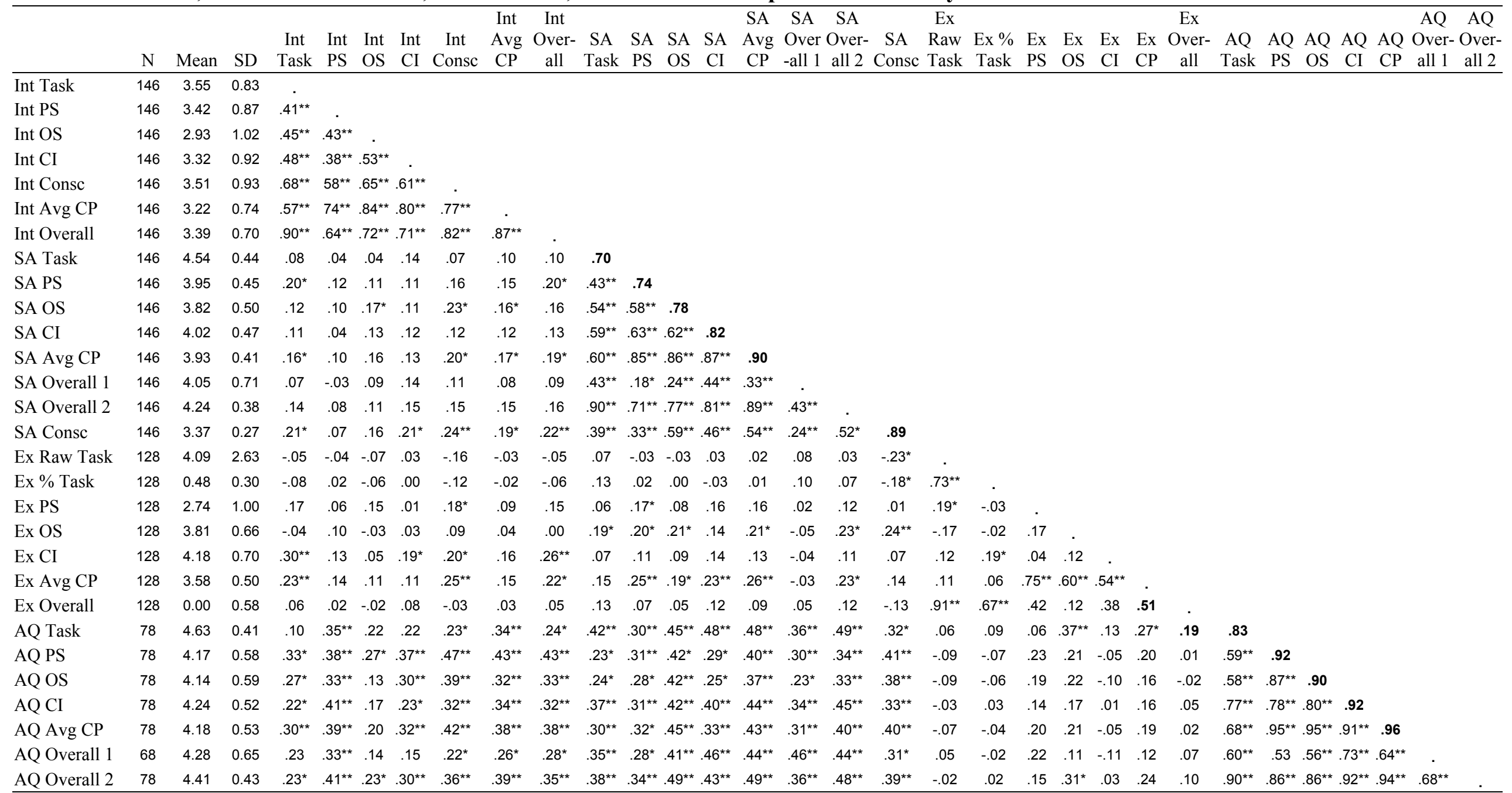

** Correlation is significant at the 0.01 level

* Correlation is significant at the 0.05 level

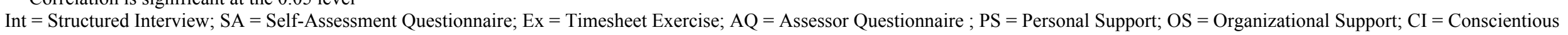
Initiative; Avg CP = Average of PS, OS, CI; Overall 1 = One-item overall performance measure on questionnaires; Overall $2=$ Calculated overall performance measure

Correlations between interview dimensions and performance measures were calculated using standardized interview scores 
Table 5: Correlations between Interview Dimensions

\begin{tabular}{lcccccc}
\hline \multicolumn{7}{c}{ Interview Dimensions } \\
\hline & Task & PS & OS & CI & Consc & Avg CP \\
\hline Task &. & & & & & \\
PS & $.41^{* *}$ &. & & & & \\
OS & $.45^{* *}$ & $.43^{* *}$ &. & & & \\
CI & $.48^{* *}$ & $.38^{* *}$ & $.53^{* *}$ &. & & \\
Consc & $.68^{* *}$ & $.58^{* *}$ & $.65^{* *}$ & $.61^{* *}$ &. & \\
Avg CP & $.57^{* *}$ & $.74^{* *}$ & $.84^{* *}$ & $.80^{* *}$ & $.77^{* *}$ &. \\
Int Overall & $.90^{* *}$ & $.64^{* *}$ & $.72^{* *}$ & $.71^{* *}$ & $.82^{* *}$ & $.87^{* *}$ \\
\hline
\end{tabular}

$\mathrm{N}=146$

** Correlation is significant at the 0.01 level

$\mathrm{PS}=$ Personal Support; OS = Organizational Support; $\mathrm{CI}=$ Conscientious Initiative; Avg $\mathrm{CP}=$ Average of PS, OS, CI 
Table 6a: Multiple regression analysis of self-assessment Personal Support with contextual performance dimensions of the interview as predictors (Hypothesis 1a)

\begin{tabular}{cccccccccc}
\hline Step & Variable & $\mathrm{B}$ & $\mathrm{SE} \mathrm{B}$ & Beta & $\mathrm{t}$ & $\mathrm{R}^{2}$ & $\Delta \mathrm{R}^{2}$ & $\mathrm{~F}$ & Sig. \\
\hline 1 & & & & & & .02 & .02 & 1.06 & .37 \\
& PS & .04 & .04 & .08 & .88 & & & & .38 \\
& OS & .02 & .05 & .05 & .49 & & & & .62 \\
& CI & .03 & .04 & .06 & .67 & & & & .51 \\
\hline
\end{tabular}

$\mathrm{N}=146$

Table 6b: Multiple regression analysis of self-assessment Organizational Support with contextual performance dimensions of the interview as predictors (Hypothesis 1a)

\begin{tabular}{cccccccccc}
\hline Step & Variable & $\mathrm{B}$ & $\mathrm{SE} \mathrm{B}$ & Beta & $\mathrm{t}$ & $\mathrm{R}^{2}$ & $\Delta \mathrm{R}^{2}$ & $\mathrm{~F}$ & Sig. \\
\hline 1 & & & & & & .03 & .03 & 1.50 & .22 \\
& PS & .02 & .05 & .04 & .39 & & & & .70 \\
& OS & .07 & .05 & .14 & 1.43 & & & & .16 \\
& CI & .02 & .05 & .03 & .33 & & & & .74 \\
\hline
\end{tabular}

$\mathrm{N}=146$

Table 6c: Multiple regression analysis of self-assessment Conscientious Initiative with contextual performance dimensions of the interview as predictors (Hypothesis 1a)

\begin{tabular}{cccccccccc}
\hline Step & Variable & $\mathrm{B}$ & $\mathrm{SE} \mathrm{B}$ & Beta & $\mathrm{t}$ & $\mathrm{R}^{2}$ & $\Delta \mathrm{R}^{2}$ & $\mathrm{~F}$ & Sig. \\
\hline 1 & & & & & & .02 & .02 & .97 & .41 \\
& PS & -.01 & .04 & -.02 & -.17 & & & & .86 \\
& OS & .05 & .05 & .10 & .96 & & & & .34 \\
& CI & .04 & .05 & .08 & .79 & & & & .43 \\
\hline
\end{tabular}

$\mathrm{N}=146$ 
Table 6d: Multiple regression analysis of self-assessment Average Contextual Performance with contextual performance dimensions of the interview as predictors (Hypothesis 1a)

\begin{tabular}{cccccccccc}
\hline Step & Variable & $\mathrm{B}$ & $\mathrm{SE} \mathrm{B}$ & Beta & $\mathrm{t}$ & $\mathrm{R}^{2}$ & $\Delta \mathrm{R}^{2}$ & $\mathrm{~F}$ & Sig. \\
\hline 1 & & & & & & .03 & .03 & .23 & .23 \\
& PS & .02 & .04 & .04 & .41 & & & & .69 \\
& OS & .05 & .04 & .11 & 1.14 & & & .26 \\
& CI & .03 & .04 & .07 & .69 & & & .49 \\
\hline
\end{tabular}

$\mathrm{N}=146$

Table 6e: Hierarchical multiple regression analysis of exercise Personal Support with group size and contextual performance dimensions of the interview as predictors (Hypothesis 1a)

\begin{tabular}{|c|c|c|c|c|c|c|c|c|c|}
\hline Step & Variable & B & SE B & Beta & $\mathrm{t}$ & $\mathrm{R}^{2}$ & $\Delta \mathrm{R}^{2}$ & $\mathrm{~F}$ & Sig. \\
\hline \multirow[t]{6}{*}{1} & & & & & & .02 & .02 & .37 & .87 \\
\hline & Group Size DMV1 & .08 & .25 & .04 & .31 & & & & .76 \\
\hline & Group Size DMV2 & -.26 & .28 & -.10 & -.92 & & & & .36 \\
\hline & Group Size DMV3 & -.06 & .28 & -.02 & -.21 & & & & .84 \\
\hline & Group Size DMV4 & -.11 & .46 & -.02 & -.24 & & & & .81 \\
\hline & Group Size DMV5 & .08 & .43 & .02 & .19 & & & & .85 \\
\hline \multirow[t]{9}{*}{2} & & & & & & .05 & .03 & 1.23 & .30 \\
\hline & Group Size DMV1 & .06 & .25 & .03 & .25 & & & & .80 \\
\hline & Group Size DMV2 & -.25 & .28 & -.10 & -.90 & & & & .37 \\
\hline & Group Size DMV3 & -.07 & .28 & -.03 & -.26 & & & & .79 \\
\hline & Group Size DMV4 & -.17 & .46 & -.04 & -.38 & & & & .71 \\
\hline & Group Size DMV5 & .16 & .43 & .04 & .36 & & & & .72 \\
\hline & PS & .03 & .10 & .03 & .31 & & & & .76 \\
\hline & OS & .20 & .11 & .20 & 1.76 & & & & .08 \\
\hline & $\mathrm{CI}$ & -.11 & .11 & -.10 & .96 & & & & .34 \\
\hline
\end{tabular}


Table 6f: Hierarchical multiple regression analysis of exercise Organizational Support with group size and contextual performance dimensions of the interview as predictors (Hypothesis 1a)

\begin{tabular}{cccccccccc}
\hline Step & Variable & $\mathrm{B}$ & $\mathrm{SE} \mathrm{B}$ & $\mathrm{Beta}$ & $\mathrm{t}$ & $\mathrm{R}^{2}$ & $\Delta \mathrm{R}^{2}$ & $\mathrm{~F}$ & Sig. \\
\hline 1 & & & & & & .13 & .13 & 3.68 & .00 \\
& Group Size DMV1 & -.22 & .15 & -.16 & -1.45 & & & & .15 \\
& Group Size DMV2 & -.43 & .17 & -.26 & -2.48 & & & & .02 \\
& Group Size DMV3 & -.69 & .17 & -.42 & -3.98 & & & & .00 \\
& Group Size DMV4 & -.48 & .28 & -.16 & -1.71 & & & & .09 \\
& Group Size DMV5 & -.51 & .26 & -.18 & -1.91 & & & & .06 \\
2 & & & & & .15 & .02 & 1.02 & .39 \\
& Group Size DMV1 & -.22 & .16 & -.15 & -1.37 & & & & .17 \\
& Group Size DMV2 & -.43 & .17 & -.26 & -2.49 & & & & .01 \\
& Group Size DMV3 & -.70 & .17 & -.42 & -4.03 & & & & .00 \\
& Group Size DMV4 & -.51 & .28 & -.16 & -1.79 & & & & .08 \\
& Group Size DMV5 & -.53 & .27 & -.19 & -1.99 & & & & .05 \\
& PS & .10 & .06 & .15 & 1.60 & & & & .11 \\
& OS & -.07 & .07 & -.10 & -1.00 & & & & .32 \\
& CI & .02 & .07 & .04 & .35 & & & & .73 \\
\hline
\end{tabular}

$\mathrm{N}=128$

Table 6g: Hierarchical multiple regression analysis of exercise Conscientious Initiative with group size and contextual performance dimensions of the interview as predictors (Hypothesis 1a)

\begin{tabular}{cccccccccc}
\hline Step & Variable & $\mathrm{B}$ & $\mathrm{SE} \mathrm{B}$ & Beta & $\mathrm{t}$ & $\mathrm{R}^{2}$ & $\Delta \mathrm{R}^{2}$ & $\mathrm{~F}$ & Sig. \\
\hline 1 & & & & & & .04 & .04 & .96 & .45 \\
& Group Size DMV1 & -.17 & .18 & -.11 & -.93 & & & & .36 \\
& Group Size DMV2 & -.30 & .20 & -.17 & -1.52 & & & & .13 \\
& Group Size DMV3 & -.08 & .20 & -.04 & -.39 & & & & .70 \\
& Group Size DMV4 & -.13 & .32 & -.04 & -.41 & & & & .68 \\
& Group Size DMV5 & .28 & .30 & .09 & .92 & & & & .36 \\
2 & & & & & .09 & .05 & 2.08 & .11 \\
& Group Size DMV1 & -.14 & .18 & -.09 & -.80 & & & & .42 \\
& Group Size DMV2 & -.28 & .19 & -.16 & -1.44 & & & & .15 \\
& Group Size DMV3 & -.09 & .19 & -.05 & -.46 & & & & .65 \\
& Group Size DMV4 & -.12 & .32 & -.04 & -.37 & & & & .71 \\
& Group Size DMV5 & .31 & .30 & .10 & 1.04 & & & & .30 \\
& PS & .06 & .07 & .10 & 1.00 & & & & .32 \\
& OS & -.06 & .08 & -.08 & -.79 & & & & .43 \\
& CI & -.15 & .08 & .21 & 2.01 & & & & .05 \\
\hline
\end{tabular}


Table 6h: Hierarchical multiple regression analysis of exercise Average Contextual Performance with group size and contextual performance dimensions of the interview as predictors (Hypothesis 1a)

\begin{tabular}{|c|c|c|c|c|c|c|c|c|c|}
\hline Step & Variable & B & SE B & Beta & $\mathrm{t}$ & $\mathrm{R}^{2}$ & $\Delta \mathrm{R}^{2}$ & $\mathrm{~F}$ & Sig. \\
\hline \multirow[t]{6}{*}{1} & & & & & & .06 & .06 & 1.56 & .18 \\
\hline & Group Size DMV1 & -.10 & .13 & -.09 & -.82 & & & & .41 \\
\hline & Group Size DMV2 & -.33 & .14 & -.26 & -2.35 & & & & .02 \\
\hline & Group Size DMV3 & -.27 & .14 & -.22 & -1.97 & & & & .05 \\
\hline & Group Size DMV4 & -.24 & .23 & -.10 & -1.06 & & & & .29 \\
\hline & Group Size DMV5 & -.05 & .21 & -.02 & -.23 & & & & .82 \\
\hline \multirow[t]{9}{*}{2} & & & & & & .09 & .03 & 1.28 & .28 \\
\hline & Group Size DMV1 & -.10 & .13 & -.09 & -.76 & & & & .45 \\
\hline & Group Size DMV2 & -.32 & .14 & -.25 & -2.31 & & & & .02 \\
\hline & Group Size DMV3 & -.29 & .14 & -.23 & -2.06 & & & & .04 \\
\hline & Group Size DMV4 & -.26 & .23 & -.11 & -1.16 & & & & .25 \\
\hline & Group Size DMV5 & -.02 & .21 & -.01 & -.10 & & & & .92 \\
\hline & PS & .07 & .05 & .13 & 1.34 & & & & .18 \\
\hline & OS & .02 & .06 & .04 & .40 & & & & .69 \\
\hline & $\mathrm{CI}$ & .02 & .05 & .05 & .43 & & & & .67 \\
\hline
\end{tabular}

$\mathrm{N}=128$

Table 6i: Multiple regression analysis of assessor questionnaire Personal Support with contextual performance dimensions of the interview as predictors (Hypothesis 1a)

\begin{tabular}{cccccccccc}
\hline Step & Variable & $\mathrm{B}$ & $\mathrm{SE} \mathrm{B}$ & $\mathrm{Beta}$ & $\mathrm{t}$ & $\mathrm{R}^{2}$ & $\Delta \mathrm{R}^{2}$ & $\mathrm{~F}$ & Sig. \\
\hline 1 & & & & & & .20 & .20 & 5.98 & .00 \\
& PS & .15 & .07 & .25 & 2.13 & & & & .04 \\
& OS & .04 & .07 & .06 & .49 & & & & .63 \\
& CI & .13 & .07 & .23 & 1.85 & & & .07 \\
\hline
\end{tabular}

$\mathrm{N}=78$ 
Table 6j: Multiple regression analysis of assessor questionnaire Organizational Support with contextual performance dimensions of the interview as predictors (Hypothesis 1a)

\begin{tabular}{cccccccccc}
\hline Step & Variable & $\mathrm{B}$ & $\mathrm{SE} \mathrm{B}$ & $\mathrm{Beta}$ & $\mathrm{t}$ & $\mathrm{R}^{2}$ & $\Delta \mathrm{R}^{2}$ & $\mathrm{~F}$ & Sig. \\
\hline 1 & & & & & & .14 & .14 & 4.06 & .01 \\
& PS & .16 & .07 & .26 & 2.15 & & & & .04 \\
& OS & -.05 & .07 & -.08 & -.63 & & & .53 \\
& CI & .13 & .07 & .22 & 1.72 & & & .09 \\
\hline
\end{tabular}

$\mathrm{N}=78$

Table 6k: Multiple regression analysis of assessor questionnaire Conscientious Initiative with contextual performance dimensions of the interview as predictors (Hypothesis 1a)

\begin{tabular}{cccccccccc}
\hline Step & Variable & $\mathrm{B}$ & $\mathrm{SE} \mathrm{B}$ & $\mathrm{Beta}$ & $\mathrm{t}$ & $\mathrm{R}^{2}$ & $\Delta \mathrm{R}^{2}$ & $\mathrm{~F}$ & Sig. \\
\hline 1 & & & & & & .17 & .17 & 5.04 & .00 \\
& PS & .20 & .06 & .38 & 3.18 & & & & .00 \\
& OS & -.01 & .06 & -.01 & -.11 & & & .91 \\
& CI & .04 & .07 & .07 & .55 & & & .58 \\
\hline
\end{tabular}

$\mathrm{N}=78$

Table 6l: Multiple regression analysis of assessor questionnaire Average Contextual Performance with contextual performance dimensions of the interview as predictors (Hypothesis 1a)

\begin{tabular}{cccccccccc}
\hline Step & Variable & $\mathrm{B}$ & $\mathrm{SE} \mathrm{B}$ & $\mathrm{Beta}$ & $\mathrm{t}$ & $\mathrm{R}^{2}$ & $\Delta \mathrm{R}^{2}$ & $\mathrm{~F}$ & Sig. \\
\hline 1 & & & & & & .18 & .18 & 5.49 & .00 \\
& PS & .17 & .06 & .32 & 2.64 & & & & .01 \\
& OS & -.01 & .06 & -.01 & -.10 & & & .92 \\
& CI & .10 & .07 & .19 & 1.51 & & & .14 \\
\hline
\end{tabular}

$\mathrm{N}=78$ 
Table 7a: Hierarchical multiple regression analysis of assessor questionnaire Personal Support with the task and contextual performance dimensions of the interview as predictors (Hypothesis 1b)

\begin{tabular}{cccccccccc}
\hline Step & Variable & $\mathrm{B}$ & $\mathrm{SE} \mathrm{B}$ & $\mathrm{Beta}$ & $\mathrm{t}$ & $\mathrm{R}^{2}$ & $\Delta \mathrm{R}^{2}$ & $\mathrm{~F}$ & Sig. \\
\hline 1 & & & & & & .11 & .11 & 9.46 & .00 \\
& Task & .23 & .07 & .33 & 3.08 & & & & .00 \\
2 & & & & & & .21 & .09 & 2.89 & .04 \\
& Task & .08 & .09 & .12 & .96 & & & .34 \\
& PS & .13 & .07 & .22 & 1.77 & & & .08 \\
& OS & .02 & .07 & .04 & .33 & & & .74 \\
& CI & .11 & .08 & .20 & 1.50 & & & \\
\hline
\end{tabular}

$\mathrm{N}=78$

Table 7b: Hierarchical multiple regression analysis of assessor questionnaire Organizational Support with the task and contextual performance dimensions of the interview as predictors (Hypothesis 1b)

\begin{tabular}{cccccccccc}
\hline Step & Variable & $\mathrm{B}$ & $\mathrm{SE} \mathrm{B}$ & Beta & $\mathrm{t}$ & $\mathrm{R}^{2}$ & $\Delta \mathrm{R}^{2}$ & $\mathrm{~F}$ & Sig. \\
\hline 1 & & & & & & .07 & .07 & 5.95 & .02 \\
& Task & .19 & .08 & .27 & 2.44 & & & & .02 \\
2 & & & & & & .15 & .08 & 2.20 & .10 \\
& Task & .08 & .09 & .11 & .84 & & & .41 \\
& PS & .14 & .08 & .23 & 1.82 & & & .07 \\
& OS & -.06 & .07 & -.10 & -.76 & & & .45 \\
& CI & .11 & .08 & .19 & 1.40 & & & .17 \\
\hline
\end{tabular}

$\mathrm{N}=78$ 
Table 7c: Hierarchical multiple regression analysis of assessor questionnaire Conscientious Initiative with the task and contextual performance dimensions of the interview as predictors (Hypothesis 1b)

\begin{tabular}{cccccccccc}
\hline Step & Variable & $\mathrm{B}$ & $\mathrm{SE} \mathrm{B}$ & Beta & $\mathrm{t}$ & $\mathrm{R}^{2}$ & $\Delta \mathrm{R}^{2}$ & $\mathrm{~F}$ & Sig. \\
\hline 1 & & & & & & .05 & .05 & 4.03 & .05 \\
& Task & .14 & .07 & .22 & 2.01 & & & & .05 \\
2 & & & & & & .17 & .12 & 3.51 & .02 \\
& Task & .02 & .08 & .03 & .23 & & & .82 \\
& PS & .20 & .07 & .38 & 2.96 & & & .00 \\
& OS & -.01 & .07 & -.02 & -.15 & & & .88 \\
& CI & .03 & .07 & .06 & .46 & & & .65 \\
\hline
\end{tabular}

$\mathrm{N}=78$

Table 7d: Hierarchical multiple regression analysis of assessor questionnaire Average Contextual Performance with the task and contextual performance dimensions of the interview as predictors (Hypothesis 1b)

\begin{tabular}{cccccccccc}
\hline Step & Variable & $\mathrm{B}$ & $\mathrm{SE} \mathrm{B}$ & Beta & $\mathrm{t}$ & $\mathrm{R}^{2}$ & $\Delta \mathrm{R}^{2}$ & $\mathrm{~F}$ & Sig. \\
\hline 1 & & & & & & .09 & .09 & 7.33 & .01 \\
& Task & .18 & .07 & .30 & 2.71 & & & & .01 \\
2 & & & & & & .19 & .10 & 3.01 & .04 \\
& Task & .06 & .08 & .10 & .75 & & & .45 \\
& PS & .16 & .07 & .29 & 2.32 & & & .02 \\
& OS & -.01 & .07 & -.03 & -.22 & & & .83 \\
& CI & .08 & .07 & .16 & 1.22 & & & .23 \\
\hline
\end{tabular}

$\mathrm{N}=78$ 
Bonness, Brian, 2007, UMSL, p. 113

Table 8: Regression analysis with self-assessment Conscientiousness as the predictor (Hypothesis 3)

\begin{tabular}{ccccccccc}
\hline $\begin{array}{c}\text { Dependent } \\
\text { Variable }\end{array}$ & $\mathrm{B}$ & $\mathrm{SE} \mathrm{B}$ & Beta & $\mathrm{t}$ & $\mathrm{R}$ & $\mathrm{R}^{2}$ & $\mathrm{~F}$ & Sig. \\
\hline SA PS & .55 & .13 & .33 & 4.21 & .33 & .11 & 17.74 & .00 \\
SA OS & 1.12 & .13 & .59 & 8.86 & .59 & .35 & 78.41 & .00 \\
SA CI & .80 & .13 & .46 & 6.21 & .46 & .21 & 38.57 & .00 \\
SA Avg CP & .82 & .11 & .54 & 7.75 & .54 & .30 & 60.12 & .00 \\
& & & & & & & & \\
Ex PS & .02 & .32 & .01 & .06 & .01 & .00 & .00 & .96 \\
Ex OS & .56 & .21 & .24 & 2.73 & .24 & .06 & 7.42 & .01 \\
Ex CI & .19 & .23 & .07 & .82 & .07 & .01 & .67 & .41 \\
Ex Avg CP & .25 & .16 & .14 & 1.57 & .14 & .02 & 2.47 & .12 \\
& & & & & & & & \\
AQ PS & .81 & .21 & .41 & 3.86 & .41 & .16 & 14.91 & .00 \\
AQ OS & .77 & .21 & .38 & 3.62 & .38 & .15 & 13.09 & .00 \\
AQ CI & .59 & .19 & .33 & 3.03 & .33 & .11 & 9.18 & .00 \\
AQ Avg CP & .72 & .19 & .40 & 3.79 & .40 & .16 & 14.40 & .00 \\
\hline $\mathrm{N}=146$
\end{tabular}


Table 9a: Hierarchical multiple regression analysis of assessor questionnaire Personal Support with self-assessment of conscientiousness and the contextual performance dimensions of the interview as predictors (Hypothesis 4)

\begin{tabular}{cccccccccc}
\hline Step & Variable & $\mathrm{B}$ & $\mathrm{SE} \mathrm{B}$ & $\mathrm{Beta}$ & $\mathrm{t}$ & $\mathrm{R}^{2}$ & $\Delta \mathrm{R}^{2}$ & $\mathrm{~F}$ & Sig. \\
\hline 1 & & & & & & .16 & .16 & 14.91 & .00 \\
& & Conscientiousness & .81 & .21 & .41 & 3.86 & & & \\
2 & & & & & .32 & .15 & 5.38 & .00 \\
& & & & & & & & \\
& Conscientiousness & .71 & .20 & .35 & 3.58 & & & .00 \\
& PS & .16 & .07 & .27 & 2.47 & & & .02 \\
& OS & .02 & .07 & .03 & .26 & & & .80 \\
& CI & .10 & .07 & .17 & 1.44 & & & .15 \\
\hline
\end{tabular}

$\mathrm{N}=78$

Table 9b: Hierarchical multiple regression analysis of assessor questionnaire Organizational Support with self-assessment of conscientiousness and the contextual performance dimensions of the interview as predictors (Hypothesis 4)

\begin{tabular}{cccccccccc}
\hline Step & Variable & $\mathrm{B}$ & $\mathrm{SE} \mathrm{B}$ & $\mathrm{Beta}$ & $\mathrm{t}$ & $\mathrm{R}^{2}$ & $\Delta \mathrm{R}^{2}$ & $\mathrm{~F}$ & Sig. \\
\hline 1 & & & & & & .15 & .15 & 13.09 & .00 \\
& Conscientiousness & .77 & .21 & .38 & 3.62 & & & & .00 \\
2 & & & & & & .26 & .12 & 3.78 & .01 \\
& Conscientiousness & .71 & .21 & .35 & 3.45 & & & .00 \\
& PS & .17 & .07 & .28 & 2.47 & & & .02 \\
& OS & -.06 & .07 & -.11 & -.94 & & & .35 \\
& CI & .09 & .07 & .16 & 1.31 & & & .20 \\
\hline
\end{tabular}

$\mathrm{N}=78$ 
Table 9c: Hierarchical multiple regression analysis of assessor questionnaire Conscientious Initiative with self-assessment of conscientiousness and the contextual performance dimensions of the interview as predictors (Hypothesis 4)

\begin{tabular}{cccccccccc}
\hline Step & Variable & $\mathrm{B}$ & $\mathrm{SE} \mathrm{B}$ & $\mathrm{Beta}$ & $\mathrm{t}$ & $\mathrm{R}^{2}$ & $\Delta \mathrm{R}^{2}$ & $\mathrm{~F}$ & Sig. \\
\hline 1 & & & & & & .11 & .11 & 9.18 & .00 \\
& & Conscientiousness & .59 & .19 & .33 & 3.03 & & & \\
2 & & & & & & .26 & .15 & 5.08 & .00 \\
& & Conscientiousness & .55 & .18 & .31 & 3.02 & & & .00 \\
& PS & .21 & .06 & .40 & 3.49 & & & .00 \\
& OS & -.02 & .06 & -.04 & -.35 & & & .73 \\
& CI & .01 & .06 & .02 & .13 & & & .90 \\
\hline
\end{tabular}

$\mathrm{N}=78$

Table 9d: Hierarchical multiple regression analysis of assessor questionnaire Average Contextual Performance with self-assessment of conscientiousness and the contextual performance dimensions of the interview as predictors (Hypothesis 4)

\begin{tabular}{|c|c|c|c|c|c|c|c|c|c|}
\hline Step & Variable & B & SE B & Beta & $\mathrm{t}$ & $\mathrm{R}^{2}$ & $\Delta \mathrm{R}^{2}$ & $\mathrm{~F}$ & Sig. \\
\hline 1 & & & & & & .16 & .16 & 14.40 & .00 \\
\hline & Conscientiousness & .72 & .19 & .40 & 3.79 & & & & .00 \\
\hline 2 & & & & & & .31 & .15 & 5.27 & .00 \\
\hline & Conscientiousness & .66 & .18 & .36 & 3.66 & & & & .00 \\
\hline & PS & .18 & .06 & .34 & 3.04 & & & & .00 \\
\hline & OS & -.02 & .06 & -.04 & -.39 & & & & .70 \\
\hline & $\mathrm{CI}$ & .07 & .06 & .13 & 1.07 & & & & .29 \\
\hline
\end{tabular}


Please provide your name on this page only. This page will be separated from the rest of the questionnaire and discarded. This will allow us to maintain complete confidentiality for participants in this study.

Participant Name: 


\section{Appendix A}

Bonness, Brian, 2007, UMSL, p. 117

\section{Section I: Performance Self-Assessment}

Instructions: The following items describe behaviors that might occur when working in an organization. Please respond based on your experience working in a specific organization. If you don't have significant work experience, answer the questions based on your experience with school or other related activities/projects. Read each statement and then decide, on average, how often you display the behavior when given the opportunity. Mark your answer in the blank next to each statement. Please answer honestly. Your individual responses will remain confidential. Your name will be separated from the questionnaire. Use the following response scale:

\section{When given the opportunity to display the following behaviors on the job or during school or other related activities/projects, I... (you may choose any number on the scale...1, 2, 3, 4 or 5 )}

\begin{tabular}{|c|c|c|c|c|}
\hline $\mathbf{1}$ & $\mathbf{2}$ & $\mathbf{3}$ & $\mathbf{4}$ & $\mathbf{5}$ \\
\hline $\begin{array}{c}\text { Almost Never } \\
\text { display this } \\
\text { behavior }\end{array}$ & $\square$ & $\square$ & $\square$ & $\begin{array}{c}\text { Almost Always } \\
\text { display this } \\
\text { behavior }\end{array}$ \\
\hline
\end{tabular}

1. Adequately complete assigned duties.

2. Put a lot of effort into fulfilling my responsibilities.

3. Help others without expecting something in return.

4. Respect authority.

5. Fulfill responsibilities specified in job description.

6. Complete tasks or assignments on time or ahead of time.

7. Help others to resolve their problems even if I am not responsible for the problem.

8. Am punctual.

9. Perform tasks that are expected of me.

10. Do more than what is expected on tasks or assignments.

11. Volunteer to help others without being asked.

12. Obtain approval before bending policies or rules.

13. Meet formal performance requirements of the job.

14. See tasks through to their completion.

15. Share expertise, knowledge, and information willingly with others.

16. Consistently attend meetings or work in spite of traffic, weather, etc.

17. Engage in activities that will directly affect my performance evaluation.

18. Do what is necessary to get the job done.

19. Am courteous toward others.

20. Follow organizational policies and rules even if there are no consequences for failing to do so.

21. Ensure work is error free.

22. Work cooperatively with others.

23. Defend the organization even when others are criticizing it.

24. Take action to resolve problems before asking others for help.

25. Offer guidance to less experienced people.

26. Talk positively about the organization.

27. Recognize potential problems and take steps to solve them. 


\begin{tabular}{|c|c|c|c|c|}
\hline $\mathbf{1}$ & $\mathbf{2}$ & $\mathbf{3}$ & $\mathbf{4}$ & $\mathbf{5}$ \\
$\square$ & $\square$ & $\square$ & $\square$ & $\square$ \\
\hline $\begin{array}{c}\text { Almost Never } \\
\text { display this } \\
\text { behavior }\end{array}$ & & $\begin{array}{c}\text { Sometimes } \\
\text { display this } \\
\text { behavior }\end{array}$ & & $\begin{array}{c}\text { Almost Always } \\
\text { display this } \\
\text { behavior }\end{array}$ \\
\hline
\end{tabular}

28. Help resolve conflicts between people.

29. Represent the organization favorably to others.

30. Provide useful suggestions on how to complete tasks more effectively or efficiently.

31. Willingly change plans/priorities to cooperate with unforeseen events.

32. Encourage others to work toward organizational objectives.

33. Seek opportunities to improve my skills or capabilities.

34. Put group objectives above personal goals.

35. Take on additional responsibility without being asked.

36. Notify others of important information/issues without being asked.

37. Try to find additional work when not busy.

Overall Performance: Please evaluate your overall job performance using the following scale. Again, if you don't have significant work experience, answer based on your experience with school or other related activities/projects. (you may choose any number on the scale...1, 2, 3, 4 or 5 )

\begin{tabular}{|c|c|c|c|c|}
\hline $\begin{array}{l}1 \\
\square\end{array}$ & $\begin{array}{l}\mathbf{2} \\
\square\end{array}$ & $\begin{array}{l}3 \\
\square\end{array}$ & $\begin{array}{l}\mathbf{4} \\
\square\end{array}$ & $\begin{array}{l}5 \\
\square\end{array}$ \\
\hline $\begin{array}{c}\text { My overall job } \\
\text { performance } \\
\text { DOES NOT MEET } \\
\text { standards and } \\
\text { expectations }\end{array}$ & & $\begin{array}{l}\text { My overall job } \\
\text { performance } \\
\text { MEETS } \\
\text { standards and } \\
\text { expectations }\end{array}$ & & $\begin{array}{l}\text { My overall job } \\
\text { performance } \\
\text { EXCEEDS } \\
\text { standards and } \\
\text { expectations }\end{array}$ \\
\hline
\end{tabular}




\section{Appendix A}

\section{Section II: Behavior Tendencies and Preferences}

Instructions: Please use the scale provided to indicate your level of agreement with the statements below.

\begin{tabular}{|c|c|c|c|}
\hline $\mathbf{1}$ & $\mathbf{2}$ & $\mathbf{3}$ & $\mathbf{4}$ \\
$\square$ & $\square$ & $\square$ & $\square$ \\
\hline $\begin{array}{c}\text { Strongly } \\
\text { Disagree }\end{array}$ & Disagree & Agree & $\begin{array}{c}\text { Strongly } \\
\text { Agree }\end{array}$ \\
\hline
\end{tabular}

1. I carry out my obligations to the best of my ability.

2. When working with others I am the one who makes sure that rules are observed.

3. I would lie without hesitation if it serves my purpose.

4. I often rush into action without thinking about potential consequences.

5. People who resist authority should be severely punished.

6. Most of the time my room is in complete disarray.

7. If I find money laying around, I'll keep it to myself.

8. When I make mistakes I often blame others.

9. Getting average grades is enough for me.

10. I frequently forget to put things back in their proper place.

11. I am easily talked into doing silly things.

12. When I was in school, I used to break rules quite regularly.

13. I can be insincere and dishonest if the situation requires me to do so.

14. I support long-established rules and traditions.

15. For me, being organized is unimportant.

16. If I could get away with it, I would not pay taxes.

17. I make every effort to do more than what is expected of me.

18. It bothers me when people cheat on their taxes.

19. I am careful with what I say to others.

20. I often feel responsible for making sure that all group project assignments are completed.

21. I dislike being around impulsive people.

22. I go out of my way to keep my promises.

23. I have high standards and work toward them.

24. Half of the time I do not put things in their proper place.

25. It is sometimes too much of a bother to do exactly what is promised.

26. I get into trouble because I act on impulses rather than on thoughts.

27. I would rather get a bad grade than copy someone else's homework and turn it in as my own.

28. I do not take unnecessary risks.

29. I would gladly spend some of my leisure time trying to improve my community. 


\section{Appendix A}

\begin{tabular}{|c|c|c|c|}
\hline $\mathbf{1}$ & $\mathbf{2}$ & $\mathbf{3}$ & $\mathbf{4}$ \\
$\square$ & $\square$ & $\square$ & $\square$ \\
\hline $\begin{array}{c}\text { Strongly } \\
\text { Disagree }\end{array}$ & Disagree & Agree & $\begin{array}{c}\text { Strongly } \\
\text { Agree }\end{array}$ \\
\hline
\end{tabular}

30. I go above and beyond what is required.

31. If I am running late to an appointment, I may decide not to go at all.

32. I am known to make quick, hot-headed decisions.

33. I do what is required, but rarely anything more.

34. The people who know me best would say that I am honest.

35. I need a neat environment in order to work well.

36. Even under time pressure, I would rather take my time to think about my answer.

37. I am usually not the most responsible group member.

38. Organization is a key component of most things I do.

39. If a cashier forgot to charge me for an item, I would tell him/her.

40. If I am running late, I try to call ahead to notify those who are waiting for me.

41. My friends say I am unpredictable.

42. Even if I knew how to get around the rules without breaking them, I would not do it.

43. I do not work as hard as the majority of people around me.

44. I become annoyed when things around me are disorganized.

45. Setting goals and achieving them is not very important to me.

46. I rarely jump into something without first thinking about it.

47. I firmly believe that it is not ok to lie under any circumstances.

48. I hate when people are sloppy.

49. In my opinion, all laws should be strictly enforced.

50. Every item in my room and on my desk has its own designated place.

51. I believe that people should be allowed to take drugs, as long as it doesn't affect others.

52. I try to be the best at anything I do.

53. In my opinion, censorship slows down progress.

54. Being neat is not exactly my strength.

55. People respect authority more than they should.

56. I have a reputation for being late for almost every meeting or event.

57. I invest little effort into my work.

58. If I accidentally scratched a parked car, I would try to find the owner to pay for the repairs.

59. I have the highest respect for authorities and assist them whenever I can.

60. I demand the highest quality in everything I do. 


\section{Appendix A}

Bonness, Brian, 2007, UMSL, p. 121

\section{Section III: Background Questions}

Instructions: Please answer the following questions as accurately as possible. This information is for data analyses purposes only and will be completely confidential. No individual data will be presented in this study.

What is your age? years

What is your sex? (circle one) Male Female

What is your race? (circle one) White Black Asian Latino Arab Other Native American Native Hawaiian/Pacific Islander

From what perspective did you rate your performance above? (check one) based on my behavior during work based on my behavior during school based on my behavior during other related activities/projects

How many years of work experience do you have? years

How many years have you been in your current work position? years

In your current job, are you considered (circle one):

Full time Part time Seasonal Temporary

In what work category would you place your current job? (circle one)

Entry level/Non-management Management Professional Executive

What is the title of your current work position?

What type of work industry do you currently work in?

How many job interviews have you had before this exercise? interviews 
Bonness, Brian, 2007, UMSL, p. 122

\section{Appendix B}

\section{Processing Timesheets for HRX Consulting}

\section{$\underline{\text { Introduction to Task }}$}

In this task, you will be working as an accounting assistant for a company called HRX Consulting, LLC. This company specializes in human resources consulting and has clients around the country and abroad. As an accounting assistant, it is your job to process weekly timesheets turned in by employees in various departments of the company. There are many employees and a lot of information to track so timesheets are often turned in with errors. It is your job to find these errors and fix them or return the timesheet to the employee for corrections before final processing and client billing.

Although you will work on the timesheets alone in your private office, you will be working as part of a team. The other members of your team will also serve as accounting assistants and will work on the same timesheet task. The project coordinator will be your team leader for this exercise. While processing timesheets, you will receive various emails from your teammates and team leader. View sample email. These emails will be delivered in the form of paper printouts passed under the door of your office. Each email will provide an opportunity to respond back to the sender by simply checking the response most closely representative of how you would personally respond to the email. Please respond to each email promptly before returning back to working on your timesheets. Once you have checked a response, slide the email reply back under the door so that it can be delivered to the sender. Keep in mind that you may be required to follow through on any actions you agree to take in your email response. For example, if you indicate in your response that you want the team leader to give you more timesheets to process, you may be expected to process those extra timesheets. While working on the timesheets and responding to emails, you are encouraged to behave in the same way that you would behave if actually in a real workplace.

\section{Processing Timesheets}

In this task, you will need to review the timesheets to be sure all the information and calculations are correct. It is critically important that all timesheets are correct and free of any errors. Some of the timesheets might be perfectly accurate and others will have various errors. View sample timesheet. You are asked to identify any errors by writing directly on a timesheet. For example, if the hours are miscalculated, write in the correct calculations. Do the best you can to edit a timesheet, and when finished, check the appropriate box in the top right corner and place it into the FINISHED basket.

\section{$\underline{\text { Task Rewards }}$}

Your performance on the timesheet task will determine your individual reward at the end of the exercise. Your performance will also be combined with that of the other individuals on your work team for a group reward. The reward for both individuals and teams will be in the form of lottery chances. Based on your performance, you will receive chances to win a $\$ 50$ individual lottery and a $\$ 100$ team lottery. The team lottery will be divided evenly among the winning team members.

Each timesheet that is processed accurately will count as one chance toward both the individual lottery as well as the group lottery. You will need to accurately process a minimum of 7 timesheets in order to qualify your timesheets for the lottery. The more chances accumulated, the greater your odds of winning the lottery. You will have 25 minutes to work on this task. 


\section{Appendix B}

Bonness, Brian, 2007, UMSL, p. 123

\section{Project Codes}

The format for project codes consists of the Client Code followed by a four-number code that identifies the project (e.g., AMD5001, FED4001, FED4002, NOR5010). After each client code on the following page is a list of projects currently under contract. If a project code appears on the timesheet but is not listed on the following page, it is a mistake. It is important that the codes in the timesheets are correct so that they are entered into the accounting system accurately and the clients are billed the appropriate amount.

\section{Billable Hours, Other Hours, and Overtime Hours}

Billable Hours are hours spent working directly on a specific client project and are billable to that client. Other Hours are hours spent working on various administrative tasks throughout a day that are not billable to a specific client. The "Total Daily Hours" column is the sum of the Billable hours and Other hours for a given day. Overtime Hours are hours spent, on a given day, in excess of 8.0 hours working on Billable hours and/or Other hours. For example, if a consultant has 7.0 Billable hours for a given day and 4.0 hours in the "Other" column, then the "Overtime Hours" column for that day should have 3.0 hours. All weekend hours are considered overtime hours. It is important that overtime hours are reported accurately because employees are paid time and a half for each overtime hour they work.

\section{$\underline{\text { Additional Expenses }}$}

Additional Expenses includes any expenses incurred for a project that are not Billable, Other, or Overtime hours. This can include such things as travel expenses, travel time, client entertaining, working meals, office supplies, etc. These additional expenses are simply listed in the far right column as a monetary sum. If the additional expenses total is above $\$ 100$, the "IR" at the top right of the timesheet must be circled. This stands for "immediate reimbursement" and means that the employee must be reimbursed his/her expenses for that week within 3 days.

\section{Other Notes}

- Each timesheet must be signed by both the employee and the supervisor in order for the employee to get paid. If a timesheet is unsigned, it must be sent back to the employee to get the appropriate signature.

- Some corrections need to be returned to the employee and some can be made by the accounting assistant. For example, a correction in the addition of hours can be made by the accounting assistant and sent along for final processing. In this case, check the box at the top right that says "Checked w/corrections" and place the timesheet in the FINISHED basket. However, a missing signature or an incorrect project code must be sent back to the employee for correction. When a timesheet must be sent back to the employee, check the box that says "Return for corrections" and place it in the FINISHED basket. If a timesheet is free of errors, simply mark the "Checked" box and place it in the FINISHED basket. 


\section{Client/Project Codes for Projects Currently Under Contract}

ALD Aldorus Brewery of Riga Latvia (6002)

ALT Alta Bates Summit Medical Center (6010)

AMD Amdocs, Inc. (5001, 6011)

AME American Red Cross $(5008,5009,6012)$

ANH Anheuser-Busch Inc.

ARM Armstrong Teasdale (5001)

BRO Brown Shoe Company $(\mathbf{6 0 0 4}, \mathbf{6 0 0 5})$

BUS Busch Creative Services, Inc.

CAM Campbell-Taggart Bakeries, Inc.

DIM Dimension Data Inc. (4003, 4007, 6024, 6026)

FED Federal Reserve Bank of St. Louis (4001, 4002, 5008, 6010)

FEH Federal Home Loan Bank of Des Moines (5002)

GUA Guam Distributors

HON Honda of America Manufacturing Company $(5009,5010,6011)$

HUB Hubbell Power Systems, Inc. (4002)

JUS Just Cruises, Inc. (6001)

KIN Kingsmill Resort and Conference Center $(\mathbf{5 0 0 3}, \mathbf{6 0 0 5})$

LEA Leadership by Design $(\mathbf{4 0 0 2}, \mathbf{5 0 1 2}, \mathbf{5 0 1 4}, \mathbf{5 0 1 5}, \mathbf{5 0 1 6}, \mathbf{5 0 1 7})$

MER Merck and Co., Inc. (6001)

MET Metal Container Corporation, Inc.

MOT Motorola, Inc. (5015, 6022)

NOR North Colorado Medical Center $(\mathbf{5 0 1 0}, \mathbf{5 0 1 1}, \mathbf{5 0 1 2})$

OWE Owens Corning, Inc. (5009, 6001)

PRE Precision Printing $(5005,5006)$

PRO ProOrbis, LLC

PUE Puerto Rico Telephone Company (6004)

ROC Rockwell Automation Global Manufacturing Services-Asia (6001)

SAI Saint John's Mercy Medical Center (4001, 5004, 5005)

SEA Sea World of California $(\mathbf{4 0 0 1}, \mathbf{4 0 0 2})$

SES Sesame Place, Inc.

SOL Solar Turbine (4001)

SOU Southern California Gas Company $(\mathbf{5 0 0 3 , 5 0 0 4 , 6 0 0 5 )}$

TRA Trans World Airlines

VER Verizon, Inc. (6002)

WIL Williams-Sonoma Inc. (5021, 6027, 6028)

WUH Wuhan Brewery-People's Republic of China (6001) 


\section{HRX Consulting}

Appendix B

Week ending:

10/29/06

Employee phone:

Position/Dept:
Employee:

Supervisor:
Weekly Time Sheet

Checked $\square$

Checked w/ corrections $\square$

Return for corrections $\square$

\begin{tabular}{|l|l|l|l|l|l|l|l|l|}
\hline Day & $\begin{array}{l}\text { Date } \\
\text { Mon }\end{array}$ 10/23/06 & Client Name & Project Code & $\begin{array}{c}\text { Billable } \\
\text { Hours }\end{array}$ & $\begin{array}{c}\text { Other } \\
\text { Hours }\end{array}$ & $\begin{array}{c}\text { Overtime } \\
\text { Hours }\end{array}$ & $\begin{array}{c}\text { Total Daily } \\
\text { Hours }\end{array}$ & $\begin{array}{c}\text { Additional } \\
\text { Expenses }\end{array}$ \\
\hline & & & & & & & \\
\hline Tues & $10 / 24 / 06$ & & & & & & & \\
\hline & & & & & & & & \\
\hline & & & & & & & & \\
\hline Weds & $10 / 25 / 06$ & & & & & & & \\
\hline & & & & & & & & \\
\hline Thurs & $10 / 26 / 06$ & & & & & & \\
\hline & & & & & & & & \\
\hline Fri & $10 / 27 / 06$ & & & & & & & \\
\hline & & & & & & & & \\
\hline Sat & $10 / 28 / 06$ & & & & & & & \\
\hline Sun & $1029 / 06$ & & & & & & & \\
\hline
\end{tabular}

Employee signature 
Bonness, Brian, 2007, UMSL, p. 126

Appendix C

\section{Using Emails to Measure Contextual Performance}

\section{SME Name:}

\section{Instructions}

In the following exercise, you are asked to serve as a subject matter expert and help validate the materials to be used in a study researching the relationship between structured employment interviews and different dimensions of job performance. Your task will include four steps.

Step 1: Review the instructions for the timesheet exercise that will be used in the study.

Step 2: Review the descriptions of the contextual performance dimensions (Personal Support, Conscientious Initiative, Organizational Support).

Step 3: Sort each email into the contextual performance dimension you feel it most closely represents.

Step 4: For each response linked to an email, indicate the level of the contextual performance dimension it represents.

All information you will need to participate in this validation effort is provided in this document. It is estimated that the entire task will require approximately 45 minutes.

\section{Step 1: Review Instructions for Study Exercise}

See instructions for timesheet task. Read through the instructions and be sure you understand the task participants will be working on and the interaction they will have with other study participants.

\section{Step 2: Review Dimensions of Contextual Performance}

Task performance contributes to the technical core of an organization. It is generally roleprescribed and can be found on an employee's performance appraisal. Conversely, contextual performance is more general in nature rather than job specific and spans across many different jobs. It is not usually role prescribed or formally appraised. Contextual performance contributes to the social and psychological context in which the technical core of the organization functions.

For this study, contextual performance has been organized into three broad dimensions based on the work of Coleman and Borman (2000). The following provides further description of each individual contextual performance dimension and lists several common behavioral indicators for each. 
Bonness, Brian, 2007, UMSL, p. 127

\section{Appendix C}

\section{Personal Support}

The Personal Support dimension includes behaviors or concepts such as helping, cooperating with others, altruism, and interpersonal facilitation. This dimension includes working cooperatively with others in order to benefit the entire organization. Individuals who demonstrate high levels of these behaviors look for opportunities to help others and volunteer to assist or train others, even if they are not asked to do so. Further, they are willing to volunteer assistance even if it requires them to work additional hours or make other personal sacrifices. Example behaviors for this dimension include:

- Helps others without expecting something in return.

- Helps others to resolve their problems even if he/she is not responsible for the problem.

- Volunteers to help others without being asked.

- Shares expertise, knowledge, and information willingly with others.

- Is courteous toward others.

- Works cooperatively with others.

- Offers guidance to less experienced people.

- Helps resolve conflicts between people.

- Willingly changes plans/priorities to cooperate with unforeseen events.

\section{Conscientious Initiative}

The Conscientiousness Initiative dimension includes behaviors such as persisting and remaining dedicated, and expending extra effort. This dimension includes taking actions necessary to complete tasks in both a quality and time-conscious manner. Individuals who demonstrate high levels of these behaviors show extraordinary concern for completing their assigned tasks in a manner that exceeds basic, minimum expectations. This dimension also includes taking extraordinary action to anticipate and solve problems, contribute to the productivity of the work unit, develop one's job-related skills, or improve methods for completing work. Individuals who demonstrate high conscientious initiative look for opportunities to contribute positively to the workgroup. Example behaviors for this dimension include:

- Puts a lot of effort into fulfilling his/her responsibilities.

- Completes tasks or assignments on time or ahead of time.

- Does more than what is expected on tasks or assignments.

- Sees tasks through to their completion.

- Does what is necessary to get the job done.

- Ensures work is error free.

- Takes action to resolve problems before asking others for help.

- Recognizes potential problems and takes steps to solve them.

- Provides useful suggestions on how to complete tasks more effectively or efficiently.

- Seeks opportunities to improve his/her skills or capabilities.

- Takes on additional responsibility without being asked.

- Notifies others of important information/issues without being asked.

- Tries to find additional work when not busy. 


\section{Appendix C}

Bonness, Brian, 2007, UMSL, p. 128

\section{Organizational Support}

The Organizational Support dimension includes behaviors such as endorsing and supporting the organization, following its policies and rules, and remaining loyal and compliant to the company. This dimension includes consistently complying with the rules and policies of the organization or workgroup. Individuals who demonstrate high levels of these behaviors consistently meet work rules and reliably complete their tasks as they are assigned. This dimension also includes demonstrating commitment to the organization or work unit both in word and action. Individuals who demonstrate high levels of these behaviors work to contribute to the success of the organization's objectives, regardless of the climate/morale of the organization. Further, they speak positively about the organization or avoid talking negatively about the organization, despite what others say. Example behaviors for this dimension include:

- Respects authority.

- Is punctual.

- Obtains approval before bending policies or rules.

- Consistently attends meetings or work in spite of traffic, weather, etc.

- Follows organizational policies and rules even if there are no consequences for failing to do so.

- Defends the organization even when others are criticizing it.

- Talks positively about the organization.

- Represents the organization favorably to others.

- Encourages others to work toward organizational objectives.

- Puts group objectives above personal goals. 


\section{Appendix C}

Bonness, Brian, 2007, UMSL, p. 129

\section{Step 3: Sort Emails}

Sort each email into one of the three contextual performance dimensions defined in Step 2 (Personal Support, Conscientious Initiative, Organizational Support). In other words, each email provides an opportunity for a participant to respond in a way that displays a certain level of contextual performance. Your task is to identify the dimension of contextual performance to which each email corresponds. Indicate the dimension of an email by checking the box next to the dimension on the top right corner of the email. Do not proceed to Step 4 (rating email responses) until finished sorting the emails. Once finished with the sorting step, proceed to Step 4.

\section{Step 4: Rate Email Responses}

For each email, review the responses and rate each response using the corresponding rating scale. For example, if the email was sorted into the Personal Support dimension, use the Personal Support rating scale below to make your ratings. For each email response, write your rating (1-5) in the box next to the response (You may also type your ratings directly into the electronic version of the document). If you feel a response does not represent the contextual performance dimension at all, at any level, then simply put NA in the blank.

\section{Personal Support}

\begin{tabular}{|c|c|c|c|c|}
\hline $\begin{array}{c}1 \\
\square\end{array}$ & $\begin{array}{c}2 \\
\square\end{array}$ & $\begin{array}{l}3 \\
\square\end{array}$ & $\begin{array}{l}4 \\
\square\end{array}$ & $\begin{array}{l}5 \\
\square\end{array}$ \\
\hline $\begin{array}{l}\text { This response } \\
\text { represents a } \\
\text { low level } \\
\text { of personal } \\
\text { support }\end{array}$ & & $\begin{array}{l}\text { This response } \\
\text { represents a } \\
\text { moderate level } \\
\text { of personal } \\
\text { support }\end{array}$ & & $\begin{array}{c}\text { This response } \\
\text { represent a } \\
\text { high level } \\
\text { of personal } \\
\text { support }\end{array}$ \\
\hline
\end{tabular}

\section{Conscientious Initiative}

\begin{tabular}{|c|c|c|c|c|}
\hline $\mathbf{1}$ & $\mathbf{2}$ & $\mathbf{3}$ & $\mathbf{4}$ & $\mathbf{5}$ \\
\hline $\begin{array}{c}\text { This response } \\
\text { represents a } \\
\text { low level } \\
\text { of conscientious } \\
\text { initiative }\end{array}$ & $\square$ & $\square$ & $\square$ & $\begin{array}{c}\text { This response } \\
\text { represent a } \\
\text { high level } \\
\text { of conscientious } \\
\text { initiative }\end{array}$ \\
\hline
\end{tabular}

\section{Organizational Support}

\begin{tabular}{|c|c|c|c|c|}
\hline $\mathbf{1}$ & $\mathbf{2}$ & $\mathbf{3}$ & $\mathbf{4}$ & $\mathbf{5}$ \\
\hline $\begin{array}{c}\text { This response } \\
\text { represents a } \\
\text { low level } \\
\text { of organizational } \\
\text { support }\end{array}$ & $\square$ & $\square$ & $\square$ & $\begin{array}{c}\text { This response } \\
\text { represent a } \\
\text { high level } \\
\text { of organizational } \\
\text { support }\end{array}$ \\
\hline
\end{tabular}




\section{Appendix D}

Bonness, Brian, 2007, UMSL, p. 130

(1Cl1H)

From: $\quad$ teammate@hrxconsulting.com

To: $\quad$ accountingassistant@hrxconsulting.com

CC:

Subject: $\quad$ Extra Timesheets

Accounting Assistant,

Did you notice the extra timesheets in our piles? We only need to do a total of 7 to get the lottery chances. Are you even going to mess with the extra timesheets?

Teammate

Check the box next to the response you want to send back to your teammate.

$\square$ I will probably do a few extra timesheets just in case I messed up some of the others.

$\square$ Heck no! I'm doing my 7 timesheets and getting out of here.

$\square$ I'm not all that concerned. I might take a look at the extras but I doubt I'll do anything with them.

$\square$ Looks like I'll finish my 7 without any problem. After that, I'm going to keep going. Might as well do all that we can.

$\square$ I'm still hoping to get to 7 so that's first priority. If I get to there, I'll probably keep going until we run out of time. No reason not to keep going. 


\section{Appendix D}

Bonness, Brian, 2007, UMSL, p. 131

(2OS1C)

From: $\quad$ teammate@hrxconsulting.com

To: $\quad$ accountingassistant@hrxconsulting.com

CC:

Subject: $\quad$ Waste of Time

Accounting Assistant,

Can you believe this task? I can't believe they have us working on this. I just don't really get the point. Seems like a waste of time. I might just stop now and not do any more of these timesheets.

Teammate

Check the box next to the response you want to send back to your teammate.

$\square$ I don't think it's all that bad. I'm sure there is a good reason behind it all. I think we should just plug away and hope for the best. The rest of the team is counting on us.

$\square$ I totally agree. This is a real joke. I really don't see the purpose and really hate working on this stuff.

$\square$ It's not the most exciting task I've worked on but we should still work hard on it. If we do a good job, we'll get a pretty nice reward with the lottery chances. I say we stick with it and do our best. The rest of the team is counting on us.

$\square$ I'm not sure it's as bad as you say but I'm not exactly having the greatest time of my life. I guess we just get through it.

I feel the same way. I'm not real sure why we are working on these. There has to be a better way to do this. 


\section{Appendix D}

Bonness, Brian, 2007, UMSL, p. 132

(3Cl2D)

From: $\quad$ teammate@hrxconsulting.com

To: $\quad$ accountingassistant@hrxconsulting.com

\section{$\mathrm{CC}$ :}

Subject: Checking the Details

Accounting Assistant,

How closely are you checking these timesheets? They seem pretty straight forward. It's probably pretty tough to miss any errors because they are all pretty obvious.

Teammate

Check the box next to the response you want to send back to your teammate.

$\square$ I'm just making sure I make at least one correction on each timesheet and that's it. Hopefully that will show that I gave it an honest effort.

$\square$ I'm checking many of the timesheets closely, but I've skimmed through a few pretty quickly if they look good at first glance.

$\square$ I'm not really checking them all that closely. I think you're right. The errors are pretty easy to spot.

$\square$ This is pretty straight forward but I've found that the errors can be somewhat hard to catch if you aren't looking closely. I'm trying really hard to catch everything.

$\square$ I'm checking the timesheets pretty closely. I want to get them correct, so I'm really looking closely to be sure I catch everything. 


\section{Appendix D}

Bonness, Brian, 2007, UMSL, p. 133

(4PS1L)

From: $\quad$ teammate@hrxconsulting.com

To: $\quad$ accountingassistant@hrxconsulting.com

CC:

Subject: Any Advice?

Accounting Assistant,

How are you doing on your timesheets? I'm having a tougher time than I anticipated. I don't think I'm going to finish processing the minimum in time. Do you have any advice for how I might be able to catch up?

Teammate

Check the box next to the response you want to send back to your teammate.

I guess I could help you with a few timesheets. I was hoping to finish early but if you can't get yours done then someone has to do them. Send what you can't get done my way.

$\square$ I can help you out if you want. It's no problem at all. Send me whatever timesheets you don't think you'll finish and I'll take care of them for you.

$\square$ I wish I could help you catch up but I've got a ton of timesheets to do myself and just can't spare any extra time at this point. I'm really sorry. Good luck.

Sorry to hear you are behind on your timesheets. Maybe I can help. I think I have time to do about 2-3 extra before they are due. Send a few my way and I'll take care of them.

$\square$ I would suggest reading through the directions again and just taking each timesheet step by step as the instructions spell out. Good luck. 


\section{Appendix D}

Bonness, Brian, 2007, UMSL, p. 134

(5PS2E)

From: $\quad$ teamleader@hrxconsulting.com

To: $\quad \underline{\text { accountingassistant } @ \text { hrxconsulting.com }}$

CC:

Subject: $\quad$ Suggestions for Task

Accounting Assistant,

I hope your work on the timesheets is going ok. I'm trying to gather some best practices or advice for how to best work on the task and develop a training guide. If you have any suggestions based on your work with the timesheets, let me know. If so, I have a form to jot down suggestions.

Team Leader

Check the box next to the response you want to send back to your team leader.

I'm sure I can come up with some suggestions. Give me the form when you get a chance and I will jot a few things down.

$\square$ I would like to help you but I don't really have anything to offer in terms of suggestions. It's pretty straight forward.

I'm having trouble thinking of anything good at the moment but let me see if I can come up with something for you.

Actually, I have some good ideas. I'll jot a few things down for you as soon as I'm done working on the task.

$\square$ I wish I could help but I'm really swamped and don't really have any advice anyway. 


\section{Appendix D}

Bonness, Brian, 2007, UMSL, p. 135

(6OS2G)

From: $\quad$ teamleader@hrxconsulting.com

To:

accountingassistant@hrxconsulting.com

\section{CC:}

Subject: $\quad$ Extra Timesheets

Accounting Assistant,

As you saw in the instructions, each timesheet you process will add to both your own lottery chances as well as the total chances for the team. Something that wasn't clarified in the instructions is that you can donate any chances from your individual total to the team total. Do you think you might want to do this? If so, how many chances would you like to contribute?

Team Leader

\section{Check the box next to the response you want to send back to your team leader.}

$\square$ I realize the group payoff would be nice but I just don't think I want to lose any of my own lottery chances. I'm going to go with zero chances to the group total.

$\square$ This is an interesting dilemma. I want to help out but not too much. I will transfer only 1 chance from my individual total to the team total.

$\square$ I really want to help out the group. We should work as a team as much as possible. I will contribute all my individual chances to the team total.

$\square$ I really want to help out the group. I will transfer half of my individual chances to the team total.

If I do any more than 7 timesheets, I will provide any extra chances beyond that to the team total. 
Bonness, Brian, 2007, UMSL, p. 136

Appendix E

\section{Dissertation Study Interview Guide}

Interviewer:

Date:

$2^{\text {nd }}$ Interviewer:
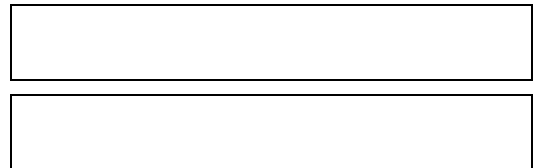

Recording:
Participant Sex:

Participant Code:

$\square$ Male $\square$ Female

Introduction Maintain a friendly and relaxed atmosphere during the interview session. Use the following statements when explaining the interview process:

- This interview is designed to be much like a typical employment interview.

- It will last approximately 20 minutes.

- I will be audio recording the interview for interviewer training purposes - is this ok?

- In this interview, I will ask you to describe specific work experiences.

- While many of your experiences might involve working in a group or team, try to emphasize your specific role - things you have done personally.

- You will do most of the talking. Don't be afraid to pause and take your time when trying to come up with specific examples from your experiences.

- Throughout the interview, I might ask various follow-up questions to get a little more information.

- I'll be taking notes throughout the interview.

- Do you have any questions about the interview process? 


\section{Dissertation Study Interview Guide}

\section{Task Performance (1)}

\section{Interview Question}

1. What is one major duty or responsibility assigned to you in your current or most recent job (or that you have as a student)? Focus on something that would be on your job description or performance appraisal. Also, focus on something you do alone rather than as part of a team. Think of the last time you completed this duty or responsibility and walk me through exactly what you did.

\section{Notes}


Bonness, Brian, 2007, UMSL, p. 138

Appendix E

Dissertation Study Interview Guide

\section{Task Performance (1) Rating}

\begin{tabular}{|c|c|c|c|c|}
\hline Ineffective & Effective & & Highly Effective \\
\hline $\mathbf{1}$ & $\mathbf{2}$ & $\mathbf{3}$ & $\mathbf{4}$ & $\square$ \\
\hline $\begin{array}{c}\text { Failed to provide a } \\
\text { clear example of... }\end{array}$ & $\begin{array}{c}\square \\
\text { satisfactory example } \\
\text { of... }\end{array}$ & & $\begin{array}{c}\text { Clearly described one } \\
\text { or more excellent } \\
\text { examples of... }\end{array}$ \\
\hline $\begin{array}{c}\text {...effectively } \\
\text { completing a major job } \\
\text { duty or responsibility }\end{array}$ & $\begin{array}{c}\text {..effectively } \\
\text { completing a major job } \\
\text { duty or responsibility }\end{array}$ & $\begin{array}{c}\text {..effectively } \\
\text { completing a major job } \\
\text { duty or responsibility }\end{array}$ \\
\hline $\begin{array}{c}\text { Example did not clearly } \\
\text { display any of the } \\
\text { behavioral indicators }\end{array}$ & $\begin{array}{c}\text { Exple displayed at } \\
\text { behavioral indicators }\end{array}$ & & $\begin{array}{c}\text { Example(s) displayed } \\
\text { multiple behavioral } \\
\text { indicators }\end{array}$ \\
\hline
\end{tabular}

\section{Task Performance Behavioral Indicators}

- Completes assigned duties.

- Fulfills responsibilities specified in job description.

- Performs tasks that are expected of him/her.

- Meets formal performance requirements of the job.

- Engages in activities that directly affect his/her performance evaluation. 


\section{Dissertation Study Interview Guide}

\section{Task Performance (2)}

\section{Interview Question}

2. Think about the last major task or project you worked on for your current or most recent job (or for a class at school). Focus on something you did alone rather than as part of a team. What steps did you take to complete the task or project? ... Were you able to complete all of your assigned duties? ... What was the outcome?

\section{$\underline{\text { Notes }}$}


Bonness, Brian, 2007, UMSL, p. 140

Appendix E

Dissertation Study Interview Guide

\section{Task Performance (2) Rating}

\begin{tabular}{|c|c|c|c|c|}
\hline Ineffective & Effective & & Highly Effective \\
\hline $\mathbf{1}$ & $\mathbf{2}$ & $\mathbf{3}$ & $\mathbf{4}$ & $\mathbf{5}$ \\
\hline $\begin{array}{c}\text { Failed to provide a } \\
\text { clear example of... }\end{array}$ & $\begin{array}{c}\text { Provided one } \\
\text { satisfactory example } \\
\text { of... }\end{array}$ & & $\begin{array}{c}\text { Clearly described one } \\
\text { or more excellent } \\
\text { examples of... }\end{array}$ \\
\hline $\begin{array}{c}\ldots \text { effectively } \\
\text { completing an } \\
\text { important task or } \\
\text { project }\end{array}$ & $\begin{array}{c}\text {.effectively } \\
\text { importeting an task or } \\
\text { project }\end{array}$ & & $\begin{array}{c}\ldots \text { effectively } \\
\text { completing an } \\
\text { important task or } \\
\text { project }\end{array}$ \\
\hline $\begin{array}{c}\text { Example did not clearly } \\
\text { display any of the } \\
\text { behavioral indicators }\end{array}$ & $\begin{array}{c}\text { Example displayed at } \\
\text { least one of the } \\
\text { behavioral indicators }\end{array}$ & & $\begin{array}{c}\text { Example(s) displayed } \\
\text { multiple behavioral } \\
\text { indicators }\end{array}$ \\
\hline
\end{tabular}

\section{Task Performance Behavioral Indicators}

- Completes assigned duties.

- Fulfills responsibilities specified in job description.

- Performs tasks that are expected of him/her.

- Meets formal performance requirements of the job.

- Engages in activities that directly affect his/her performance evaluation. 
Bonness, Brian, 2007, UMSL, p. 141

Appendix E

\section{Dissertation Study Interview Guide}

\section{Personal Support}

\section{Interview Questions}

1. Tell me about a time when you noticed that someone else (e.g., co-worker, classmate) needed help accomplishing an important task. How did you respond? ... What did you do? ... What was the outcome?

2. (backup) Think of a time when you had the opportunity to help with something at work that was not officially a part of your job. How did you respond? ... How did you decide what to do? ...What did you do? ...What was the outcome? (or) Think of a time when you had the opportunity to help with an activity or event (e.g., at school) that was not required of you. How did you respond? ... How did you decide what to do? ...What did you do? ...What was the outcome?

\section{$\underline{\text { Notes }}$}


Bonness, Brian, 2007, UMSL, p. 142

Appendix E

\section{Dissertation Study Interview Guide}

\section{Personal Support Rating}

\begin{tabular}{|c|c|c|c|c|}
\hline Ineffective & & Effective & & Highly Effective \\
\hline 1 & 2 & $\begin{array}{l}3 \\
\square\end{array}$ & 4 & $\begin{array}{l}\mathbf{5} \\
\square \\
\end{array}$ \\
\hline $\begin{array}{l}\text { Failed to provide a } \\
\text { clear example of... }\end{array}$ & & $\begin{array}{c}\text { Provided one } \\
\text { satisfactory example } \\
\text { of... }\end{array}$ & & $\begin{array}{l}\text { Clearly described one } \\
\text { or more excellent } \\
\text { examples of... }\end{array}$ \\
\hline $\begin{array}{l}\text { Q1...helping someone } \\
\text { accomplish an } \\
\text { important task (or) } \\
\text { Q2...helping with } \\
\text { something not a part of } \\
\text { his/her job }\end{array}$ & & $\begin{array}{l}\text { Q1...helping someone } \\
\text { accomplish an } \\
\text { important task (or) } \\
\text { Q2...helping with } \\
\text { something not a part of } \\
\text { his/her job }\end{array}$ & & $\begin{array}{l}\text { Q1...helping someone } \\
\text { accomplish an } \\
\text { important task (or) } \\
\text { Q2...helping with } \\
\text { something not a part of } \\
\text { his/her job }\end{array}$ \\
\hline $\begin{array}{l}\text { Example did not clearly } \\
\text { display any of the } \\
\text { behavioral indicators }\end{array}$ & & $\begin{array}{l}\text { Example displayed at } \\
\text { least one of the } \\
\text { behavioral indicators }\end{array}$ & & $\begin{array}{l}\text { Example(s) displayed } \\
\text { multiple behavioral } \\
\text { indicators }\end{array}$ \\
\hline
\end{tabular}

\section{Personal Support Behavioral Indicators}

- Helps others without expecting something in return.

- Helps others to resolve their problems.

- Volunteers to help others without specifically being asked.

- Shares expertise, knowledge, and information willingly with others.

- Is courteous toward others.

- Works cooperatively with others.

- Offers guidance to less experienced people.

- Helps resolve conflicts between people.

- Changes plans/priorities to cooperate with unforeseen events. 
Bonness, Brian, 2007, UMSL, p. 143

Appendix E

\section{Dissertation Study Interview Guide}

\section{Conscientious Initiative}

\section{Interview Questions}

1. Think of a time when a specific obstacle (e.g., technology, customer, co-worker, supervisor) got in the way of you finishing your work task. How did you react to the obstacle? ... What did you do? ... What was the outcome? (or) Think of a time when a specific obstacle got in the way of you finishing a school assignment. How did you react to the obstacle? ...What did you do? ...What was the outcome?

2. (backup) Tell me about a time when you were assigned a very difficult work task/project. How did you respond?... What steps did you take to complete the task/project? ... What was the outcome? (or) Tell me about a time when you were assigned a very difficult school project or assignment. How did you respond? ... What steps did you take to complete the project or assignment? ...What was the outcome?

\section{$\underline{\text { Notes }}$}


Bonness, Brian, 2007, UMSL, p. 144

Appendix E

Dissertation Study Interview Guide

\section{Conscientious Initiative Rating}

\begin{tabular}{|c|c|c|c|c|}
\hline Ineffective & & Effective & & Highly Effective \\
\hline 1 & $\stackrel{2}{\square}$ & $\begin{array}{l}3 \\
\square\end{array}$ & $\stackrel{4}{\square}$ & $\begin{array}{l}\mathbf{5} \\
\square \\
\end{array}$ \\
\hline $\begin{array}{l}\text { Failed to provide a } \\
\text { clear example of... }\end{array}$ & & $\begin{array}{c}\text { Provided one } \\
\text { satisfactory example } \\
\text { of... }\end{array}$ & & $\begin{array}{c}\text { Clearly described one } \\
\text { or more excellent } \\
\text { examples of... }\end{array}$ \\
\hline $\begin{array}{l}\text { Q1...overcoming an } \\
\text { obstacle to complete a } \\
\text { work task or project } \\
\text { (or) Q2...persisting to } \\
\text { complete a difficult } \\
\text { task or project }\end{array}$ & & $\begin{array}{l}\text { Q1...overcoming an } \\
\text { obstacle to complete a } \\
\text { work task or project } \\
\text { (or) Q2 ...persisting to } \\
\text { complete a difficult } \\
\text { task or project }\end{array}$ & & $\begin{array}{l}\text { Q1...overcoming an } \\
\text { obstacle to complete a } \\
\text { work task or project } \\
\text { (or) Q2 ...persisting to } \\
\text { complete a difficult } \\
\text { task or project }\end{array}$ \\
\hline $\begin{array}{l}\text { Example did not clearly } \\
\text { display any of the } \\
\text { behavioral indicators }\end{array}$ & & $\begin{array}{l}\text { Example displayed at } \\
\text { least one of the } \\
\text { behavioral indicators }\end{array}$ & & $\begin{array}{l}\text { Example(s) displayed } \\
\text { multiple behavioral } \\
\text { indicators }\end{array}$ \\
\hline
\end{tabular}

\section{Conscientious Initiative Behavioral Indicators}

- Puts a lot of effort into fulfilling his/her responsibilities.

- Completes tasks or assignments on time or ahead of time.

- Does more than what is expected on tasks or assignments.

- Sees tasks through to their completion.

- Does what is necessary to get the job done.

- Ensures work is error free.

- Takes action to resolve problems before asking others for help.

- Recognizes potential problems and takes steps to solve them.

- Provides useful suggestions on how to complete tasks more effectively or efficiently.

- Seeks opportunities to improve his/her skills or capabilities.

- Takes on additional responsibility without being asked.

- Notifies others of important information/issues without being asked to do so.

- Tries to find additional work when not busy. 


\section{Dissertation Study Interview Guide}

\section{Organizational Support}

\section{Interview Questions}

1. Think of a time when a co-worker was complaining about his/her work or about the company. How did you respond to this co-worker? ... What was the outcome? (or) Think of a time when a classmate or friend was complaining about a project you were working on together. How did you respond? ...What was the outcome?

2. (backup) Describe a time when your company had a rule or policy that was not enforced and many of your co-workers did not like it and did not follow it. How did you respond to your co-workers? ... What exactly did you do? ...What was the outcome? (or) Describe a time when your school had a rule or policy that many of your classmates did not like. How did you respond to your classmates? ...What exactly did you do? ... What was the outcome?

\section{$\underline{\text { Notes }}$}


Bonness, Brian, 2007, UMSL, p. 146

Appendix E

Dissertation Study Interview Guide

\section{Organizational Support Rating}

\begin{tabular}{|c|c|c|c|c|}
\hline Ineffective & & Effective & & Highly Effective \\
\hline 1 & $\stackrel{2}{\square}$ & $\begin{array}{l}3 \\
\square\end{array}$ & $\stackrel{4}{\square}$ & $\begin{array}{l}\mathbf{5} \\
\square \\
\end{array}$ \\
\hline $\begin{array}{l}\text { Failed to provide a } \\
\text { clear example of... }\end{array}$ & & $\begin{array}{c}\text { Provided one } \\
\text { satisfactory example } \\
\text { of... }\end{array}$ & & $\begin{array}{l}\text { Clearly described one } \\
\text { or more excellent } \\
\text { examples of... }\end{array}$ \\
\hline $\begin{array}{l}\text { Q1...responding } \\
\text { positively to a } \\
\text { complaining coworker } \\
\text { and supporting the } \\
\text { organization (or) } \\
\text { Q2...following an } \\
\text { organizational rule or } \\
\text { policy even when } \\
\text { coworkers were not }\end{array}$ & & $\begin{array}{l}\text { Q1...responding } \\
\text { positively to a } \\
\text { complaining coworker } \\
\text { and supporting the } \\
\text { organization (or) } \\
\text { Q2...following an } \\
\text { organizational rule or } \\
\text { policy even when } \\
\text { coworkers were not }\end{array}$ & & $\begin{array}{l}\text { Q1...responding } \\
\text { positively to a } \\
\text { complaining coworker } \\
\text { and supporting the } \\
\text { organization (or) } \\
\text { Q2...following an } \\
\text { organizational rule or } \\
\text { policy even when } \\
\text { coworkers were not }\end{array}$ \\
\hline $\begin{array}{l}\text { Example did not clearly } \\
\text { display any of the } \\
\text { behavioral indicators }\end{array}$ & & $\begin{array}{l}\text { Example displayed at } \\
\text { least one of the } \\
\text { behavioral indicators }\end{array}$ & & $\begin{array}{l}\text { Example(s) displayed } \\
\text { multiple behavioral } \\
\text { indicators }\end{array}$ \\
\hline
\end{tabular}

\section{Organizational Support Behavioral Indicators}

- Obtains approval before bending policies or rules.

- Follows organizational policies and rules.

- Defends the organization when others are criticizing it.

- Talks positively about the organization.

- Represents the organization favorably to others.

- Encourages others to work toward organizational objectives.

- Puts group objectives above personal goals.

- Respects authority.

- Is punctual.

- Attends meetings and work when traffic and weather is a problem. 


\section{Dissertation Study Interview Guide}

\section{Assessment of Conscientiousness}

\section{Definition of Conscientiousness from Roberts et al (2004)}

Industriousness: Hard working, ambitious, confident, and resourceful.

Order: Able to plan and organize tasks and activities.

Self-Control: $\quad$ Cautious and levelheaded; able to delay gratification and be patient.

Responsibility: Likes to be of service to others, frequently contributes time and money to community projects, and tends to be cooperative and dependable.

Traditionalism: Tends to comply with current rules, customs, norms, and expectations; dislike changes and does not challenge authority.

Virtue: $\quad$ Tends to act in accordance with accepted rules of good or moral behavior, and strives to be a moral exemplar.

Based on the information gathered in the interview, please assess this participant's level of conscientiousness.

\begin{tabular}{|c|c|c|c|c|}
\hline 1 & $\mathbf{2}$ & $\mathbf{3}$ & $\mathbf{4}$ & $\mathbf{5}$ \\
\hline $\begin{array}{c}\text { VERY LOW } \\
\text { level of } \\
\text { conscientiousness }\end{array}$ & $\begin{array}{c}\text { LOW } \\
\text { level of } \\
\text { conscientiousness }\end{array}$ & $\begin{array}{c}\text { MODERATE } \\
\text { level of } \\
\text { conscientiousness }\end{array}$ & $\begin{array}{c}\text { HIGH } \\
\text { level of } \\
\text { conscientiousness }\end{array}$ & $\begin{array}{c}\text { VERY HIGH } \\
\text { level of } \\
\text { conscientiousness }\end{array}$ \\
\hline
\end{tabular}




\section{Introduction to Questionnaire}

In the sections that follow, you are asked to assess the performance of the person who gave you this questionnaire. You were chosen to complete this questionnaire because you are familiar with this person's performance in either a work setting, an academic setting, or based on some other related activities/ projects. Your participation in this assessment is an important part of a research study being conducted by Brian Bonness, a graduate student with the University of Missouri-St. Louis. Before beginning, please read the enclosed consent form.

In order to complete the following questionnaire, please follow the instructions for each section. Once finished, please insert the completed questionnaire into the self-addressed return envelope and place it in the mail (do not return the consent form). Rest assured that all information collected on this questionnaire will remain completely anonymous. The person whom you are assessing will not see your ratings and all data will be reported in aggregate format. It is very important that you complete and return this questionnaire in a timely manner in order for the participant being assessed to receive full extra credit and/or other incentives for this exercise. Thank you in advance for your help. If you have any questions or concerns at all, feel free to contact Brian at 314.361.2204 or brianbonness@hotmail.com.

\section{Section I: Performance Assessment}

Instructions: The following items describe behaviors that might occur when working in an organization. If possible, please respond based on your experience working with this person in a specific organization. If you don't have significant experience observing this person in a work setting, answer the questions based on your experience with him/her in school or other related activities/projects. Read each statement and then decide, on average, how often this person displays the behavior when given the opportunity. Mark your answer in the blank next to each statement. Please answer honestly. Your individual responses will remain completely anonymous. Use the following response scale:

When given the opportunity to display the following behaviors on the job or during school or other related activities/projects, he/she... (you may choose any number on the scale...1, $2,3,4$ or 5 )

\begin{tabular}{|c|c|c|c|c|}
\hline $\begin{array}{c}1 \\
\square\end{array}$ & $\stackrel{2}{\square}$ & $\begin{array}{c}3 \\
\square\end{array}$ & $\begin{array}{c}4 \\
\square\end{array}$ & $\begin{array}{r}5 \\
\square\end{array}$ \\
\hline $\begin{array}{l}\text { Almost Never } \\
\text { displays this } \\
\text { behavior }\end{array}$ & & $\begin{array}{l}\text { Sometimes } \\
\text { displays this } \\
\text { behavior }\end{array}$ & & $\begin{array}{c}\text { Almost Always } \\
\text { displays this } \\
\text { behavior }\end{array}$ \\
\hline
\end{tabular}

1. Adequately completes assigned duties.

2. Puts a lot of effort into fulfilling his/her responsibilities.

3. Helps others without expecting something in return.

4. Respects authority.

5. Fulfills responsibilities specified in job description.

6. Completes tasks or assignments on time or ahead of time.

7. Helps others to resolve their problems even if he/she is not responsible for the problem. 


\begin{tabular}{|c|c|c|c|c|}
\hline 1 & $\begin{array}{c}2 \\
\square\end{array}$ & $\begin{array}{c}3 \\
\square\end{array}$ & $\begin{array}{r}4 \\
\square\end{array}$ & 5 \\
\hline $\begin{array}{l}\text { Almost Never } \\
\text { displays this } \\
\text { behavior }\end{array}$ & & $\begin{array}{c}\text { Sometimes } \\
\text { displays this } \\
\text { behavior }\end{array}$ & & $\begin{array}{c}\text { Almost Always } \\
\text { displays this } \\
\text { behavior }\end{array}$ \\
\hline
\end{tabular}

8. Is punctual.

9. Performs tasks that are expected of him/her.

10. Does more than what is expected on tasks or assignments.

11. Volunteers to help others without being asked.

12. Obtains approval before bending policies or rules.

13. Meets formal performance requirements of the job.

14. Sees tasks through to their completion.

15. Shares expertise, knowledge, and information willingly with others.

16. Consistently attends meetings or work in spite of traffic, weather, etc.

17. Engages in activities that will directly affect his/her performance evaluation.

18. Does what is necessary to get the job done.

19. Is courteous toward others.

20. Follows organizational policies and rules even if there are no consequences for failing to do so.

21. Ensures work is error free.

22. Works cooperatively with others.

23. Defends the organization even when others are criticizing it.

24. Takes action to resolve problems before asking others for help.

25. Offers guidance to less experienced people.

26. Talks positively about the organization.

27. Recognizes potential problems and takes steps to solve them.

28. Helps resolve conflicts between people.

29. Represents the organization favorably to others.

30. Provides useful suggestions on how to complete tasks more effectively or efficiently.

31. Willingly changes plans/priorities to cooperate with unforeseen events.

32. Encourages others to work toward organizational objectives.

33. Seeks opportunities to improve his/her skills or capabilities.

34. Puts group objectives above personal goals.

35. Takes on additional responsibility without being asked.

36. Notifies others of important information/issues without being asked.

37. Tries to find additional work when not busy. 


\section{Section II: Overall Performance Assessment}

Instructions: Please evaluate the person's overall job performance using the following scale. Again, if you don't have significant experience observing this person in a work setting, rate the person based on your experience with him/her in school or other related activities/projects. (you may choose any number on the scale...1, 2, 3, 4 or 5)

\begin{tabular}{|c|c|c|c|c|}
\hline $\mathbf{1}$ & $\mathbf{2}$ & $\mathbf{3}$ & $\mathbf{4}$ & $\mathbf{5}$ \\
\hline $\begin{array}{c}\text { His/her overall job } \\
\text { performance }\end{array}$ & $\square$ & $\square$ & $\square$ & $\square$ \\
$\begin{array}{c}\text { DOES NOT MEET } \\
\text { standards and } \\
\text { expectations }\end{array}$ & & $\begin{array}{c}\text { His/her overall job } \\
\text { performance } \\
\text { MEETS }\end{array}$ & & $\begin{array}{c}\text { His/her overall job } \\
\text { performance } \\
\text { EXCEEDS } \\
\text { standards and } \\
\text { expectations }\end{array}$ \\
\hline
\end{tabular}

\section{Continue to Section III on next page...}




\section{Appendix F}

Bonness, Brian, 2007, UMSL, p. 151

\section{Section III: Background Questions}

Instructions: Please answer the following questions as accurately as possible. This information is for data analyses purposes only and will remain completely anonymous. No individual data will be presented in this study.

1. What is your age? years

2. What is your sex? (circle one) Male Female

3. What is your race? (circle one) White Black Asian Latino Arab Other Native American Native Hawaiian/Pacific Islander

4. How many years of work experience do you have? years

5. How many years have you been in your current work position? years

6. In your current job, are you considered (circle one):

Full time Part time Seasonal Temporary

7. In what work category would you place your current job? (circle one)

Entry level/Non-management Management Professional Executive

8. What is the title of your current work position?

9. What type of work industry do you currently work in?

10. From what perspective did you rate the person in section I and II above? (check one)

based on the participant's behavior during work based on the participant's behavior during school based on the participant's behavior during other related activities/projects

11. How long have you worked with this person or observed the behavior of this person during school or other related activities/projects? years

12. How do you have knowledge of the person's performance? (check one)

I am this person's supervisor

I am this person's co-worker

I am this person's classmate at school

I am familiar with this person's performance on other related activities/projects

Other. Please explain 


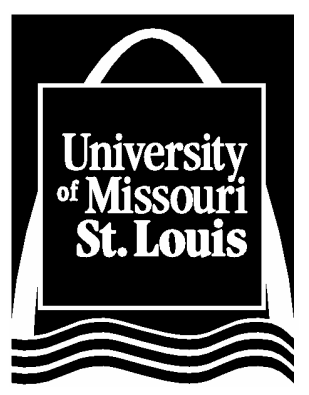

College of Arts and Sciences

Department of Psychology 8001 Natural Bridge Road

St. Louis, Missouri 63121-4499

Telephone: 314-516-5391

\section{Informed Consent for Participation in Research Activities}

Structured Interviews and Performance

Participant UMSL Student

Principal Investigator

Brian Bonness
HSC Approval Number

$\underline{061005 B}$

PI’s E-mail _brianbonness@hotmail.com

\section{Why am I being asked to participate?}

You are invited to participate in a research study that will evaluate structured employment interviews. It is being conducted by Brian Bonness in the Department of Psychology at the University of Missouri-St. Louis. You have been asked to participate in this study because you are enrolled in a course from which participants are being recruited and may be eligible to participate. Please read this form and ask any questions you may have before agreeing to be in the research. Your participation in this research is voluntary. Your decision whether to participate will not affect your current or future relations with the University. If you decide to participate, you are free to withdraw at any time without affecting that relationship.

\section{What is the purpose of this research?}

The purpose of this study is to investigate structured employment interviews.

\section{What procedures are involved?}

If you participate in this study, you can expect to complete a questionnaire with background questions concerning your work experiences and performance as well as behavioral tendencies and preferences. Next, you will work on an administrative task where you will be asked to process a set of timesheets and respond to several printed email messages. Finally, you will go through a short structured interview, which will be audio recorded. The entire study will last approximately one hour. Approximately 120 individuals from the University of Missouri-St. Louis will participate in this research.

\section{Are there benefits to taking part in the research?}

This study will provide you with a valuable opportunity to go through a structured interview very similar to an actual employment interview. No risks to participants are anticipated in this study.

\section{What about privacy and confidentiality?}

This consent form will be stored in a separate location from study questionnaires. Your questionnaires will be assigned a random code that is not linked to your name in any way. Although interviews will be audio recorded, your name will not be connected to the recordings in any way and all tapes will be destroyed following the study. Recordings will be used for ongoing interviewer training only. The principal investigator and research assistants conducting interviews will be the only individuals with access to the recordings. 


\section{Appendix G}

Bonness, Brian, 2007, UMSL, p. 153

\section{Can I withdraw or be removed from the study?}

You can choose whether to be in this study. If you volunteer to be in this study, you may withdraw at any time. You also may refuse to answer any questions you do not want to answer and still remain in the study. The investigator may withdraw you from this research if circumstances arise which warrant doing so.

\section{Who should I contact if I have questions?}

The principle investigator conducting this study is Brian Bonness. You may ask any questions you have now. If you have questions later, you may contact Brian at brianbonness@, hotmail.com or (314) 361-2204.

\section{What are my rights as a research participant?}

If you have any questions about your rights as a research participant, you may call the Chairperson of the Institutional Review Board at (314) 516-5897.

\section{What if I am a UMSL student?}

You may choose not to participate, or to stop your participation in this research, at any time. This decision will not affect your class standing or grades at UMSL. The investigator also may end your participation in the research. If this happens, your class standing will not be affected. You will not be offered or receive any special consideration if you participate in this research.

Remember: Your participation in this research is voluntary. Your decision whether to participate will not affect your current or future relations with the University. If you decide to participate, you are free to withdraw at any time without affecting that relationship.

You will be given a copy of this form for your information and to keep for your records.

We may need to contact you at a later time so please provide your email address and phone number below.

I have read the above statement and have been able to express my concerns, to which the investigator has responded satisfactorily. I believe I understand the purpose of the study, as well as the potential benefits and risks that are involved.

Participant's Signature

Date

Participant's Printed Name

Date
Participant's E-mail Address 


\title{
INTERVIEWER
}

\section{Training GuIDE}

\section{Using Structured Employment Interviews to Predict Task and Contextual Performance}

\author{
Brian M. Bonness
}

University of Missouri - St. Louis 
Appendix $\mathrm{H}$

Bonness, Brian, 2007, UMSL, p. 155

\section{Contents}

I. INTRODUCTION TO THE RESEARCH STUDY............................. 1

II. Timeline/Process OF StUdy Sessions................................. 1

III. INTERVIEW GUIDE AND INTERVIEW QUESTIONS..................... 1

IV. Audio Recording Interviews And Providing FeEdback............ 2

V. CONDUCTING THE INTERVIEW - WHAT TO DO, WHAT TO AVOID, AND HOW TO DRESS................................ 2

VI. INTERVIEWS USED IN THIS STUDY - STRUCTURED INTERVIEWS.......... 3

VII. GATHERING BEHAVIOR-BASED INFORMATION.......................... 3

A. Behavior Based Questions................................... 3

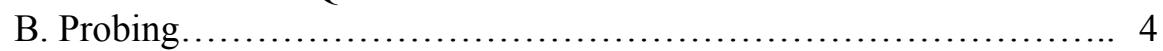

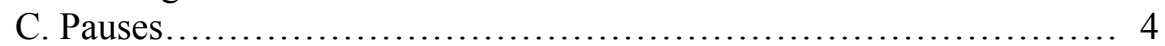

D. Context (of Participant's Past Experience)....................... 4

E. Recognizing Behaviors................................... 5

VIII. RECORDING BEHAVIORS IN THE INTERVIEW NOTES................... 6

IX. SCORING INTERVIEW RESPONSES................................. 6

X. Dimensions of Performance Assessed

IN THE INTERVIEWS (TASK, CI, PS, OS) $\ldots \ldots \ldots \ldots \ldots \ldots \ldots \ldots \ldots \ldots \ldots \ldots . \ldots \ldots$

XI. INTERVIEWER/RATER ERRORS.................................... 11

XII. QUESTIONS TO AVOID.............................................. 13 


\section{INTRODUCTION TO THE RESEARCH STUDY}

This interviewer training is a part of a research study intended to evaluate the predictive quality of interviews designed to measure different dimensions of performance. Interview prediction of three dimensions of contextual performance (personal support, organizational support, conscientious initiative) will be compared to interview prediction of task performance. To do this, we will use structured, behavior-based interviews to evaluate undergraduate psychology and business students and then assess their performance on the same dimensions using three different measures (performance assessment exercise, self-assessment, peer/supervisor assessment). We will also compare the prediction of interviews to the prediction of a paper-and-pencil measure of conscientiousness. See study proposal for additional details and background.

\section{Timeline/Process OF STUdY Sessions}

Each study session will include approximately 3-5 participants and last approximately one hour. After receiving a brief orientation to the study session, participants will begin the performance assessment exercise. This part of the study session will last approximately 30 minutes. Once finished with the exercise, participants will be interviewed. An interviewer will take each participant into a separate room and proceed with the interview. The interview will last approximately 15-25 minutes. When extra interviewers are present for a session, the extra interviewer(s) will double up with another interviewer. The extra interviewer will take notes and make ratings but will not ask any questions of the participant. The research sessions will overlap such that interviews will be conducted back-to-back. Following the interview, participants will be asked to take questionnaires to two additional assessors and will then be excused from the session.

\section{INTERVIEW GUIDE AND INTERVIEW QUESTIONS}

Interviewers will be provided with an interview guide with instructions and recommendations for conducting interviews. This guide will contain the most important information to remember when preparing for and conducting an interview. It is important that the interviewer become very familiar with this guide before conducting his/her first interview. Try to anticipate questions or distractions that might arise during the interview and how you might handle these issues.

Additionally, for each individual interview, an interviewer will use a separate packet of questions on which he/she will take notes and make ratings. These packets will be clipped together with the other materials for each participant in the study.

See Interview Guide and Interview Questions in study materials. 


\section{Audio Recording Interviews ANd Providing FeEdBaCK}

Study interviews will be audio recorded and reviewed by the researcher. After conducting the first few interviews, each interviewer will receive feedback concerning how to refine the interview process and maintain consistency throughout all interviews in the study. Interviews will be recorded throughout the study.

\section{ConduCting the InTERVIEW - What to Do, What to AVoid, \& How to Dress}

Standardization is crucial to the effectiveness of the interview process. It is imperative that each participant goes through the exact same process and thus has the same opportunity to demonstrate her/his potential. Please note the following guidelines when interacting with participants:

\section{TO DO:}

- Be pleasant (e.g., smile, greet them) to put them at ease.

- Follow the instructions and prompts of the interview.

- Read each question slowly and audibly to participants.

- Try to maintain sufficient eye contact while also taking notes.

- Reread the question if necessary.

- Maintain professional behavior as if you are an actual hiring manager.

\section{TO AVOID:}

- Use probing questions only when necessary and be consistent across participants. Avoid such questions as: Is that all? Don't you want to say anything else?

- Do not engage the participant in conversation other than that required by the interview administration process.

- Do not make evaluative comments or gestures regarding their responses.

- Do not do things that would indicate you are restless or impatient (e.g., tapping your fingers on the table, sighing, closing your eyes, etc.).

- Do not leave your cell phones on.

\section{DRESS:}

- Dress conservatively but professionally as if an actual hiring manager in a company.

- Nice Business Casual

- Women: dress pants, blouse, sweaters, dresses, skirts, dress shoes.

- Men: dress pants, long sleeve button down dress shirts, dress shoes. 
Bonness, Brian, 2007, UMSL, p. 158

Appendix $\mathrm{H}$

\section{INTERVIEWS USED IN THIS STUDY - STRUCTURED INTERVIEWS}

Structured interviews will be used in this study. A structured interview may be described as a series of job-related questions with established response standards that are consistently applied across all interviews. Unlike traditional interviews where the interviewer and interviewee interact freely or follow loose guidelines, structured interviews follow a fairly rigid format with little or no deviation from it. The standardization of the format, questions, and scoring guidelines is what makes structured interviews superior to traditional ones. Interview research has provided strong evidence to suggest that structured interviews are more effective at evaluating an interviewee's ability and can be administered more consistently. This is because subjectivity and other factors leading to bias are reduced in the interview, allowing for better evaluation of the interviewee's ability.

Interview questions and scoring guidelines have been carefully developed. However, the administration of the interview is as important as the quality of the interview itself. It will be important to ensure that each participant is treated equally and offered the same opportunity to demonstrate his or her abilities.

\section{GATHERING BEHAVIOR-BASED INFORMATION}

Interviews are especially valuable tools when they are structured, behavior-based, and focus on job-related information. In order to gather job-related, behavioral information in a structured manner, a few general guidelines are offered:

- Focus on factual information; what a person has done in a given situation; focus on the person's past behaviors

- Past behavior is the best predictor of future behavior/performance

- Focusing on behavior reduces the impact of interviewer error/bias

- Behavioral information provides a much clearer picture of an applicant's skills and ability and fit with the job

- Beware of going with your gut feeling! Subjective information (feelings) is not nearly as predictive of job performance as objective information (past behavior).

\section{A. Behavior Based Questions}

The interviews in this study will use behavior-based questions. These questions will ask participants for examples of times when they have handled specific situations in the past. When responding, participants will be asked to provide an example of the particular situation related to the question. Participants will need to be specific when stating what they actually did to handle the situation they are describing. 
Bonness, Brian, 2007, UMSL, p. 159

\section{Appendix H}

\section{B. Probing}

It might become necessary to probe for more detail in the interview in order to help clarify a point the participant is making or to hit upon an important point the participant might have missed. In addition, the participant might fail to explain what he/she specifically did in the situation. Some example probes that can be used include:

- What action did you take? What steps did you take to solve the problem? What was your specific role in this situation? What did you specifically do? Can you think of a specific situation you were in and walk me through it? (Get the applicant to use phrases such as, "I did this," "Then, I did that," etc.)

- How did the problem originate? Who was involved?

- How did you approach the situation? What information did you use?

- What was the outcome of your actions? How did this affect your company or work group?

Try to limit the number of probing questions used in the interview and be consistent across candidates when using probes.

\section{Pauses}

When asking questions, an applicant will often pause while he/she thinks of a specific example. Tell the applicant that pauses are okay; he/she should take all the time needed to come up with an answer.

\section{Context (of Participant's Past Experience)}

A participant might have trouble answering a question due to a lack of work experience. In these situations, encourage the participant to answer the question in the context of school or other general experiences. The interviewer might need to use the "backup" question in this instance. 


\section{E. Recognizing Behaviors}

Below is a list of statements interviewers might use in his/her notes to describe a participant's responses in an interview. Some statements are clearly behavioral, some are evaluative, and some are behavioral but too general.

\section{Behavioral}

- Used examples the customer could easily relate to.

- Weighed pros and cons of each option before making a decision.

- Sent customer a replacement part.

- Asked the customer questions to figure out the specific problem.

- Came to work on the weekend when the store was short staffed.

\section{Evaluative}

- Responded really well to feedback from manager.

- Cared about coworker's feelings.

- Responded poorly to a difficult customer.

- Had difficulty working on multiple tasks.

- Is a good problem solver.

\section{Too General}

- Addressed manager's concerns.

- Was able to solve a problem.

- Followed up on a customer's question.

- Helped a coworker who was new on the job.

- Worked a lot with kids for a summer.

Remember to always focus on behaviors during the interview. As a result, your interview notes should include behavioral statements for each question. 


\section{RECORDING BEHAVIORS IN THE INTERVIEW NOTES}

Recognizing and noting behaviors described by the participant is very important. Do not try to note everything a participant says during the interview. A good way to keep track of the potentially large amount of information obtained in an interview is to write down "memory-joggers" which summarize the participant's answer to an interview question. Try to limit notes to behaviors related to the question being asked. Interview notes should be as concise as possible because it is difficult to write lengthy notes and attend to a participant at the same time.

The following guidelines will be helpful in developing a workable system of taking notes.

- Become familiar with the behavioral indicators that define the various dimensions and use these as a guide.

- Summarize the participant's responses, recording both positive and negative aspects of his/her answers.

- Limit notes to the job-related and question-related aspects of the participant's responses.

- Make notes as concise as possible.

- Include "key words" in notes as memory-joggers; don't take verbatim notes.

- Pay attention to the participant while taking notes. Maintain a comfort level and sense that you are listening and care about what he/she is saying.

- At the first opportunity, elaborate on your notes before forgetting what the memoryjoggers represent.

- Avoid being evaluative; just document the facts and the behaviors.

\section{SCORING INTERVIEW RESPONSES}

\section{Ratings Steps}

- Make a rating after each interview question response

- After the interview, go back and review your notes again and make changes if necessary

- Use the rating standards; use the entire scale (1, 2, 3, 4, and 5)

See example rating standards on the next page. It is important that the interviewer become very familiar with the rating standards and the behavioral indicators for each question before conducting an interview. 
Appendix $\mathrm{H}$

Bonness, Brian, 2007, UMSL, p. 162

\section{Personal Support Rating}

\begin{tabular}{|c|c|c|c|c|}
\hline Ineffective & & Effective & & Highly Effective \\
\hline 1 & $\stackrel{2}{\square}$ & $\begin{array}{l}3 \\
\square\end{array}$ & $\stackrel{4}{\square}$ & $\begin{array}{l}\mathbf{5} \\
\square \\
\end{array}$ \\
\hline $\begin{array}{l}\text { Failed to provide a } \\
\text { clear example of... }\end{array}$ & & $\begin{array}{c}\text { Provided one } \\
\text { satisfactory example } \\
\text { of... }\end{array}$ & & $\begin{array}{l}\text { Clearly described one } \\
\text { or more excellent } \\
\text { examples of... }\end{array}$ \\
\hline $\begin{array}{l}\text { Q1...helping someone } \\
\text { accomplish an } \\
\text { important task (or) } \\
\text { Q2...helping with } \\
\text { something not a part of } \\
\text { his/her job }\end{array}$ & & $\begin{array}{l}\text { Q1...helping someone } \\
\text { accomplish an } \\
\text { important task (or) } \\
\text { Q2...helping with } \\
\text { something not a part of } \\
\text { his/her job }\end{array}$ & & $\begin{array}{l}\text { Q1...helping someone } \\
\text { accomplish an } \\
\text { important task (or) } \\
\text { Q2...helping with } \\
\text { something not a part of } \\
\text { his/her job }\end{array}$ \\
\hline $\begin{array}{l}\text { Example did not clearly } \\
\text { display any of the } \\
\text { behavioral indicators }\end{array}$ & & $\begin{array}{l}\text { Example displayed at } \\
\text { least one of the } \\
\text { behavioral indicators }\end{array}$ & & $\begin{array}{l}\text { Example(s) displayed } \\
\text { multiple behavioral } \\
\text { indicators }\end{array}$ \\
\hline
\end{tabular}

\section{Personal Support Behavioral Indicators}

- Helps others without expecting something in return.

- Helps others to resolve their problems.

- Volunteers to help others without specifically being asked.

- Shares expertise, knowledge, and information willingly with others.

- Is courteous toward others.

- Works cooperatively with others.

- Offers guidance to less experienced people.

- Helps resolve conflicts between people.

- Changes plans/priorities to cooperate with unforeseen events. 
Bonness, Brian, 2007, UMSL, p. 163

Appendix $\mathrm{H}$

\section{Dimensions of Performance Assessed in the InTerviews (Task, CI, PS, OS)}

\section{The dimensions of performance that will be evaluated include the following:}

Task

Personal Support

Conscientious Initiative

Organizational Support

Note: please see study proposal for a clearer idea of the overall purpose of the study and more detail on the different performance dimensions, etc.

\section{Task and Contextual Performance Dimensions}

Task performance contributes to the technical core of an organization. It is generally roleprescribed and can be found on an employee's performance appraisal. Conversely, contextual performance is more general in nature rather than job specific and spans across many different jobs. It is not usually role prescribed or formally appraised.

Task performance and contextual performance separately contribute important value to organizations in distinct ways. Task performance promotes organizational effectiveness by contributing to the technical core of the organization. This can occur directly by transforming raw materials into the organization's products or indirectly by providing services necessary to support ongoing product creation. An example might be replenishing the supplies needed for production efforts. In comparison, contextual performance contributes to the social and psychological context in which the technical core of the organization functions.

Borman and Motowidlo (1993) proposed a five-dimension model of contextual performance that includes: (1) persisting with enthusiasm and extra effort as necessary to complete one's own task activities; (2) volunteering to carry out task activities that are not formally part of one's own job; (3) helping and cooperating with others; (4) following organizational rules and procedures; and (5) endorsing, supporting and defending organizational objectives. Examples of contextual performance might include going out of one's way to help a co-worker complete a task, cooperating with a supervisor or with an organizational policy, or volunteering for extra responsibility.

The various dimensions of contextual performance found in the literature are generally reduced to two or three general factors. For example, Williams and Anderson (1991) used factor analysis to distinguish between person-directed or interpersonal organizational citizenship behavior, referred to as OCB-I, and organization-directed organizational citizenship behavior referred to as OCB-O. More recently, Coleman and Borman (2000) proposed a three-dimension model of contextual performance that includes the following dimensions: Personal Support, Organizational Support, and Conscientious Initiative. This study asked industrial and organizational psychologists to sort a list of 27 dimensions from all related constructs in the contextual performance literature (e.g., OCB, POB, MSE). The three resulting dimensions represent broad categories that vary based on the target toward which the behavior is directed. Behaviors in the Personal Support 


\section{Appendix $\mathrm{H}$}

Bonness, Brian, 2007, UMSL, p. 164

dimension are directed toward and benefit individuals in the organization; behaviors making up the Organizational Support dimension promote the organization; and Conscientious Initiative behaviors are directed toward an employee's job.

The Personal Support dimension includes behaviors or concepts such as helping, cooperating with others, altruism, and interpersonal facilitation. It is essentially the same as the helping and cooperating dimension in the Borman and Motowidlo (1993) model of contextual performance. The Conscientiousness Initiative dimension includes behaviors such as persisting and remaining dedicated, and expending extra effort. It is essentially the same as the persisting and volunteering dimensions in the Borman \& Motowidlo (1993) model. Lastly, the Organizational Support dimension includes behaviors such as endorsing and supporting the organization, following its policies and rules, and remaining loyal and compliant to the company. This factor is a combination of the following rules and procedures and endorsing, supporting and defending dimensions in the Borman and Motowidlo (1993) model.

Some specific behaviors that define each of the performance dimensions are listed below. Note that these are the same behavioral indicators that will be used in the rating standards to help you make accurate evaluations of participant interview responses. These are also the same indicators used for the performance assessment measures.

\section{$\underline{\text { Task }}$}

- Adequately completes assigned duties.

- Fulfills responsibilities specified in job description.

- Performs tasks that are expected of him/her.

- Meets formal performance requirements of the job.

- Engages in activities that will directly affect his/her performance evaluation.

\section{Personal Support}

This dimension includes working cooperatively with others in order to benefit the entire organization. Individuals who demonstrate high levels of these behaviors look for opportunities to help others and volunteer to assist or train others, even if they are not asked to do so. Further, they are willing to volunteer assistance even if it requires them to work additional hours or make other personal sacrifices. Example behaviors for this dimension include:

- Helps others without expecting something in return.

- Helps others to resolve their problems even if he/she is not responsible for the problem.

- Volunteers to help others without being asked.

- Shares expertise, knowledge, and information willingly with others.

- Is courteous toward others.

- Works cooperatively with others.

- Offers guidance to less experienced people.

- Helps resolve conflicts between people.

- Willingly changes plans/priorities to cooperate with unforeseen events. 
Bonness, Brian, 2007, UMSL, p. 165

\section{Appendix $\mathrm{H}$}

\section{Conscientious Initiative}

This dimension includes taking actions necessary to complete tasks in both a quality and time-conscious manner. Individuals who demonstrate high levels of these behaviors show extraordinary concern for completing their assigned tasks in a manner that exceeds basic, minimum expectations. This dimension also includes taking extraordinary action to anticipate and solve problems, contribute to the productivity of the work unit, develop one's job-related skills, or improve methods for completing work. Individuals who demonstrate high conscientious initiative look for opportunities to contribute positively to the workgroup. Example behaviors for this dimension include:

- Puts a lot of effort into fulfilling his/her responsibilities.

- Completes tasks or assignments on time or ahead of time.

- Does more than what is expected on tasks or assignments.

- Sees tasks through to their completion.

- Does what is necessary to get the job done.

- Ensures work is error free.

- Takes action to resolve problems before asking others for help.

- Recognizes potential problems and takes steps to solve them.

- Provides useful suggestions on how to complete tasks more effectively or efficiently.

- Seeks opportunities to improve his/her skills or capabilities.

- Takes on additional responsibility without being asked.

- Notifies others of important information/issues without being asked.

- Tries to find additional work when not busy.

\section{Organizational Support}

This dimension includes consistently complying with the rules and policies of the organization or workgroup. Individuals who demonstrate high levels of these behaviors consistently meet work rules and reliably complete their tasks as they are assigned. This dimension also includes demonstrating commitment to the organization or work unit both in word and action. Individuals who demonstrate high levels of these behaviors work to contribute to the success of the organization's objectives, regardless of the climate/morale of the organization. Further, they speak positively about the organization or avoid talking negatively about the organization, despite what others say. Example behaviors for this dimension include:

- Respects authority.

- Is punctual.

- Obtains approval before bending policies or rules.

- Consistently attends meetings or work in spite of traffic, weather, etc.

- Follows organizational policies and rules even if there are no consequences for failing to do so.

- Defends the organization even when others are criticizing it.

- Talks positively about the organization.

- Represents the organization favorably to others.

- Encourages others to work toward organizational objectives.

- Puts group objectives above personal goals. 


\section{INTERVIEWER/RATER ERRORS}

Ratings made by human judges can vary considerably in their accuracy. Research on ratings has uncovered many sources of error in ratings. Rater awareness of these errors, however, can help to considerably reduce the error portion of ratings.

Halo Error. Halo error is the generalization of an overall favorable (or unfavorable) evaluation of an individual based on the perception of one favorable (or unfavorable) characteristic. This error is extremely common and occurs when a rater rates an applicant as either high or low on almost all of the dimensions.

Remedy: Evaluate performance on each dimension independently of performance on other dimensions, and rate on the basis of actual dimension behavior.

Logical Error. This error occurs whenever a rater rates one dimension as high or low because the applicant scored high or low on another dimension which the rater feels is logically related. For example, if an assessor rates a participant as "3" in Customer Service Orientation and then feels that the applicant should automatically receive a "3" in Selling/Influencing Others as well, the assessor has committed a logical error.

Remedy: Reread the definitions of the dimensions and then evaluate performance on each dimension independently of performance on other dimensions.

Central Tendency Error. This error occurs when interviewers hesitate to commit themselves by giving extreme ratings such as 1's and 5's and instead settle for ratings around the center of the rating scale (3's).

Remedy: The interviewer should remember that very few applicants will be average on all dimensions. Similarly, few applicants will be high or low on all dimensions. Everyone has a different pattern of strengths and weaknesses. Don't be afraid to use the high and low ends of the rating scale.

Leniency/Toughness. Some raters are too lenient in their ratings and never rate anyone less than average even though performance may be very poor. Other raters are too tough and never rate anyone higher than average.

Remedy: Use the entire rating scale at the appropriate times.

Rater Bias. This is a tendency to rate an applicant higher or lower on some, or all, dimensions because of irrelevant characteristics of the participant. For instance, rater bias would be evident if a rater tended to rate female participants higher or lower than males simply because they are females.

Remedy: Be objective. Personal likes and dislikes should not be permitted to influence ratings. Don't use irrelevant information; focus on relevant, job-related information. 
Funneling. This is a tendency to arrive at a final rating before all relevant information is at hand. For example, if an interviewer decides very early in the interview response that an applicant should be rated below average on oral Dependability, the interviewer may not consider information later in the response which could contradict that rating.

Remedy: Don't make premature evaluations of an applicant. Wait until all relevant information has become available.

Comparing/Contrasting Applicants. This occurs when an interviewer makes ratings based on how the applicant compares to other applicants that have interviewed.

Remedy: Rather than basing ratings on how one applicant compares to another, try to focus on the scoring standards provided with the interview guide.

Similar to Me. This is the tendency to rate someone who is similar to oneself highly. We tend to like those who seem to be the same as us and thus tend to rate them favorably.

Remedy: Avoid letting your liking for someone affect the ratings you give that person in the interview. The more you maintain structure in the interview and keep the applicant focused on information related to the question, the easier this will be.

Stereotypes. This is the tendency to allow certain stereotypes we have affect the ratings we give to applicants. Applicants who fit a particularly negative stereotype maintained by the interviewer might receive lower ratings than an applicant who does not fit the stereotype.

Remedy: Try to recognize the stereotypes we might hold, even if not very strong, and ask yourself if your rating of an applicant was in any way impacted by that stereotype.

First Impression. This is when an interviewer's ratings are affected by the information gathered about an applicant in the very beginning of the interview. This "first impression," whether positive or negative, impacts the interviewer ratings throughout the rest of the interview.

Remedy: Try to focus on each response to an interview question separate from all the others preceding it. And try to not let the introductory small talk that takes place before the interview impact the ratings you make during the interview. 


\section{QUESTIONS TO AVOID}

This is a list of topic areas that are not a good idea to ask about in the interview. Remember, focus on job-related information. Rule of Thumb -- If you aren't certain that your question is job-related, don't ask it!

Race

Color

Ancestry

National origin

Place of birth

Date of birth/age

Marital status

Number of children

Family plans

Religious affiliation or church attendance Nature of military discharge
Political party membership or activities

Gender-specific questions

Physical characteristics or disabilities

Emotional illness

Current state of health

Spouse's career information

Credit/financial information

Arrest/conviction record

Height/weight

Sexual preference 
Bonness, Brian, 2007, UMSL, p. 169

\section{Appendix I}

\section{Assessor Performance Assessment Instructions}

As part of your participation in this study, you are asked to deliver a short questionnaire to your current work supervisor and one work peer or someone with whom you have a close working relationship. If you are unable to deliver a questionnaire to your supervisor, please deliver both questionnaires to work peers or individuals with whom you have a close working relationship. If this is not a co-worker or you do not work at the present time, you may deliver it to someone who has knowledge of your behavior and performance in an academic setting (e.g., classmate, professor) or in some other way is familiar with your performance on related projects/activities.

In order to complete this part of the study, you will receive two sets of questionnaires and consent forms and two envelopes with return address and postage. You are asked to deliver these to your supervisor and/or work peer(s), who will complete the questionnaires and send them back to the project coordinator by using the self-addressed envelope and simply dropping them in the mail. It is very important that you deliver these materials promptly and that we receive them from the assessors in a timely manner. We will follow up with an email and phone call if we do not receive the questionnaires within two weeks of the study participation date. All information collected in this study will remain completely confidential. You will not see the ratings provided on these questionnaires at any time. 


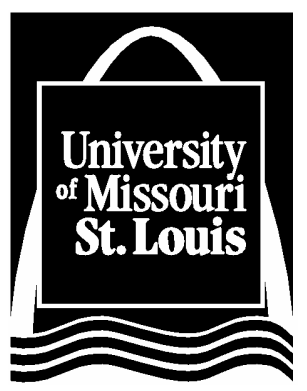

College of Arts and Sciences

Department of Psychology 8001 Natural Bridge Road

St. Louis, Missouri 63121-4499

Telephone: $314-516-5391$

\section{Informed Consent for Participation in Research Activities}

Structured Interviews and Performance

Participant

Performance Assessor

Principal Investigator

Brian Bonness
HSC Approval Number

$\underline{061005 \mathrm{~B}}$

PI's E-mail__brianbonness@hotmail.com

\section{Why am I being asked to participate?}

You are invited to participate in a research study that will evaluate structured employment interviews. It is being conducted by Brian Bonness in the Department of Psychology at the University of Missouri-St. Louis. You have been asked to participate as a performance assessor in this study because you have knowledge of the performance of the individual delivering the enclosed questionnaire to you. Please read this form thoroughly before agreeing to be in the research. Your participation in this research is voluntary. Your decision whether to participate will not affect any current or future relations you or anyone else might have with the University. If you decide to participate, you are free to withdraw at any time without affecting that relationship.

\section{What is the purpose of this research?}

The purpose of this study is to investigate structured employment interviews.

\section{What procedures are involved?}

If you participate in this study, you can expect to assess the performance of the individual who delivered this questionnaire to you. The questionnaire will require approximately 20 minutes to complete. Approximately 240 individuals will participate as performance assessors in this research.

\section{Are there benefits to taking part in the research?}

This study will provide you with an opportunity to see some of the key dimensions companies use to assess the performance of their employees. No risks to participants are anticipated in this study.

\section{What about privacy and confidentiality?}

You will not be required to sign and return this consent form. In order to maintain complete anonymity, receipt of your completed questionnaire will signify your informed consent.

\section{Can I withdraw or be removed from the study?}

You can choose whether to be in this study. If you volunteer to be in this study, you may withdraw at any time. You also may refuse to answer any questions you do not want to answer and still remain in the study. The investigator may withdraw you from this research if circumstances arise which warrant doing so. 


\section{Appendix $\mathbf{J}$}

Bonness, Brian, 2007, UMSL, p. 171

\section{Who should I contact if I have questions?}

The principle investigator conducting this study is Brian Bonness. If you have questions before or after completing the questionnaire, you may contact Brian at brianbonness@hotmail.com or (314) 361-2204.

\section{What are my rights as a research participant?}

If you have any questions about your rights as a research participant, you may call the Chairperson of the Institutional Review Board at (314) 516-5897.

\section{What if I am a UMSL student?}

You may choose not to participate, or to stop your participation in this research, at any time. This decision will not affect yours or anyone else's class standing or grades at UMSL. The investigator also may end your participation in the research. If this happens, your class standing or the class standing of anyone else will not be affected. You will not be offered or receive any special consideration if you participate in this research.

Remember: Your participation in this research is voluntary. Your decision whether to participate will not affect your or anyone else's current or future relations with the University. If you decide to participate, you are free to withdraw at any time without affecting that relationship.

Again, you are NOT asked to return this consent form. In order to maintain complete anonymity, receipt of your completed questionnaire will signify your informed consent.

\section{Thank you.}

